\title{
DEVELOPMENT OF A HIGH-PERFORMANCE COAL-FIRED POWER GENERATING SYSTEM WITH PYROLYSIS GAS AND CHAR-FIRED HIGH TEMPERATURE FURNACE (HITAF)
}

DE-AC22-91PC91154

Quarterly Progress Report 3

July through October 1992

\author{
Prepared for \\ Pittsburgh Energy Technology Center \\ Pittsburgh, Pennsylvania
}

FWDC Project 9-41-3492

November 1992

FOSTER WHEELER DEVELOPMENT CORPORATION

12 Peach Tree Hill Road, Livingston, New Jersey 07039 


\section{Contents}

Page

$\begin{array}{lll}\text { INTRODUCTION } & \cdots & 1\end{array}$

$\begin{array}{ll}\text { PROJECT WORK } & 2\end{array}$

Task 1-Project Work Plan $\quad 2$

Task 2-Concept Definition and Analysis $\ldots$

Subtask 2.1-Preliminary Cycle Analysis $\quad 2$

$\begin{array}{ll}\text { Task 3-Preliminary R\&D } & 7\end{array}$

Subtask 3.1-Analytical Determination of Pyrolyzer Yields $\quad 7$

Subtask 3.2-Characterization of Secondary Air Heater Gas-Side Environment 8

Subtask 3.5-Char Reactivity and Transport Gas Requirements 10

Subtask 3.6-Char Combustor Technical Assessment $\quad 17$

Subtask 3.7-Candidate Air Heater Materials 38

Subtask 3.8-Evaluation of Secondary Air Heater Corrosion 38

Subtask 3.10-Char Characterization Tests $\quad 41$

Subtask 3.13-Preliminary Design of Secondary Air Heater $\quad 45$

Subtask 3.14-Secondary Air Heater/Furnace Compatibility $\quad 52$

Subtask 3.20-Analyze Sorbent Reactions in Char Combustor 52

Subtask 3.21-Pollution Control Systems $\quad 55$

\section{DISCLAIMER}

This report was prepared as an account of work sponsored by an agency of the United States Government. Neither the United States Government nor any agency thereof, nor any of their employees, makes any warranty, express or implied, or assumes any legal liability or responsibility for the accuracy, completeness, or usefulness of any information, apparatus, product, or process disclosed, or represents that its use would not infringe privately owned rights. Reference herein to any specific commercial product, process, or service by trade name, trademark, manufacturer, or otherwise does not necessarily constitute or imply its endorsement, recommendation, or favoring by the United States Government or any agency thereof. The views and opinions of authors expressed herein do not necessarily state or reflect those of the United States Government or any agency thereof. 


\section{Figures}

1 Simplified Process Flow Diagram 3

2 Modified HITAF Base Arrangement 4

3 Fuel Gas-to-Char Precombustor 5

4 Coal-to-Char Precombustor 6

5 Pyrolyzer Heat and Material Balance $\quad 9$

6 Fuel Gas Sodium Concentration vs. Temperature 11

7 Pyrolyzer-to-Char Combustor-Char Transport System With Char $\begin{array}{ll}\text { Pulverized } & 14\end{array}$

8 Pyrolyzer-to-Char Combustor-Char Transport System Without $\begin{array}{ll}\text { Char Pulverized } & 15\end{array}$

$9 \quad$ Circulating Fluidized Bed Pyrolyzer Arrangement 16

10 Char Combustor Fuel Options 20

11 Coal-Fired Precombustor With Char-Fired Slagging Stage 22

12 Precombustor Exit Gas Temperature vs. Precombustor Fuel Thermal Input-Coal-Fired Precombustor 23

13 Pyrolysis Gas-Fired Precombustor With Char-Fired Slagging Stage 25

14 Precombustor Exit Gas Temperature vs. Precombustor Fuel Thermal Input/Coal-Fired Precombustor $/ 1150^{\circ} \mathrm{F}$ Air Inlet Temperature 26

15 Precombustor Exit Gas Temperature vs. Precombustor Fuel Thermal Input/Coal-Fired Precombustor $/ 750^{\circ} \mathrm{F}$ Inlet Air Temperature 27

16 Equilibrium Gas Temperature vs. Carbon Burnout 29

17 Gas Oxygen Content vs. Carbon Burnout 30

18 Gas $\mathrm{CO}_{2}$ Content vs. Carbon Burnout 31

19 Gas $\mathrm{H}_{2} \mathrm{O}$ Content vs. Carbon Burnout 32 
Figures (Cont)

Number

Page

20 Effect of Volatile Content (initial carbon burnout) on Carbon Burnout vs. Residence Time 10 to 0.05 seconds)

21 Effect of Volatile Content (initial carbon burnout) on Carbon Burnout vs. Residence Time (0.015 to 0.200 seconds)

22 Effect of Particle Size on Carbon Burnout vs. Residence Time (0 to 0.05 seconds)

23 Effect of Particle Size on Carbon Burnout vs. Residence Time (0.015 to 0.200 seconds)

24 Particulate Flow Rates in Fuel Gas Stream 39

25 Char Combustor Test Configuration 43

$26 \quad$ Flat Flame Burner $\quad 44$

27 Heat Exchanger/Enclosure, Front View 47

28 Heat Exchanger/Enclosure, Top View 48

29 Conceptual Arrangement of Furnace/Air Heater Combination 53

30 Preliminary Prediction of Furnace Exit Temperature 54

31 Effect of Coal Sulfur on Adsorption Capacity

32 Effect of Temperature on Adsorption Capacity 58

33 Char Adsorption With Wash $\quad 59$

34 Adsorption Capacities of Chars Derived From Pittsburgh No. 8 Coal 60

35 Recirculating Reactor $\quad 61$

36 Effect of Coal Sulfur on Required Absorber Efficiency 64 
Tables

Number

Page

1 Effects of Char Precombustor Fuel on System

2 Soluble Sodium and Potassium in Coal

3 Comparison of Jetting and Circulating Bed Pyrolyzers - 290-MW Plant

Effect of Air Inlet Temperature on Precombustor Coal Heat Input and

Slagging-Stage Char Heat Input

28

Candidate Secondary Air Heater Materials

38

Particle Collection Efficiency

40

Char Combustion Experiments

45

Secondary Air Heater Radiation Heat-Transfer Assumptions

46

Secondary Air Heater Preliminary Prices

Preliminary Cost of Full-Size Air Heater Module

Preliminary Cost of 3/4-Size Air Heater Module

Preliminary Cost of Half-Size Air Heater Module

Recirculating Reactor Mass Balance

Reactivation of Furnace Injected Limestone Wellman-Lord, Ammonia Injection, and Baghouse Capital Costs-With Limestone Injection

Wellman-Lord, Ammonia Injection, and Baghouse Operating Costs - With Limestone Injection 
Ref.: DE-AC22-91PC911542

Tables (Cont)

Number

Page

22 Wellman-Lord, Ammonia Injection and Baghouse Operating CostsWithout Limestone Injection 75

23 Pollution Control Systems Cost Summary

76 


\section{QUARTERLY PROGRESS REPORT 3 (July through September 1992)}

\section{INTRODUCTION}

A concept for an advanced coal-fired combined-cycle power generating system is currently being developed. The first phase of this three-phase program consists of conducting the necessary research and development to define the system, evaluate the economic and technical feasibility of the concept, and prepare an R\&D plan to develop the concept further.

Foster Wheeler Development Corporation is leading a team of companies involved in this effort. The team consists of:

- Allied Signal Aerospace Company-AiResearch Division

- Bechtel Corporation

- Research-Cottrell

- TrW, Inc.

- Foster Wheeler Energy Corporation.

The power generating system being developed in this project will be an improvement over current coal-fired systems. Goals have been specified that relate to the efficiency, emissions, costs, and general operation of the system. These goals are:

- Total station efficiency of at least 47 percent.

- No more than: $0.15 \mathrm{lb} \mathrm{NO}_{x} / 10^{\circ} \mathrm{Bru}$ of fuel heat input $0.15 \mathrm{lb} \mathrm{SO} / 10^{\circ} \mathrm{Btu}$ of fuel heat input $0.0075 \mathrm{lb}$ of particulates $/ 10^{\circ} \mathrm{Btu}$ of fuel heat input.

- All solid wastes must be benign. Generation of solid wastes is minimized through production of usable by-products.

- Greater than 95 percent of the total heat input is ultimately from coal, with initial systems capable of using coal for at least 65 percent of the heat input.

- Efficient and economic baseload power generation:

- Operation with a range of U.S. coals

- Anivial capacity factor of 65 percent

- Loxd following with minimal degradation in efficiency

- Net electrical output as low as $100 \mathrm{MW}$

- 10-percent lower COE relative to a modern coal-fired plant conforming to NSPS. 
- Safety, reliability, and maintainability to meet or exceed conventional coal-fired power plants.

- Amenable to construction using factory-assembled modular components based upon standard design.

The system proposed to meet these goals is a combined-cycle system where air for a gas turbine is indirectly heated to approximately $1800^{\circ} \mathrm{F}$ in furnaces fired with coal-derived fuels and then directly heated in a natural-gas-fired combustor up to about $2400^{\circ} \mathrm{F}$. The system is based on a pyrolyzing process that converts the coal into a low-Btu fuel gas and char. The fuel gas is a relatively clean fuel, and it is fired to heat tube surfaces that are susceptible to corrosion and problems from ash deposition. In particular, the high-temperature air heater tubes, which will need to be a ceramic material, will be located in a separate furnace or region of a furnace that is exposed to combustion products from the low-Btu fuel gas only. A simplified process flow diagram is shown in Figure 1.

\section{PROJECT WORK}

\section{Task 1-Prolect Work Plan}

A Project Work Plan was developed and submitted to DOE. The work effort was divided into 60 subtasks, and these subtasks were organized to achieve the project objectives.

\section{Task 2-Concept Definition and Analysis}

\section{Subtask 2.1-Preliminary Cycle Analysis}

Bechtel did a second iteration of the plant heat and material balance based on a revised pyrolyzer balance. In addition to the changes in pyrolyzer output, the plant was reconfigured in a few areas to incorporate information from Task 3 work. These changes were:

- Fuel gas cooling

- Char cooling

- Wellman-Lord desulfurizing system

- Auxiliary fuel for char combustor precombustor

These modifications to the system arrangements are shown in Figures 2, 3, and 4. Figure 2 shows the addition of the char cooler and fuel gas (syngas) cooler. Figure 3 shows the modification with fuel gas firing in the char combustor precombustor, and Figure 4 depicts the arrangement with coal as the char combustor precombustor fuel. 


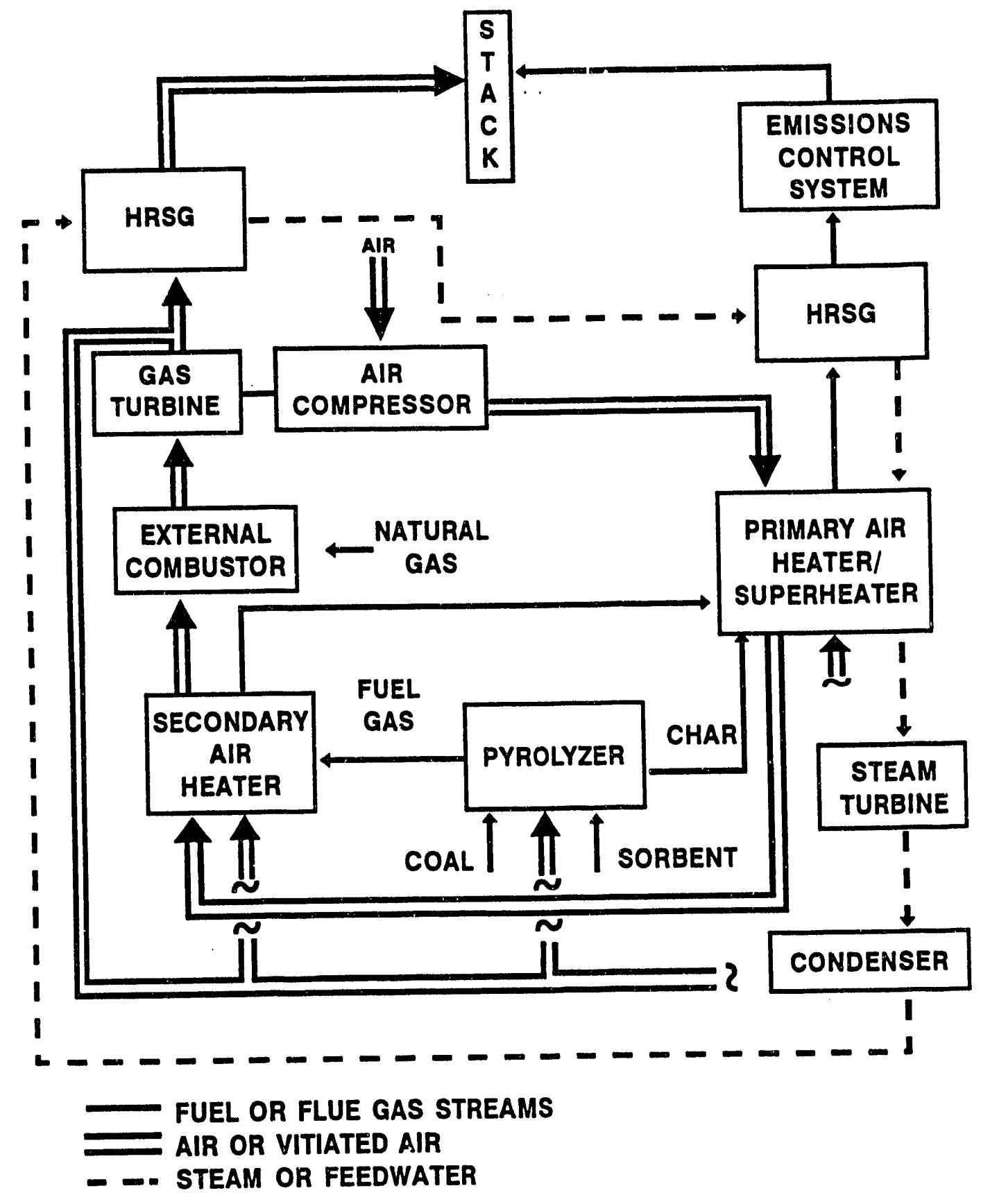

Figure 1 Simplifled Process Flow Diagram 


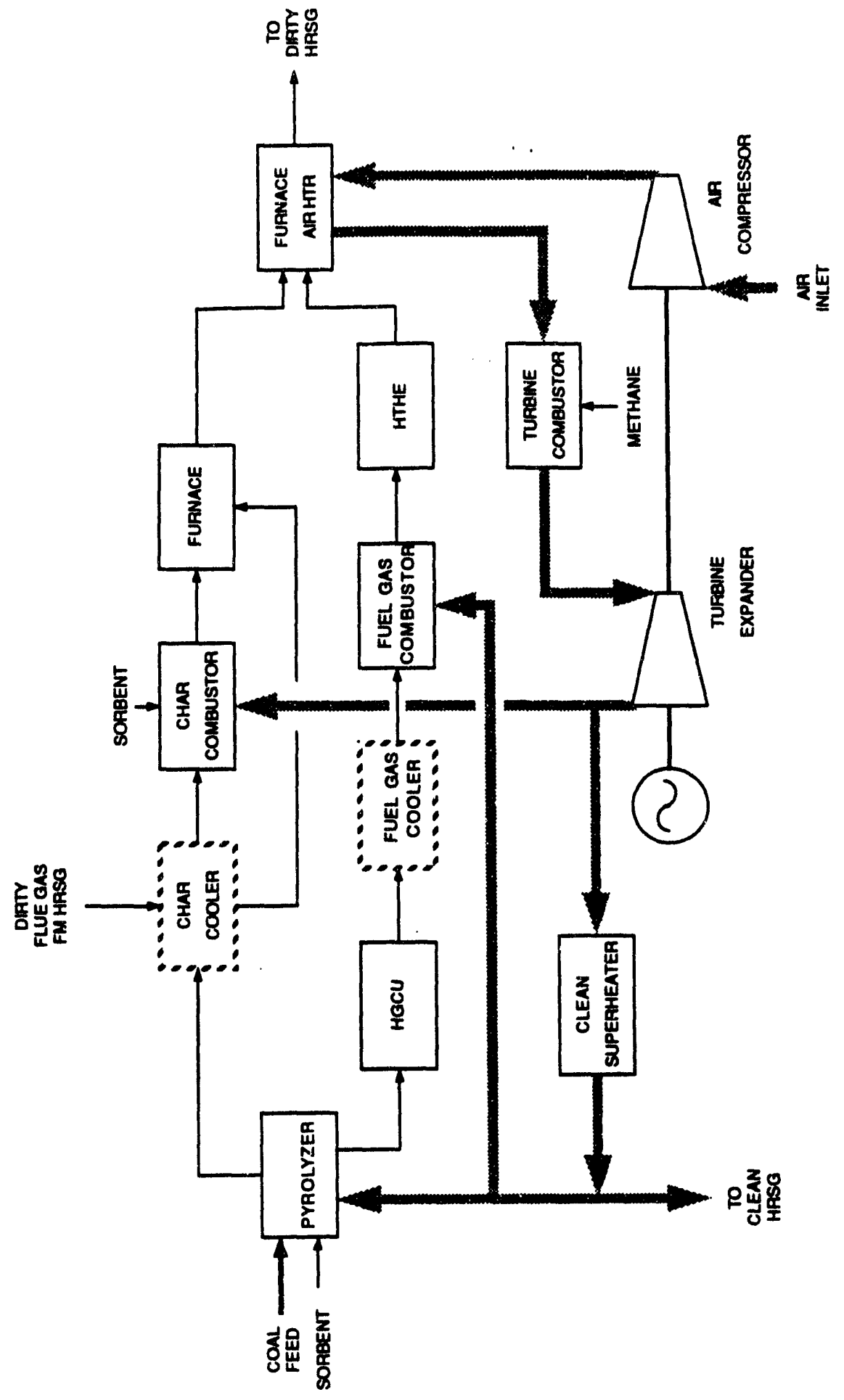

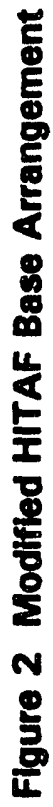




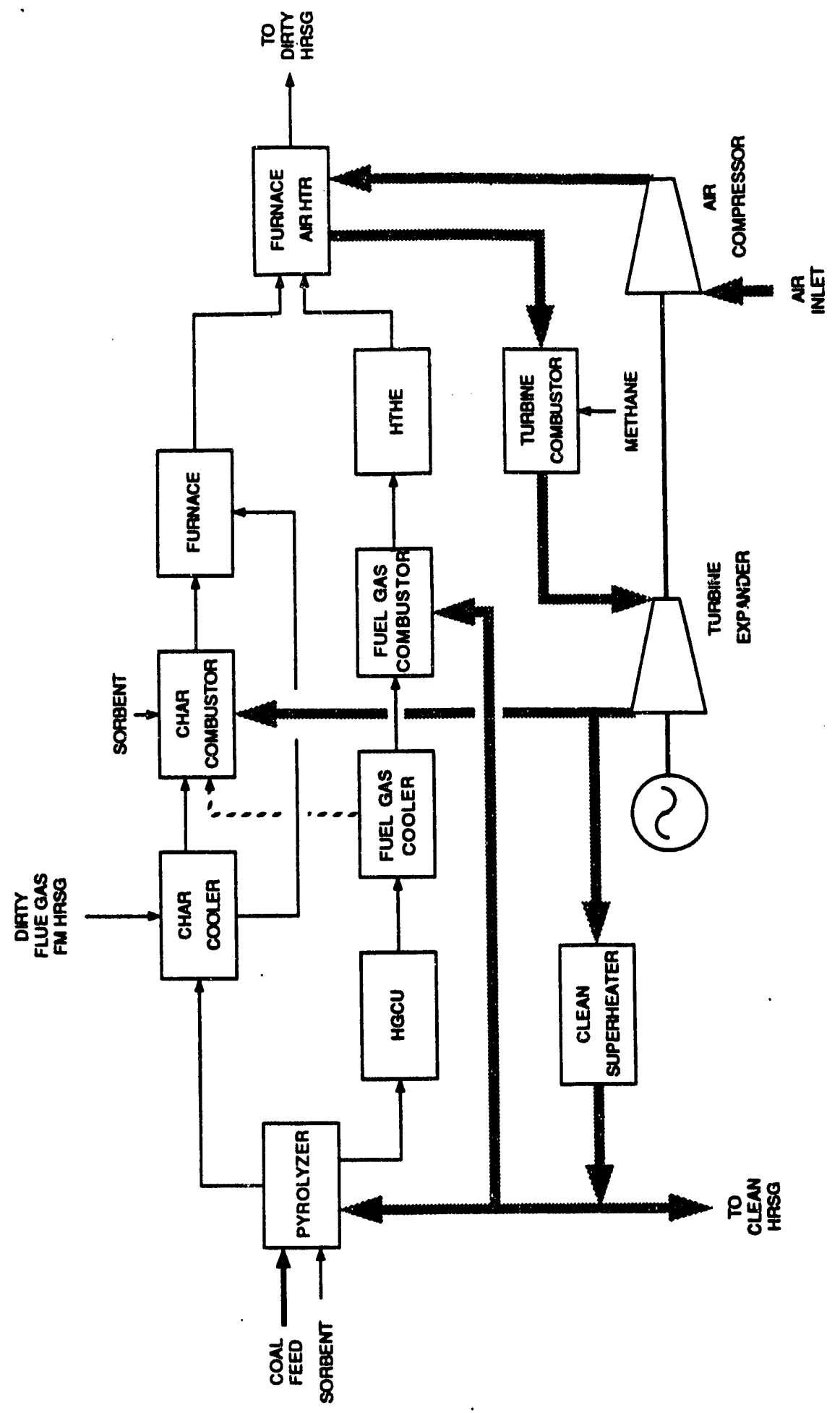




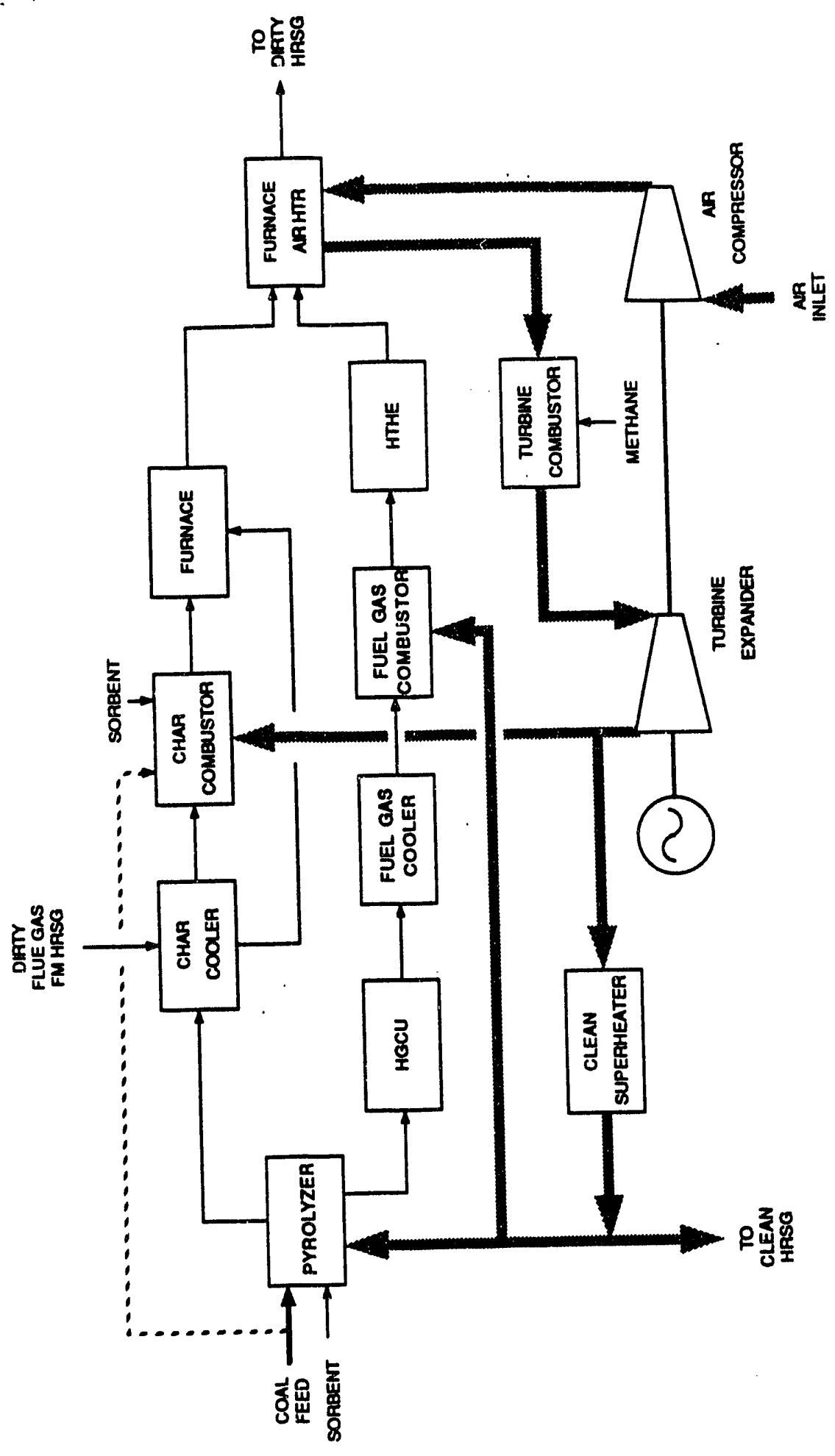


The fuel gas cooling system was added because FWDC analyses showed the alkali levels entering the ceramic air heater could be reduced to very low levels by cooling the fuel gas to $1000^{\circ} \mathrm{F}$ before combustion. The original proposal specified a ceramic barrier filter and alkali getter vessel to clear the fuel gas. Cooling the fuel gas replaces this equipment with more proven gas-cooling and particulate-removal equipment. Two means of cooling the fuel gas were investigated-direct injection of water and indirect heat transfer to the steam cycle. Although the impact on overall performance was negligible for both approaches, the indirect cooling method is preferred because of pinch-point considerations.

Char cooling was added to the model because no commercial equipment could be found that would pulverize char at the pyrolyzi: temperature. The team determined that the impact on plant performance would be negligible if the system used the recovered heat in an air stream, in the flue gas steam, or in the bottoming cycle. The char cooling and pulverizing system is discussed in more detail in Subtask 3.5. Although the impact on cycle performance will be small, the equipment required to perform these functions will be costly and will likely require considerable maintenance. More emphasis will now be placed on matching the pyrolyzer char output size with the char combustor requirements. If the char is not pulverized, it will not need to be cooled either.

Desulfurizing systems are discussed in Subtask 3.2.1. Based on work done so far, the Wellman-Lord system appears to be a likely candidate. This system will meet the emissions goals and can provide sulfur as an end product; however, operating costs are significant, including the need for natural gas. A subsystem was added to the system model to account for the utilities and fuel consumption. Unfortunately, the change was made along with several other updates; thus the effect of this process was not precisely determined. However, it does appear to have resulted in a reduction of about 1 percent in overall efficiency.

TRW is investigating the use of the fuel gas or raw coal as a fuel for the char combustor precombustor section. The effects on the char combustor operation of using these fuels are discussed in Subtask 3.6. Table 1 summarizes the major system parameters for cases with no auxiliary fuel, with fuel gas, and with char.

\section{Task 3-Preliminary R\&D}

\section{Subtask 3.1-Analytical Determination of Pyrolyzer Yields}

The Institute of Gas Technology (IGT) and City College of New York (CCNY) pyrolyzer computer models were compared with the test results from the FWDC Second-Generation PFBC pilot plant. At bed temperature of around $1600^{\circ} \mathrm{F}$, the yields from both models are close; but at higher bed temperatures, the CCNY program predicts greater carbon conversion than the IGT program. The CCNY program results matched the results of the FWDC pilot plant tests well; thus we decided to use this model for the HITAF system. 
Table 1 Effects of Char Precombustor Fuel on System

\begin{tabular}{|l|c|c|c|}
\hline \multicolumn{1}{|c|}{ Data } & $\begin{array}{c}\text { Char to Pre- } \\
\text { combustor }\end{array}$ & $\begin{array}{c}\text { Fuel Gas to } \\
\text { Precombustor }\end{array}$ & $\begin{array}{c}\text { Coal to } \\
\text { Precombustor }\end{array}$ \\
\hline Air to compressor $\left(10^{6} \mathrm{lb} / \mathrm{h}\right)$ & 3.4 & 3.4 & 3.4 \\
\hline Bypass air $(\%)$ & 15 & 15 & 15 \\
\hline Fuel gas produced $\left(10^{3} \mathrm{lb} / \mathrm{h}\right)$ & 397 & 396.3 & 374.5 \\
\hline Fuel gas to char combustor $\left(10^{3} \mathrm{lb} / \mathrm{h}\right)$ & 0 & 351 & 0 \\
\hline Coal to char combustor $\left(10^{3} \mathrm{lb} / \mathrm{h}\right)$ & 0 & 0 & 5.8 \\
\hline Net Power $(\mathrm{MWe})$ & 278 & 278.1 & 278.9 \\
\hline Power from gas turbine $(\%)$ & 52.5 & 53.1 & 53 \\
\hline Overall cycle efficiency $(\%)$ & 48.1 & 48.1 & 48.2 \\
\hline
\end{tabular}

A pyrolyzer heat and material balance for a bed at 2 atm $/ 1700^{\circ} \mathrm{F}$ is shown in Figure 5 . This pyrolyzer heat and material balance was used for a second iteration of plant heat and material balances done as part of Subtask 2.1.

\section{Subtask 3.2-Characterization of Secondary Air Heater Gas-Side Environment}

Potential flue gas alkali levels in the secondary air heater are being analyzed. These analyses will be used to evaluate the need for an alkali-removal system in the fuel gas stream and will be a factor in the selection of the ceramic materials that will be used in the secondary air heaters (Subtasks 3.7, 3.8, and 3.9).

The analysis consists of chemical fractionation of the coal to estimate how much of the alkali will be released into the fuel gas during the partial gasification process. This technique extracts the organically bound, water-soluble and carbonate forms of the alkalies from the coal sample. The alkalies that remain in the coal are present as clays and will not be released during the partial gasification process. The alkalies estimated to be released in this manner constitute a worst-case analysis, because gettering of the alkalies by the ash is not considered.

The chemical fractionation procedure consists of three extractions. Water extracts the water-soluble alkali species. The residue is then treated with ammonium acetate to extract the organically bound sodium. Finally, a solution of hydrochloric acid extracts the carbonate compounds. The results of these laboratory tests are summarized in Table 2. 


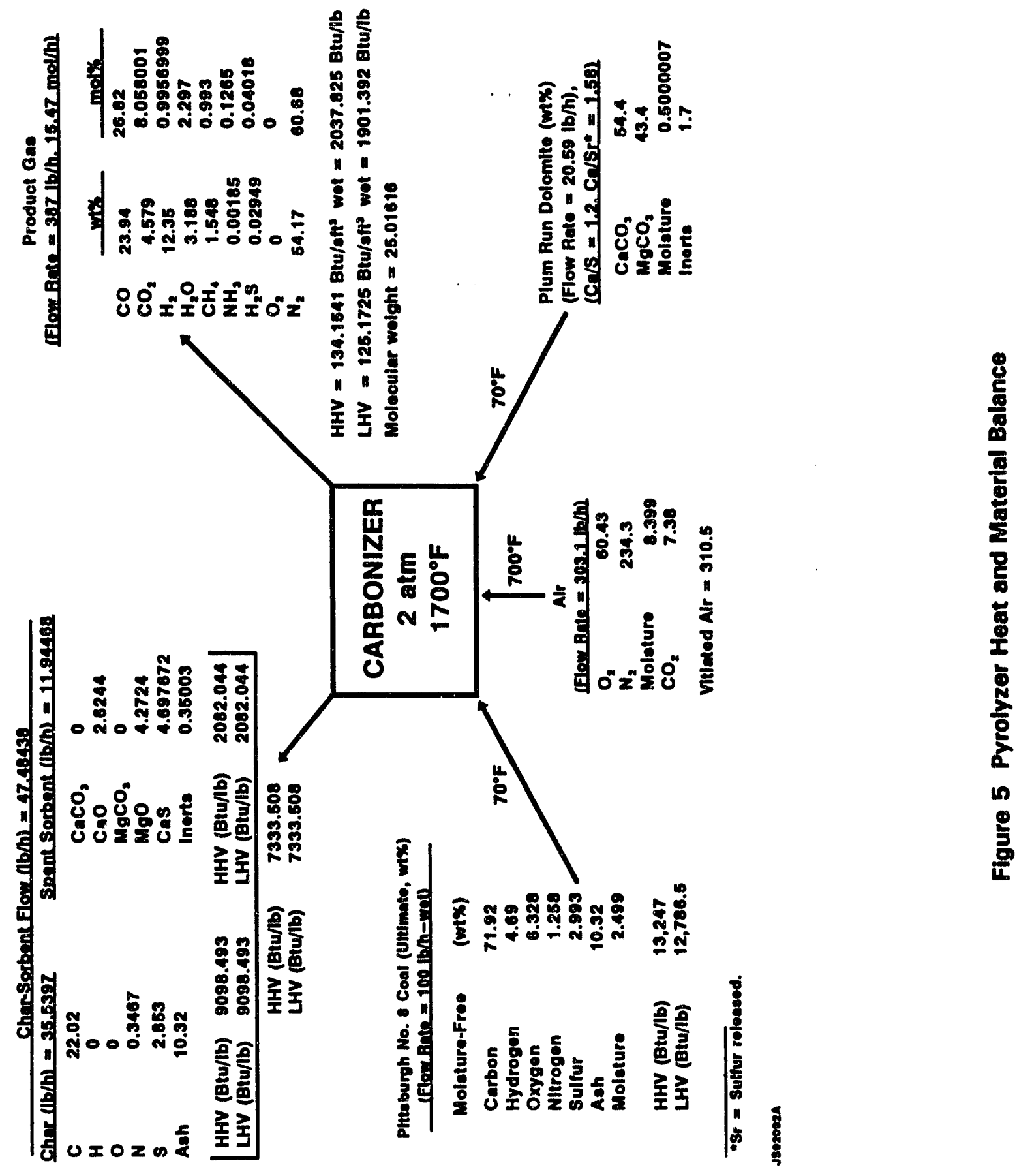


Table 2 Soluble Sodium and Potassium in Coal

\begin{tabular}{|l|c|c|c|c|c|c|}
\hline \multirow{2}{*}{ Description } & \multicolumn{3}{|c|}{ Sodium [ppm(w)] } & \multicolumn{3}{c|}{ Potassium [ppm(w)] } \\
\cline { 2 - 7 } & $\begin{array}{c}\text { Woter } \\
\text { Extrection }\end{array}$ & $\begin{array}{c}\text { Ammonium } \\
\text { Acetate } \\
\text { Extraction }\end{array}$ & $\begin{array}{c}\text { Hydrochloric } \\
\text { Acid } \\
\text { Extraction }\end{array}$ & $\begin{array}{c}\text { Water } \\
\text { Extraction }\end{array}$ & $\begin{array}{c}\text { Ammonium } \\
\text { Acotate } \\
\text { Extraction }\end{array}$ & $\begin{array}{c}\text { Hydrochloric } \\
\text { Acid } \\
\text { Extraction }\end{array}$ \\
\hline Phttsburgh No. 8 & 112 & 50 & 72 & 29 & 25 & 40 \\
\hline minois No. 6 & 507 & 173 & 105 & 40 & 44 & 86 \\
\hline Eogle Butte & 645 & 167 & 77 & 38 & 34 & 38 \\
\hline
\end{tabular}

The results of the chemical fractionation tests were used with the pyrolyzer heat and material balance to determine the concentration of alkali in the fuel gas. The fuel gas composition was then used in a thermodynamic equilibrium program to determine the liquid and vapor species as the fuel gas was cooled. Typical plots of vapor-phase sodium concentration in the fuel gas vs. the fuel gas temperature are showr in Figure 6. The curves for both Pittsburgh No. 8 and Illinois No. 6 at 2 atm are plotted in this figure. Although the sodium concentrations for the two coals differ at $1700^{\circ} \mathrm{F}$, below $1200^{\circ} \mathrm{F}$ the concentrations are almost identical. At $1000^{\circ} \mathrm{F}$, the vapor-phase sodium concentration is only about $0.3 \mathrm{ppm}(\mathrm{w})$.

Cooling the fuel gas appears to be the best method to reduce the concentration of alkalies entering the ceramic air heater. The cooling can be done by heat transfer to the feedwater system or by direct injection of water. A good portion of the required heat duty could even be transferred in water-cooled cyclones, thereby combining particulate removal and cooling functions.

The alternative to cooling the fuel gas would be alkali gettering or air heater materials that will withstand the untreated alkali levels. Alkali getter systems are generally fixed beds of granular material that operate simply. However, to keep the beds from being plugged with fine particulates from the fuel gas, a ceramic barrier filter is generally specified upstream of an alkali getter vessel. High-temperature operation with a filter of this type would be less reliable than a gas cooler.

Economically viable ceramic materials not harmed by the untreated alkali levels would, of course, be the best situation-if they were available. We will know better whether this is possible when the ceramic corrosion tests in Subtask 3.8 are started. These tests should begin during the next quarter.

\section{Subtask 3.5-Char Reactivity and Transport Gas Requirements}

Some concepts of pyrolyzer and char transport systems were developed during this quarter. These two systems are interrelated, and there are basically twn approaches to their 
Ref.: DE-AC22-91PC91154

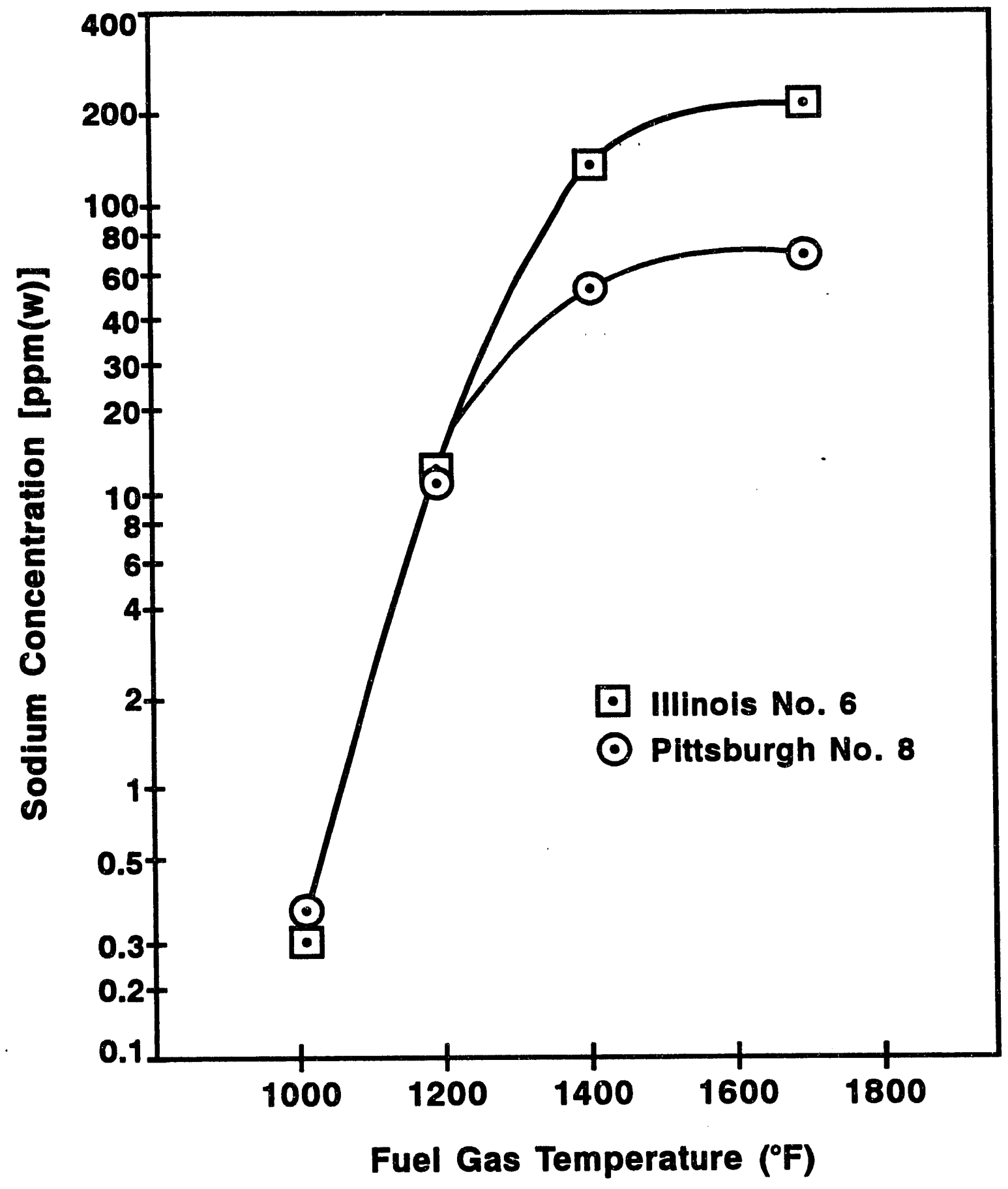

Figure 6 Fuel Gas Sodium Concentration vs. Temperature 
design. One approach is to cool and pulverize the char before it is fed to the char combustor. With this approach, crushed coal and sorbent would be fed to the pyrolyzer. The pyrolyzer could either be a jetting fluidized bed or a circulating fluidized bed. The other approach is to size the coal sorbent fed to the pyrolyzer so that the resultant char/sorbent mixture sent to the char combustor is within the size range that the char combustor can tolerate. This approach would require a circulating fluidized bed.

Table 3 lists some dimensional information comparing the jetting and circulating fluidized beds. This information is based on the second iteration of the 290-MW plant heat and material balance. Both pyrolyzer inside diameters were set to $11 \mathrm{ft}$ in the bed area. The resultant designs were barge shippable. With the higher fuel gas yields now predicted, six jetting bed pyrolyzers or two circulating bed pyrolyzers would be required at 40 psia operating pressure. The large number of jetting bed pyrolyzers required is a drawback, although the vessels and cyclones would be smaller.

Table 3 Comparison of Jetting and Circulating Bed Pyrolyzers - 290-MW Plant
- Pressure
$=40$ psia
- Temperature
$=1700^{\circ} \mathrm{F}$
- Reactor ID
$=11 \mathrm{ft}$

\begin{tabular}{|l|c|c|}
\hline \multicolumn{1}{|c|}{ Parameters } & Jetting Bed & Circulating Bed \\
\hline Superficial Velocity (ft/s) & 5 & 15 \\
\hline Number of Vessels & 6 & 2 \\
\hline Height of Vessels (ft) & 46 & 76 \\
\hline Cyclone ID (ft) & 6.0 & 10.4 \\
\hline Cyclone Length (ft) & 26 & 45 \\
\hline
\end{tabular}


Figures 7. and 8 are diagrams of two possible char transport systems. The system in Figure 7 includes the functions of cooling and pulverizing the char. Char cooling is required because we were not able to find commercial pulverizing equipment that can handle temperatures over $400^{\circ} \mathrm{F}$.

In the char transport system with cooling and pulverizing, the bed char and cyclone drain char are combined in collecting hoppers. One hopper is required for each pulverizer. The char pressure will be reduced using a restrictive pipe discharge (RPD) system, with the char then cooled in screw coolers. Even though the bulk temperature of the char would be below the ignition temperature, there is the possibility of higher-temperature particles. For this reason, an inert gas would be used for transport. Fuel gas is a good candidate; it will be readily available and can be used for combustion after serving as the transport medium.

Near the pulverizer, the solids will be separated from the transport gas and fed to the pulverizer through a seal pot. A commercial pulverizer will be used, most likely with fuel gas as the transport medium. Any seal air requirements for the pulverizer would have to be met with nitrogen. Any excess transport air would be separated at the char combustor with a cycione.

A char transport system without pulverizing the char is shown in Figure 8. Because no pulverizing takes place in this system, the char need not be cooled. Without these two functions, the char transport system is significantly simpler.

To take advantage of the simpler char transport system, the pyrolyzer and coal feed system must be designed to ensure that the char particle size will be within limits for acceptable char combustor operation. Appropriate char sizing would be accomplished by using a finer coal feed to a circulating fluidized bed.

The circulating fluidized bed arrangement is shown in Figure 9. With this type of bed, higher gas velocities are used and more solids are elutriated from the bed. These solids are captured in a cyclone. A portion of the captured char and sorbent is taken off for the char combustors, and the rest is reinjected into the bed, establishing a recirculation of solids that can be many times the feed rate of coal and sorbent.

The circulating bed is the preferred type of fluidized bed if no char is pulverized downstream of the pyrolyzer. The char and sorbent going to the char combustor are removed in the downcomer part of the recirculation system. Since all of these particles must be elutriated from the bed, there is a mechanism to minimize the inclusion of larger particles that may form through agglomeration or ash fusion. The recirculation of solids also tends to make the bed temperature more uniform, inhibiting agglomeration or ash fusion. 


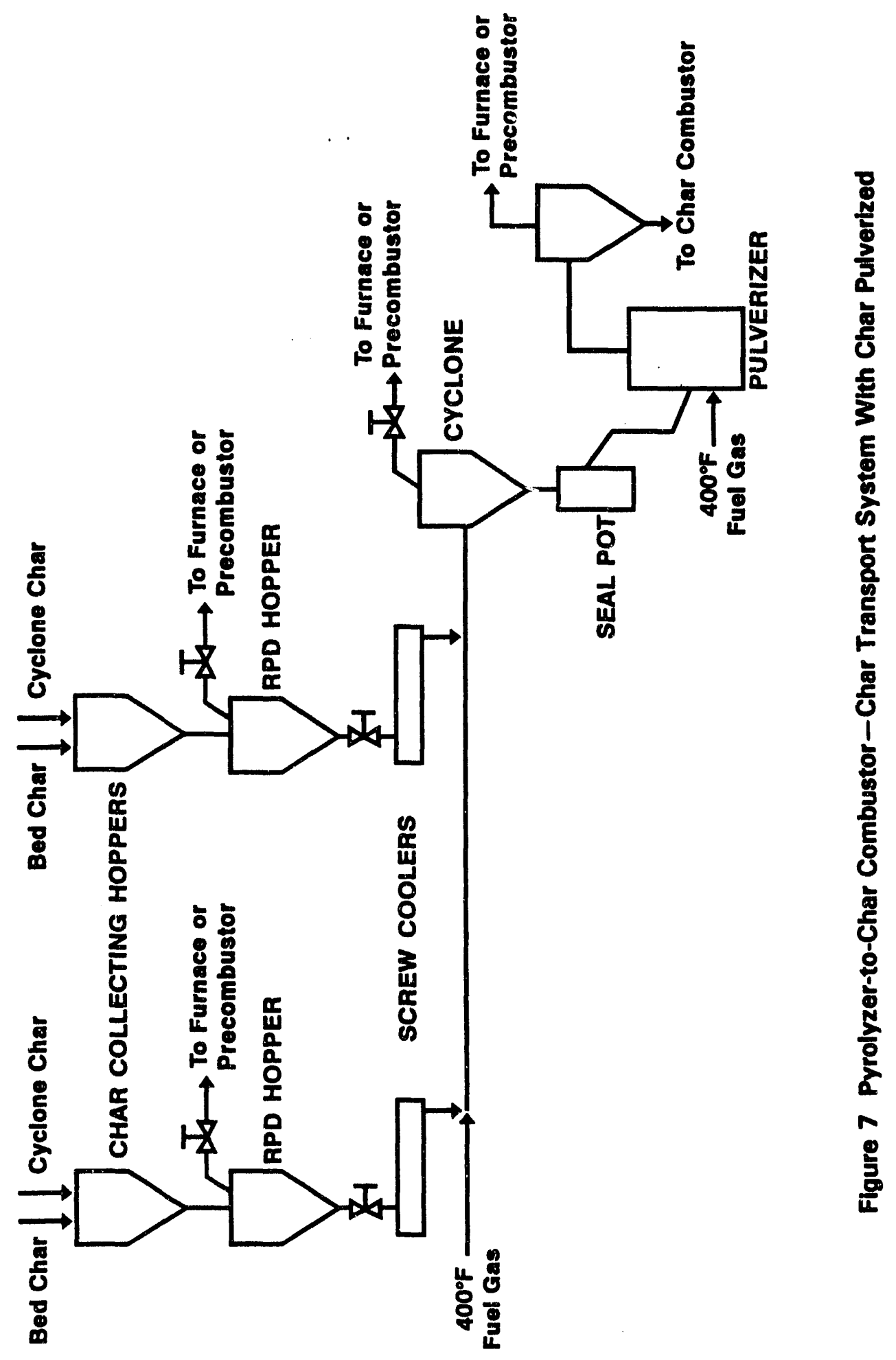




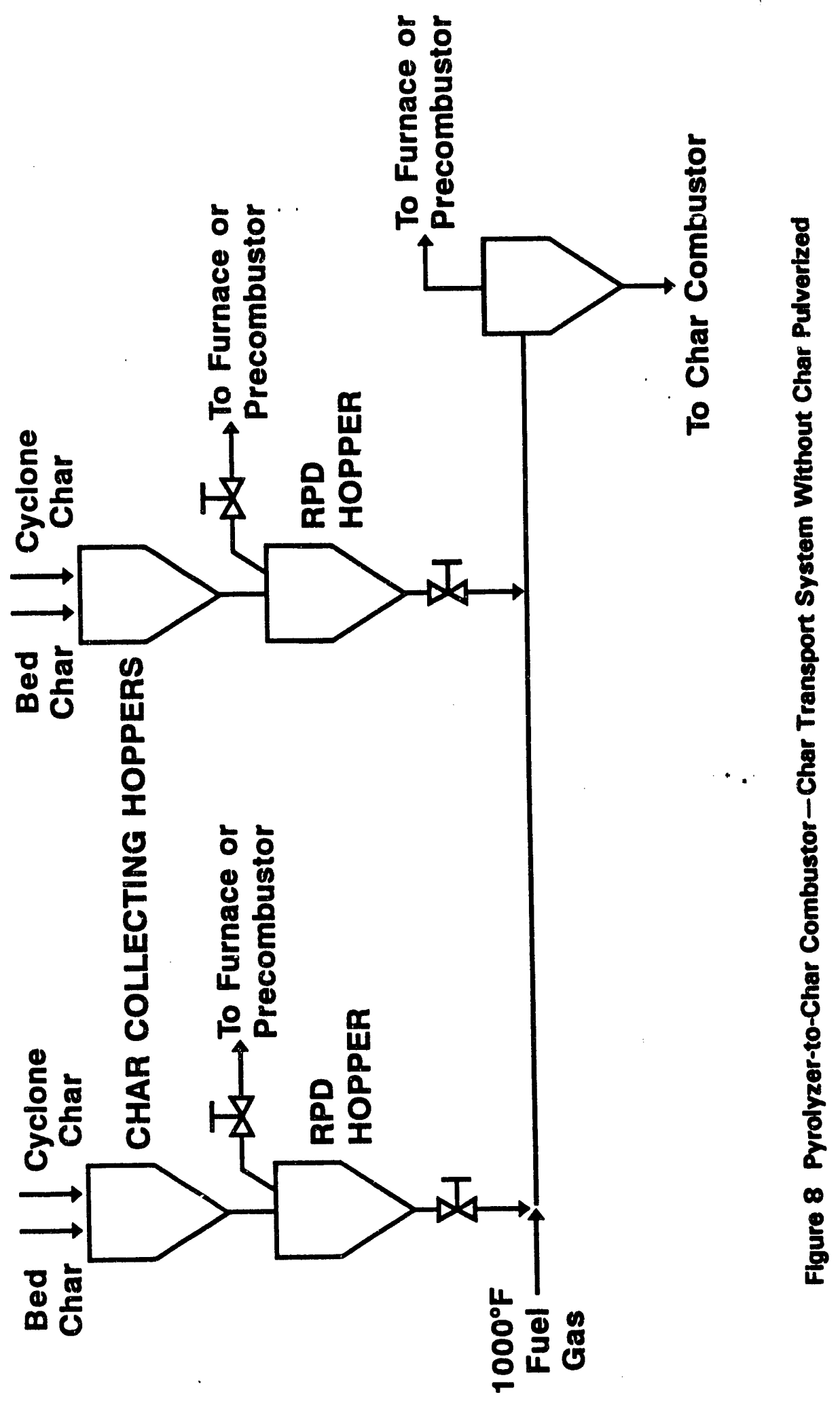




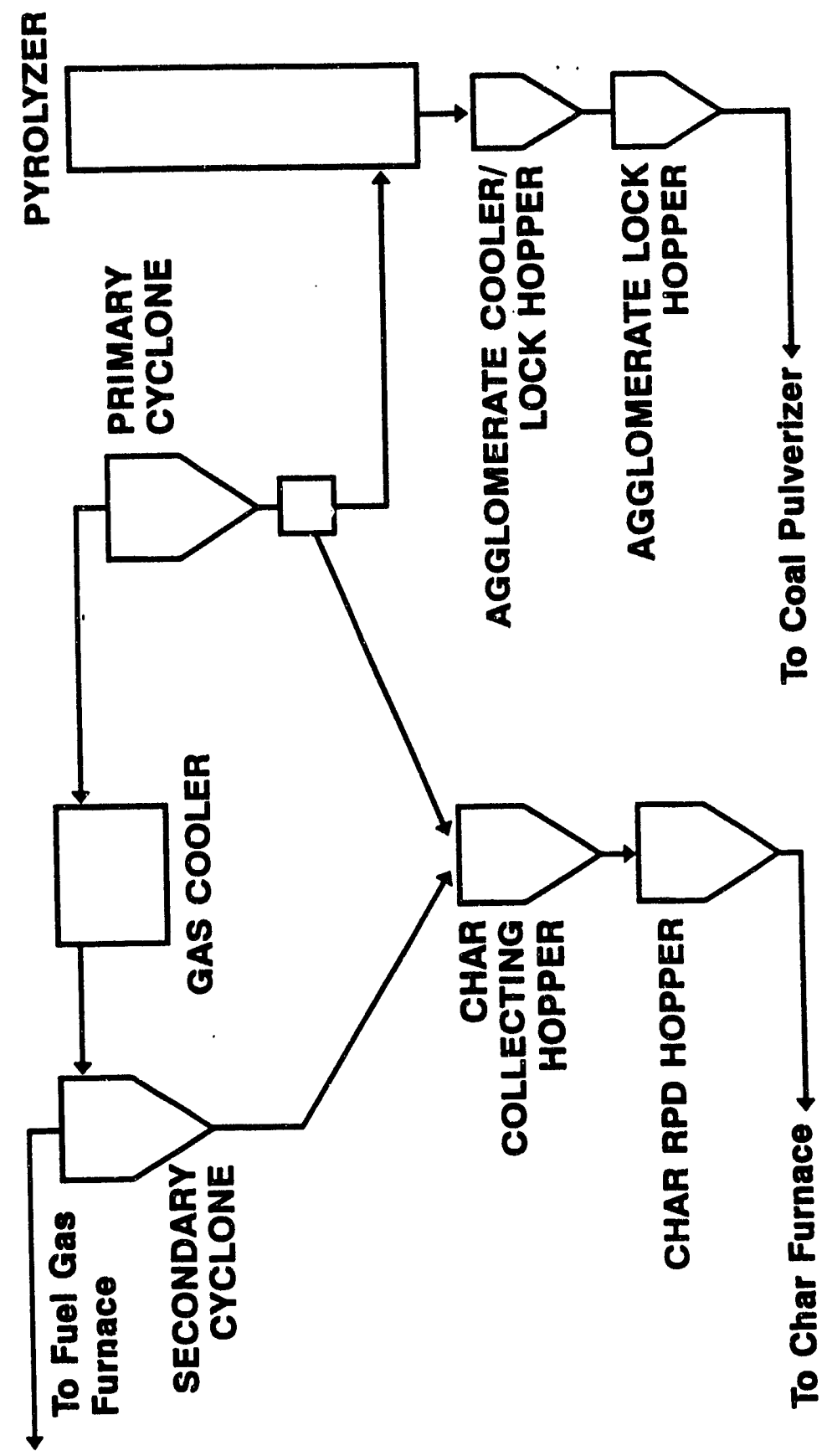


The circulating bed/direct char feed system does have some negative aspects. The major drawbacks are:

- Char size will be determined by both pulverizer and pyrolyzer operating conditions and therefore cannot be as easily adjusted.

- If a dry feed system is used for the pyrolyzer, it will probably require nitrogen inerting because of the fine coal sizing.

A bed drain system will still be required with the circulating bed, to remove oversized particles that never elutriate; but the flow rate from this drain will be relatively small. After being cooled, these solids could be mixed with the raw coal and fed to the pulverizers.

Based on the systems analysis so far, the circulating bed/direct char feed system appears to be the better approach. With the revised pyrolyzer fuel gas yield estimates, six jetting bed pyrolyzers are required for the 290-MW plant. Only two circulating bed pyrolyzers will be required, reducing system complexity and cost. Several approaches were investigated for pulverizing char downstream of the pyrolyzer, but they all require a significant amount of additional equipment. During the next quarter, work will be done to characterize the particle size distribution we can expect from a circulating bed and the required feed size of particles to the pyrolyzer.

\section{Subtask 3.6-Char Combustor Technical Assessment}

The overall objective of this task is to perform a technical assessment of the char combustor to determine preliminary performance and operating requirements and to identify char combustor development issues.

The char combustor must be capable of operating with char from the pyrolyzer as its primary fuel. Together, the char combustor and furnace are required to complete combustion of the char in a manner that minimizes the formation of $\mathrm{NO}_{\mathrm{x}}$, removes most of the ash from the gas stream, and facilitates the removal of $\mathrm{SO}_{2}$ from the gas stream.

A number of issues related to the performance and operating requirements of the char combustor must be addressed early in the HITAF program. These issues include:

- The size and combustion characteristics of the char feed

- The method of char transport to the combustor

- The combustor air preheat temperature

- The need for precombustor auxiliary fuel 
- Combustor emissions and slag rejection requirements

- Combustor heat loads and cooling water requirements.

A slagging-type combustor has been selected as the baseline approach to achieve high combustion efficiency while firing the low-volatile char produced by the pyrolyzer. The primary advantages of such a combustor system are high combustion intensity, low $\mathrm{NO}_{\mathrm{x}}$ formation, removal of up to 90 percent of the original coal ash as slag, and compact size. A slagging combustor also produces a high-temperature well-mixed gas product under conditions that are ideal for injection of lime-based sorbents for subsequent furnace calcination and sulfur capture.

The selection of char particle size is critical to slagging combustor design. Two basic combustion strategies have been considered:

- A wall burner, in which most of the combustion occurs along the walls of the combustor.

- An entrained-flow burner, in which most of the combustion occurs while the char particles are entrained in the gas.

The first approach would require crushed coal, with median particle sizes in the range of 1 to $5 \mathrm{~mm}$, while the second approach would require pulverizing the coal (either before or after the pyrolyzers) to produce a median particle size of approximately 50 microns (70 percent through 200 mesh screen).

In a wall burner, the fuel particles are so large that most of them are centrifuged to the walls before burnout. The residual char becomes embedded in the molten slag layer and is subsequently oxidized. The combustion rate is primarily limited by diffusion of oxidizing species to the wall. Such combustors are typically operated under excess oxygen conditions to ensure complete combustion of the char particles prior to the slag tap. Wall burners have demonstrated high carbon burnout for a variety of coals. One disadvantage has been the relatively high levels of $\mathrm{NO}_{x}$ formation because of the excess oxygen conditions. Experience in running such devices under fuel-rich conditions is limited, particularly for low-volatile fuels.

In an entrained slagging combustor, combustion takes place primarily in the gas, with only a minimal amount of wall burning. Combustion rates are typically limited by the diffusion of oxidizer species to the surface of the particle, at rates generally higher than diffusion rates along a flat, or slightly curved, surface. The highly turbulent confined vortex flow also promotes particle scrubbing, which tends to further increase combustion rates. Excellent mixing between the fuel and oxidizer is also achieved through careful design of the combustion chamber and fuel injectors. NO formation is minimized by both fuel and oxidizer staging. The main, or slagging stage of the combustor is operated under high-temperature fuel-rich conditions, in a regime that minimizes the formation of thermal $\mathrm{NO}_{x}$ and $\mathrm{NO}_{x}$ precursors. The remaining oxidizer is added under controlled conditions to complete combustion while further minimizing $\mathrm{NO}_{\mathrm{x}}$ formation. 
Because of the importance of combustion efficiency and low-NO formation to the overall design and operation of the HITAF plant, an entrained combustion approach has been selected as the baseline. Typically, this requires pulverized coal grinds in which 50 to 90 percent of the product passes through a 200 mesh screen. (Another backup combustion approach, involving a conventional arch-type furnace, would also require a coal grind of this type.) Within this range, the grind can be varied as desired to emphasize a particular aspect of combustor performance. To improve carbon burnout, a finer grind can be selected; however, this choice usually lowers combustor slag recovery, especially in larger units. Increasing the grind has the opp osite effect. The final selection of particle size will be made based on combustor requirernents, following detailed analytical combustor modeling to be performed as part of the preliminary research and development effort (Task 3).

Another important design consideration is the selection of a precombustor fuel. Figure 10 shows the different precombustor fuel options that have been considered. The first major decision, as discussed in the previous section, is the selection of fuel particle size. Once a fine grind is selected, the combustor can consist of single or multiple stages. Selection of a single-stage combustor has several disadvantages, including lower operating flexibility and lower oxidizer temperature. Adding a supplemental fuel such as natural gas or fuel oil may gain back some margin; however, fuel costs may be unacceptable. A lower grade fuel such as the parent coal or fuel gas generated in the pyrolyzer would be less expensive, but is not likely to provide the quick energy release that is required to initiate rapid char oxidation.

An alternative approach, which has been followed frequently in the past, is to add a precombustor stage. In many slagging combustor configurations, a precombustor is included for several reasons. First, most coals in the U.S. have ash fusion temperatures above $2100^{\circ} \mathrm{F}$. To properly operate the combustor in a fluid regime, the combustion gas temperature must be at least several hundred degrees above the fusion point. It must be able to initially melt the ash species as well as maintain them in a fluid state all the way to the slag tap. A higher oxidizer temperature entering the slagging stage facilitates :his process. Another consideration is gas temperatures in the primary flame zone. Higher oxidizer inlet temperatures facilitate the processes of particle heating and devolatilizing, which are important for flame stability, as well as for their impact on the level of carbon burnout at the exit of the combustor.

A variety of fuels can be considered for the precombustor, including an expensive, but easy-to-burn, gas or liquid fuel (natural gas, fuel oil, or fuel gas); a solid fuel (coal, char, or both); or several different combinations of these (char and fuel gas, char and natural gas, char and oil).

A key issue is the required combustion time for the solid fuel. Typically, the precombustor is designed to be nonslagging. A large amount of heat can be gained just through combustion of the volatiles, provided rapid, high levels of devolitalization can be achieved. The residual char particles are subsequently oxidized in the main-or slagging-stage, and the residual slag particles are centrifuged to the wall and tapped. Refractory-lined surfaces are 


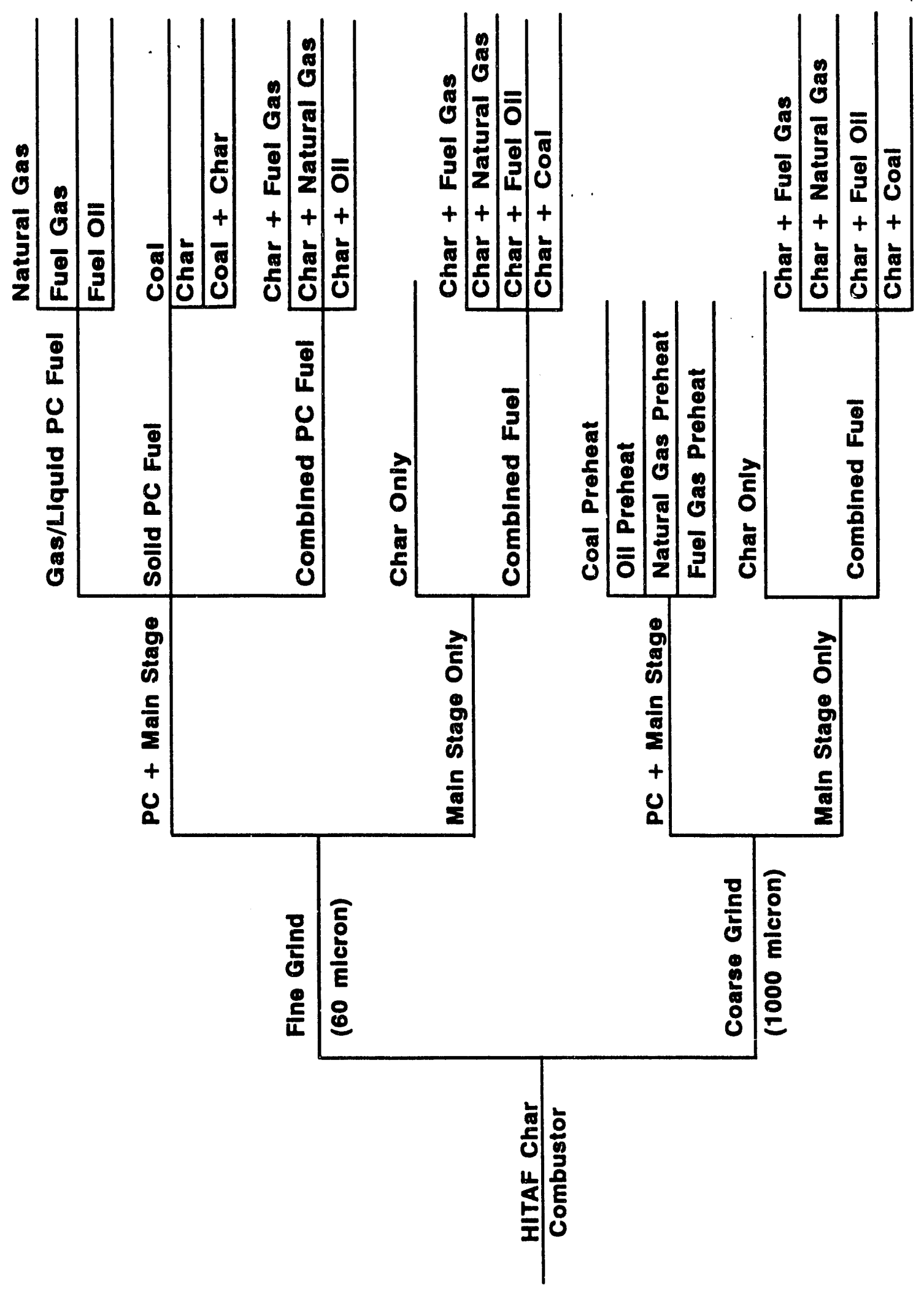

도을 
inclisded in the precombustor to reduce heat loss to the cooling water and to maintain the required oxidizer temperature.

The char produced in the pyrolyzer has very little volatile content and thus cannot be expected to add much heat to the oxidizer in the time available in the typical precombustor. This being the case, there is no sense to adding a clean fuel, or even coal, with char in the precombustor, since the char will be little more than $a$ heat sink on the overall process. In addition, delivery of char to orly one location in the combustor is advantageous, since this approach would eliminate the need for accurate control and metering of the precombustor/ combustor fuel split.

Based on these discussions, the best option apparent is to burn a low-cost fuel other than char in the precombustor. The prime candidate is coal, since this fuel is readily available in the plant and the experience base for a coal-fired precombustor is high. One alternative is to burn a portion of the low-Btu gas in the precombustor. These two options are discussed in the following paragraphs.

Figure 11 is a simple schematic of a system involving a coal-fired precombustor coupled with a char-fired slagging stage. In this case, the coal is assumed to be pulverized before it is fed to the pyrolyzer. The majority of coal is fed to the pyrolyzer, where the fuel is partially gasified. A cyclone (or series of cyclones) is used to separate the low-Btu gas produced in the pyrolyzer from the residual char. The char is fed directly to the slagging stage of the char combustor. The remaining coal is directly fed to the precombustor, where it is burned with turbine exhaust air to yield a precombustor exit temperature of at least $2000^{\circ} \mathrm{F}$ before it is injected into the slagging stage.

Combustion calculations were performed to characterize the precombustor exit temperature as a function of precombustor firing rate. The combustor air is delivered from the turbine exhaust. An air inlet temperature of $1150^{\circ} \mathrm{F}$ was assumed, with an oxygen content of 19.5 percent as a result of natural gas combustion upstream of the gas turbine. Calculations were performed over a range of combustor stoichiometries-from 70 to 95 percent of the theoretical air - for combustion of both the precombustor coal and slagging-stage char. Precombustor fuel input is shown as a fraction of the total fuel input to the combustor (coal and char). For example, a precombustor fuel thermal input of 20 percent translates into a $20 \times 10^{6} \mathrm{Btu} / \mathrm{h}$ coal for every $80 \times 10^{\circ} \mathrm{Btu} / \mathrm{h}$ char.

The results of the combustinn calculations are shown in Figure 12. Note that the relationship between precombustor exit temperature and precombustor fuel input is fairly linear up to approximately $2500^{\circ} \mathrm{F}$, after which further additions of precombustor fuel will yield increasingly smaller rises in precombustor exit temperature. Also note that, for a given precombustor fuel input, higher precombustor exit temperatures can be achieved at lower overall combustor stoichiometries, because the same amount of heat from the fuel is being used to heat up a smaller amount of air. For the baseline case, to achieve a minimum temperature of $2000^{\circ} \mathrm{F}$ at a combustor stoichiometry of 0.80 ( 80 percent of theoretical air), approximately 18 percent of the total combustor fuel thermal input must be in the form of coal. 
$$
\text { Date: November } 1992
$$

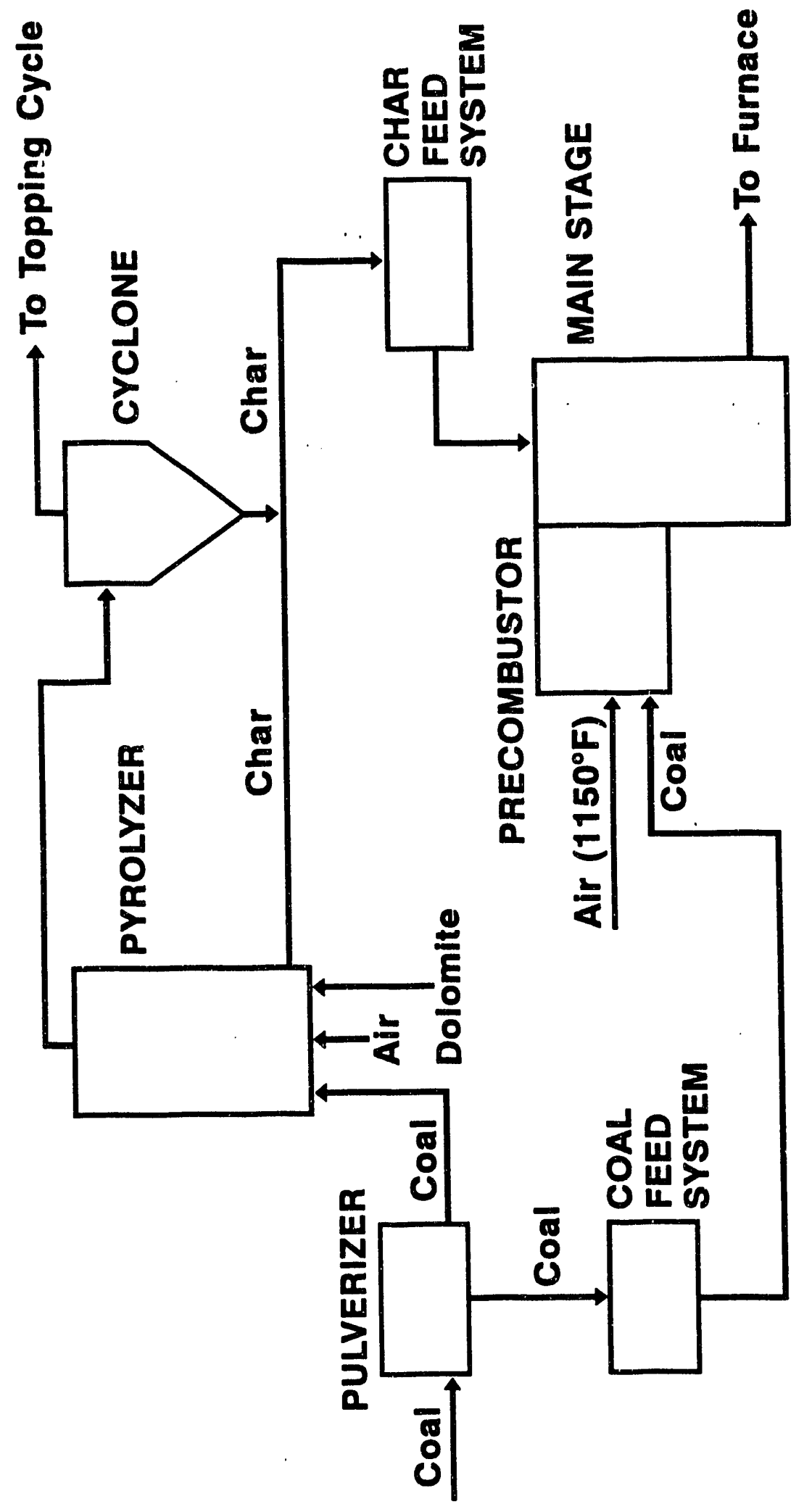




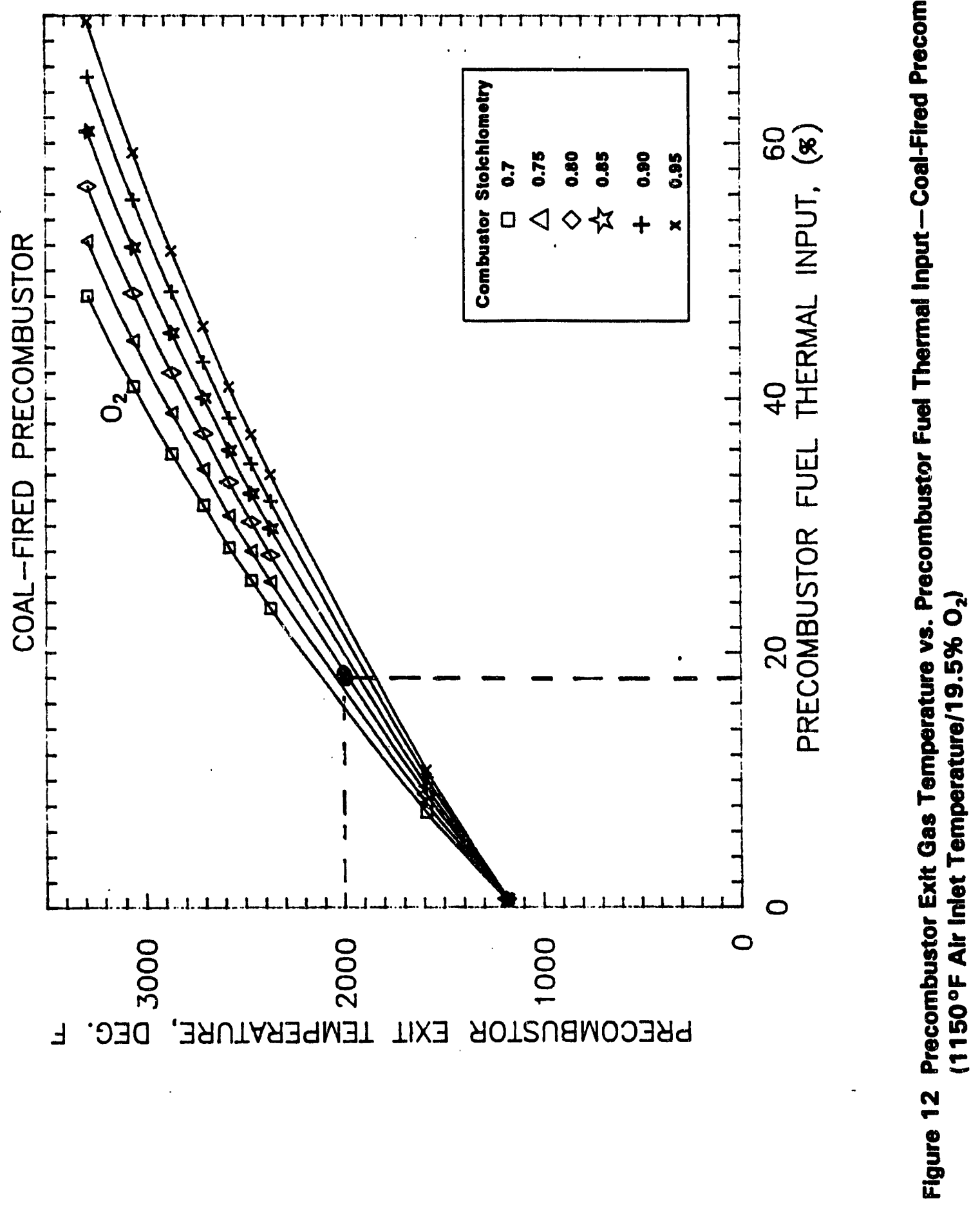


Another approach considered was firing a portion of the low-Btu gas in the precombustor. A schematic of this approach is shown in Figure 13. Here, all of the coal is fed to the pyrolyzer first (either in crushed or pulverized form). The residual char is fed from the pyrolyzer and cyclone to the main stage of the combustor. A portion of the low-Btu gas is diverted from the topping cycle and transported to the precombustor, where it is fired with air from the turbine exhaust at $1150^{\circ} \mathrm{F}$ and 19.5 percent oxygen. Plots of precombustor exit temperature as a function of precombustor fuel thermal input for a fuel-gas-fired precombustor are shown in Figure 14. In general, for a given thermal input, the fuel-gas will yield a lower precombustor exit temperature relative to a coal-fired precombustor. The primary reason for this is that the low-Btu gas contains a larger amount of diluent $\left(\mathrm{N}_{2}, \mathrm{CO}_{2}\right)$ relative to coal, which decreases combustion temperature. Note also that the slope of the curves in the range of 2000 to $3000^{\circ} \mathrm{F}$ is considerably flatter than the slope of the coal curves, which indicates that a larger increase in fuel-gas thermal input (relative to coal) would be required to achieve a given increase in precombustor outlet temperature.

One of the important system trade-offs involving the char combustor is the selection of air inlet temperature. For the HITAF project, we propose using a portion of the gas turbine exhaust as oxidizer for the char in the char combustor. The temperature at which this stream is available depends on several factors, including the gas turbine inlet temperature and pressure ratio, gas turbine rating, and the number of heat exchangers downstream of the gas turbine exit. For the char combustor, an oxidizer temperature of at least $2000^{\circ} \mathrm{F}$ is expected to be required at the inlet of the slagging stage to ensure a good head-end combustion and high carbon burnout. As the temperature at the inlet of the precombustor is lowered, additional precombustor fuel will be required to achieve this minimum temperature, as shown by comparing Figures 12 and 15, which show the precombustor exit temperature for air inlet temperatures of 1150 and $750^{\circ} \mathrm{F}$ respectively. To achieve a minimum precombustor exit temperature of $2000^{\circ} \mathrm{F}$ at an overall combustor stoichiometry of 0.80 , the precombustor firing rate must be 26 percent of the total combustor firing rate for the $750^{\circ} \mathrm{F}$ case. For the $1150^{\circ} \mathrm{F}$ case, the required precombustor firing rate is 18 percent, as noted in Figure 12. Thus, for a combustor firing $100 \times 10^{\circ} \mathrm{Btu} / \mathrm{h}$ fuel, the fuel splits would be those shown in Table 4.

Alternatively, for every $100 \times 10^{\circ} \mathrm{Btu} / \mathrm{h}$ char, $35.1 \times 10^{\circ} \mathrm{Btu} / \mathrm{h}$ coal would be required for the $750^{\circ} \mathrm{F}$ air inlet temperature, while $22 \times 10^{\circ} \mathrm{Btu} / \mathrm{h}$ would be required for the $1150^{\circ} \mathrm{F}$ air inlet temperature. The optimum air inlet temperature will be determined based on overall cycle considerations. These results are being evaluated relative to the complete system to determine the optimum air inlet temperature for the cycle.

Preliminary char combustion kinetic calculations were performed as part of the char combustor technical assessment subtask to define conditions for the proposed fuel characterization tests (Subtask 3.10) and to assess the impact on carbon burnout of char particle size, fuel volatile content, particle residence time, precombustor preheat temperature, and overall combustor stoichiometry. These preliminary calculations were performed primarily to help define the preliminary combustor operating envelope. More detailed analytical modeling will be performed starting in the next quarter to more accurately define combustor operating envelope and performance as well as provide technical criteria for the char combustor conceptual design. 


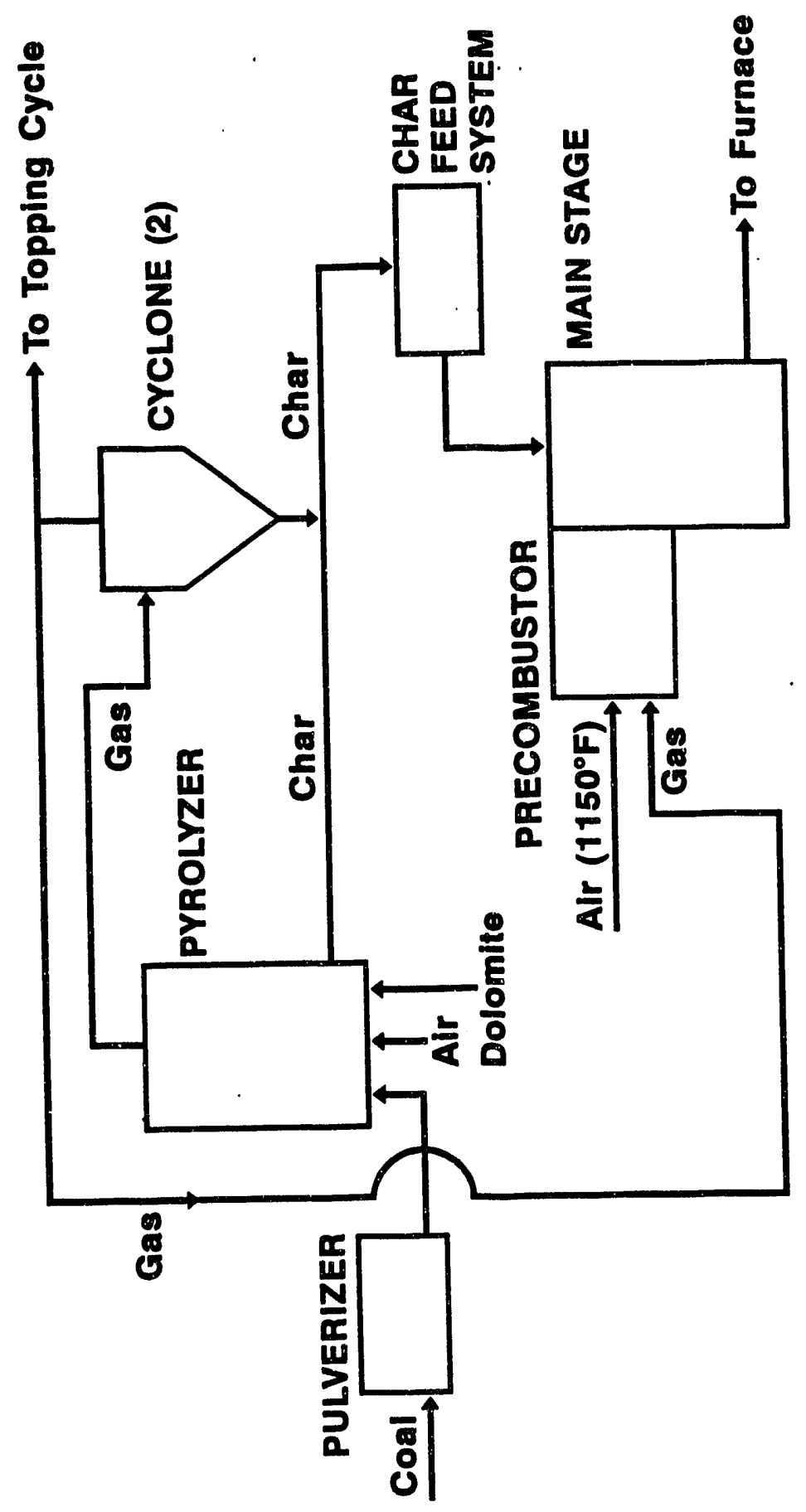


Ref.: DE-AC22-91PC91154

Date: November 1992

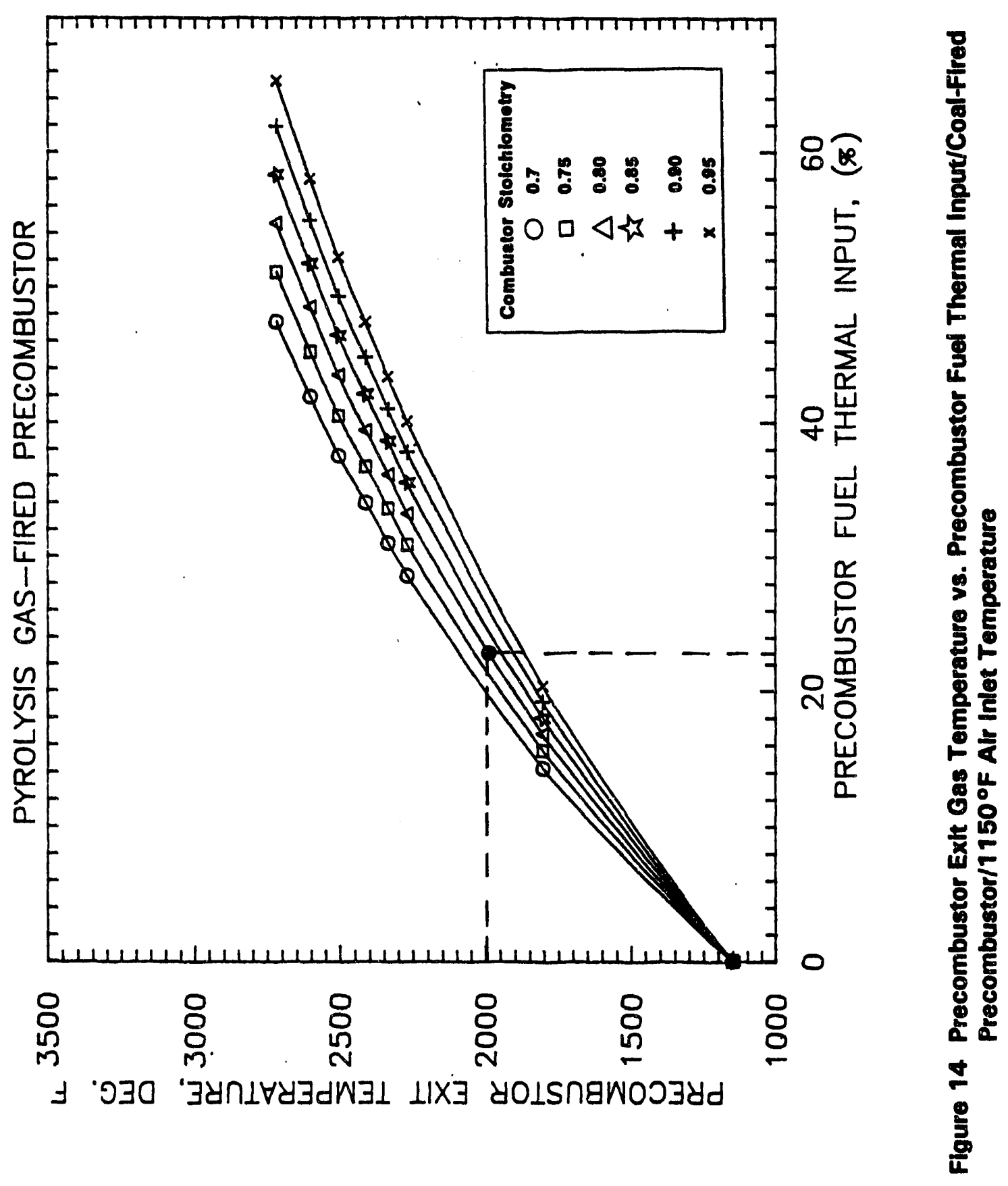




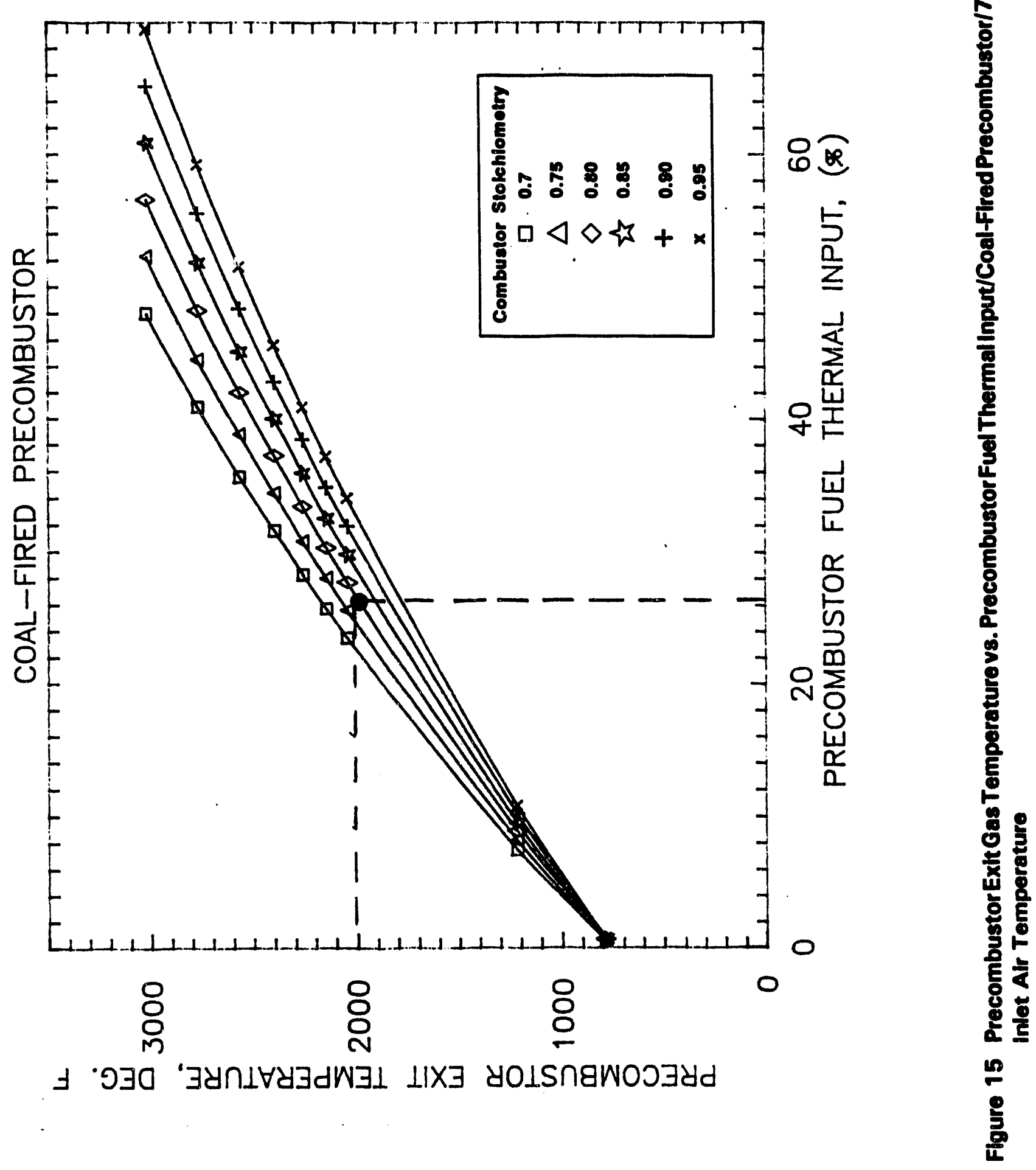


Table 4 Effect of Alr Inlet Temperature on Precombustor Coal Heat Input and SlaggingStage Char Heat Input

\begin{tabular}{|c|c|c|}
\hline $\begin{array}{c}\text { Air Inlet Temperature } \\
\left({ }^{\circ} \mathrm{F}\right)\end{array}$ & $\begin{array}{c}\text { Precombustor Firing Rate- } \\
\text { Coal }\left(10^{\circ} \mathrm{Btu} / \mathrm{h}\right)\end{array}$ & $\begin{array}{c}\text { Slagging-Stage Firing Rate- } \\
\text { Char (10 Btu/h) }\end{array}$ \\
\hline 750 & 26 & 74 \\
\hline 1150 & 18 & 82 \\
\hline
\end{tabular}

The model calculates overall carbon burnout as a function of particle residence time. For these preliminary calculations, a simple one-dimensional char oxidation model was used. It assumes that the coal particles are uniformly mixed throughout the flow cross section and are fully entrained by the gas. One-dimensional plug flow is also assumed. Both shrinking-core and constant-core char particle models are included. In the shrinking-core model, the char burns with steadily decreasing size, but at constant density. In the constant-core model, the char burns with steady reduction in density (pore enlargement), but at constant size. Available data suggest that the changes in particle structure of the coal chars are often between those described by these two models, tending to vary as a function of coal type, gas temperature, and gas composition.

Equilibrium gas temperatures and compositions at different levels of carbon burnout are determined by the NASA-Lewis thermochemical program. Figure 16 plots equilibrium gas temperature as a function of carbon burnout, assuming a combustor equivalence ratio of 0.8 (80 percent of theoretical air required for stoichiometric combustion). The air temperature at the inlet of the combustor is assumed to be $1150^{\circ} \mathrm{F}$. Note that the gas temperature increases for most of the reaction and then decreases slightly at the end. This change occurs as a result of operating the combustor under fuel-rich conditions. Initially, a relatively large amount of oxygen is available to react with the char particles to form carbon dioxide. Since this reaction is exothermic, the overall gas temperature rises. However, as combustion nears completion, the oxygen in the gas stream is depleted, as shown in Figure 17. At this point, provided the gas and particle temperatures are high enough, oxidation proceeds by $\mathrm{H}_{2} \mathrm{O}$ and $\mathrm{CO}_{2}$. These reactions, being endothermic, require heat from the gas if they are to proceed. As a result, the overall gas temperature drops in this regime. Plots of $\mathrm{CO}_{2}$ and $\mathrm{H}_{2} \mathrm{O}$ gas concentrations are shown in Figures 18 and 19 respectively. As expected, $\mathrm{CO}_{2}$ concentration increases up to the point at which the oxygen concentration becomes zero; it then decreases slightly as it reacts with the residual char to form carbon monoxide. $\mathrm{H}_{2} \mathrm{O}$ concentration, on the other hand, remains fairly constant throughout the reaction, except for a small decrease at the end after the oxygen has been depleted. 


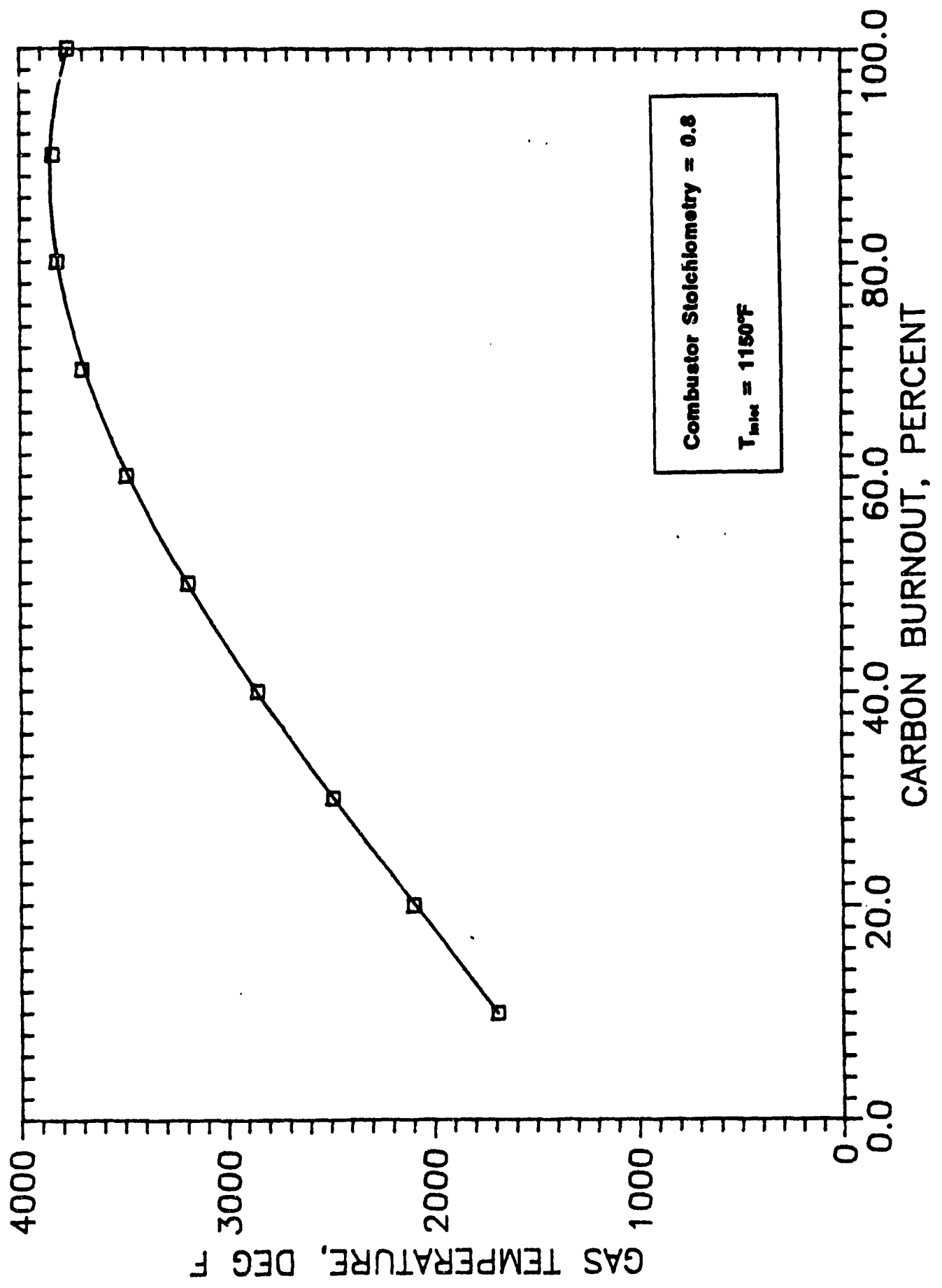




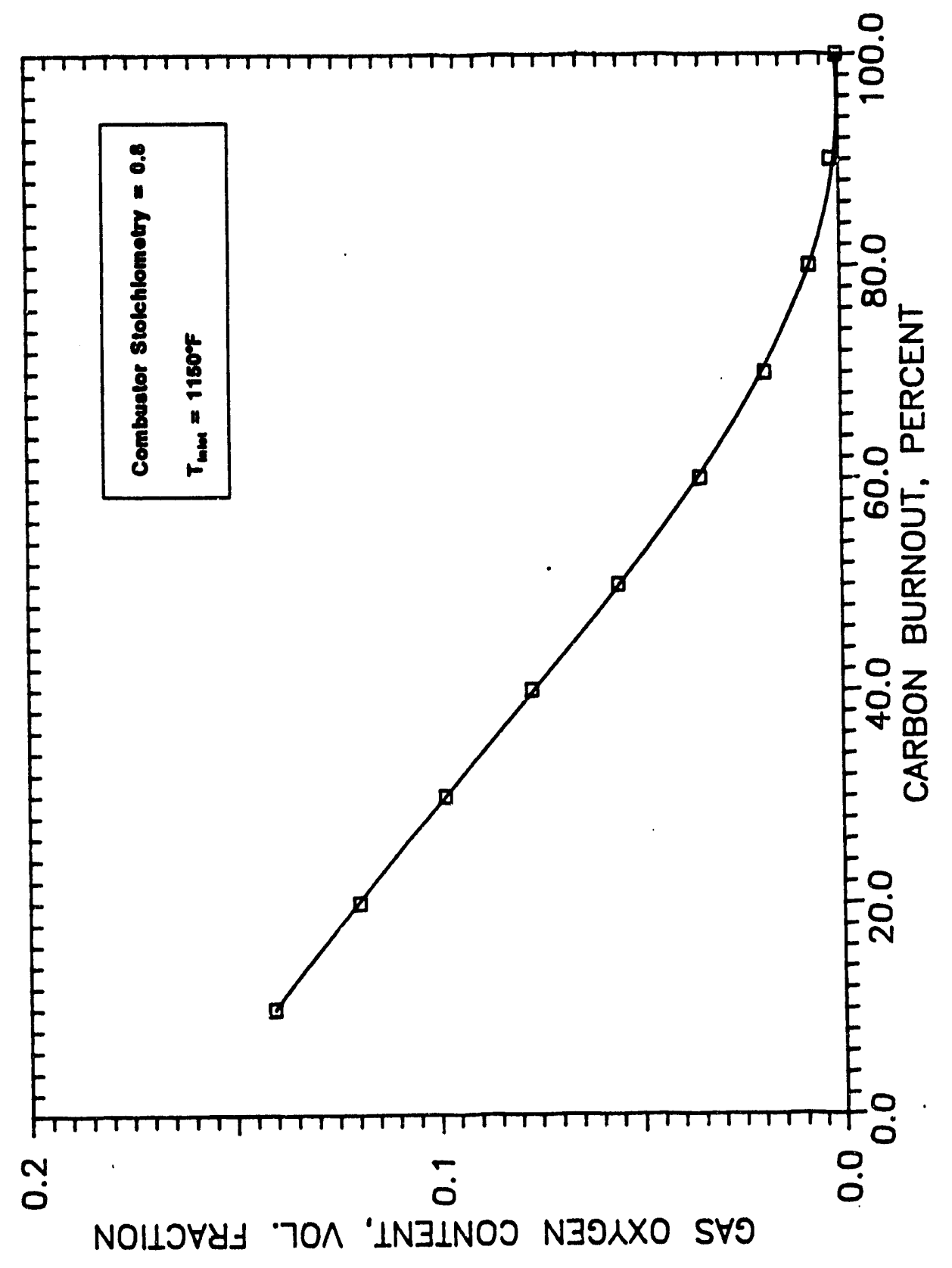




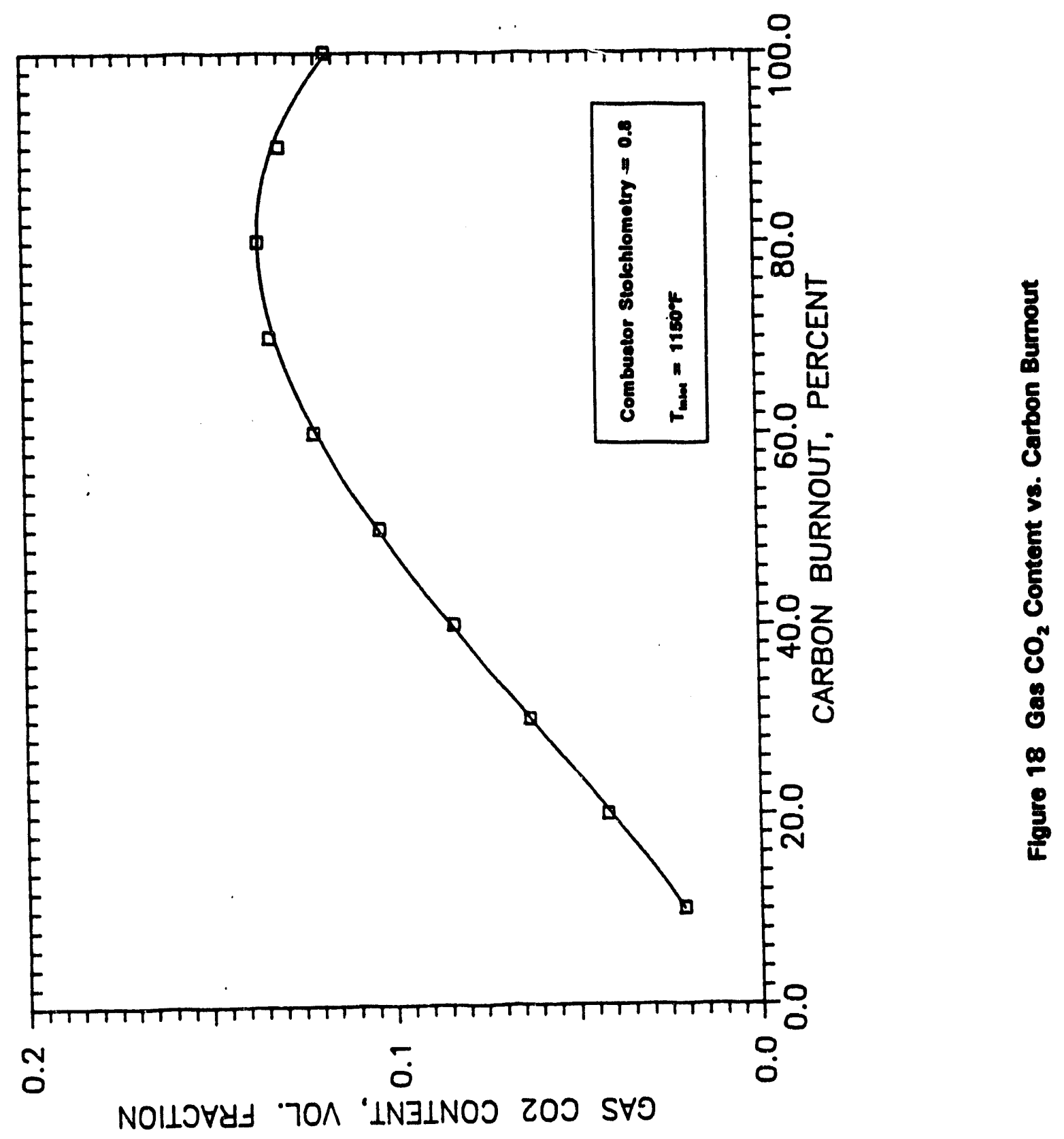




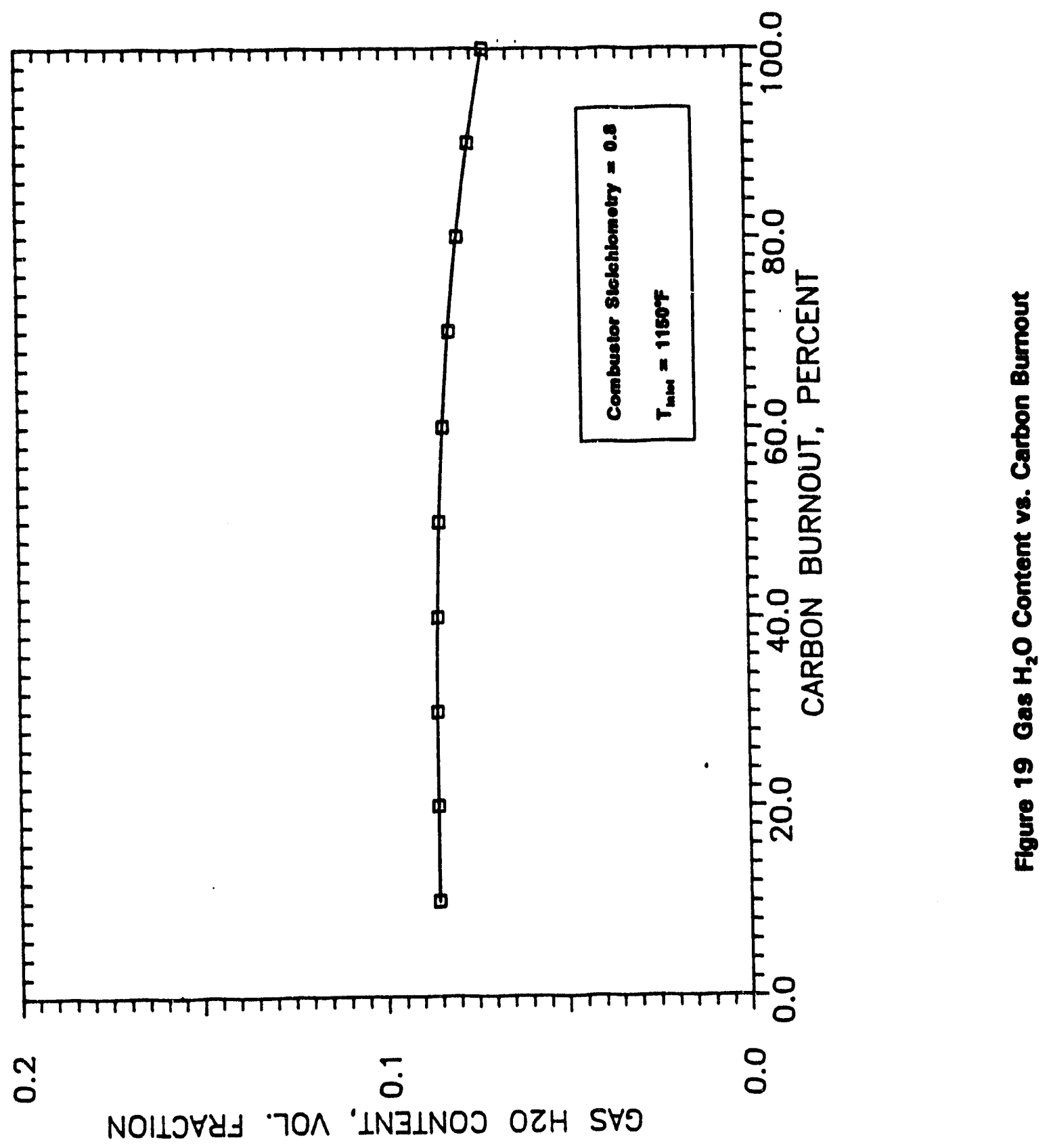


For the purpose of these preliminary char oxidation calculations, the reactions of char with oxygen, carbon dioxide, and steam were assumed to be mass transfer, limited following initial particle heating and devolatilization. This assumption is valid for very high particle temperatures (on the order of $3000^{\circ} \mathrm{F}$ or higher). It will be relaxed in future modeling efforts after the kinetics of the char of interest have been adequately characterized through experimental study. Another assumption that is made in the model is that particle heating and devolatilization are extremely rapid. The char oxidation "clock" in the model thus starts after these processes have occurred. In addition, an initial level of carbon burnout must be specified, which corresponds approximately to the fraction of coal that is released as volatiles.

Figures 20 and 21 plot carbon burnout as a function of particle residence time for different initial levels of carbon burnout (10 and 40 percent). Figure 20 plots carbon burnout for the first $50 \mathrm{~ms}$, while Figure 21 shows the first $200 \mathrm{~ms}$ for carbon burnout above 90 percent. For these calculations, a nominal 70 percent through 200 mesh coal grind has been assumed. During the early stages of burnout, the reaction rates for the lower volatile case (initial carbon burnout $=0.1$ ) are higher than those for the higher volatile case (initial carbon burnout $=0.4$ ), since less oxygen has been consumed during volatile combustion. This reaction rate allows the lower volatile case to close the gap, but never quite catch the higher volatile case. To achieve a certain level of carbon burnout, the lower volatile case requires approximately 50 percent more residence time than the higher volatile case. Additionally, for a given residence time, the shrinking-core model yields a lower level of carbon burnout relative to the constant-core model; thus it is the more conservative model.

Preliminary calculations were also performed to assess the impact of char particle size on carbon burnout. The results of these calculations are shown in Figures 22 and 23, where coal grinds of 70 percent through 200 mesh and 90 percent through 200 mesh are compared for an assumed initial carbon burnolt of 0.1 . The median particle sizes for these two grinds are 48 and 30 microns respectively. As expected, the coarser grind requires approximately 50 percent additional residence time to achieve a given level of carbon burnout. A comparison of Figures 20 and 22 shows that the curves for the 90 percent through, 200 mesh coal with an initial carbon burnout of 0.1 are approximately equivalent to the curves for the 70 percent through 200 mesh coal with an initial carbon burnout of 0.4 . In other words, one possible way to compensate for a lower volatile content is to fire the combustor with a finer coal grind.

To summarize, preliminary char oxidation calculations were performed to help define the operating conditions for char combustion testing (gas temperature and composition) as well as to assess the impact of volatile content and char particle size on combustor residence time requirements. These calculations showed that approximately 50 percent more residence time may be required to achieve a given level of carbon burnout. However, this requirement may be reduced by utilizing a finer coal grind. Additional preliminary calculations are being performed to assess the impact of precombustor preheat temperature and combustor stuichiometry on carbon burnout in support of system trade-off studies. More detailed combustor modeling will be performed once kinetic data from the char combustion tests are available. 

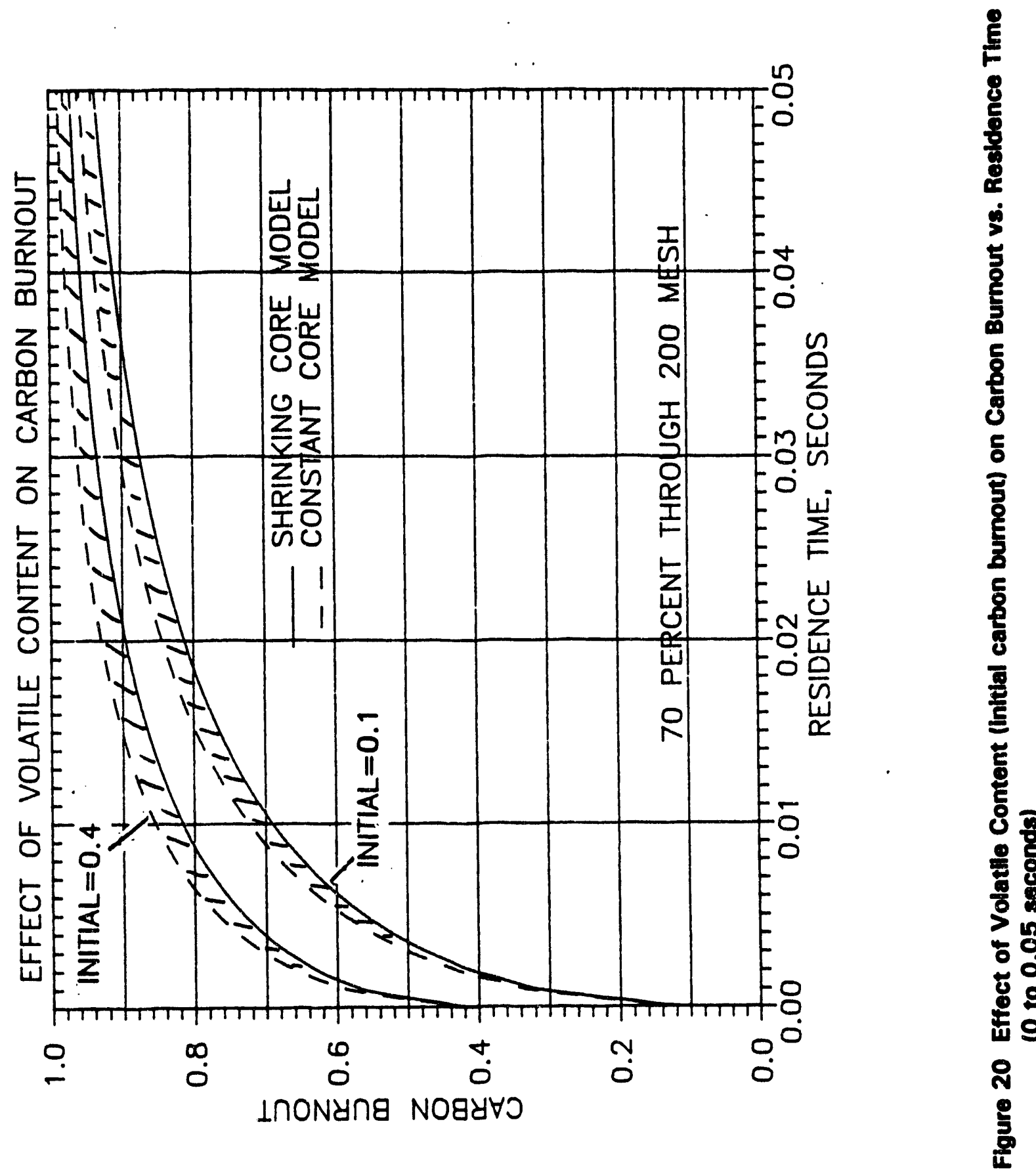


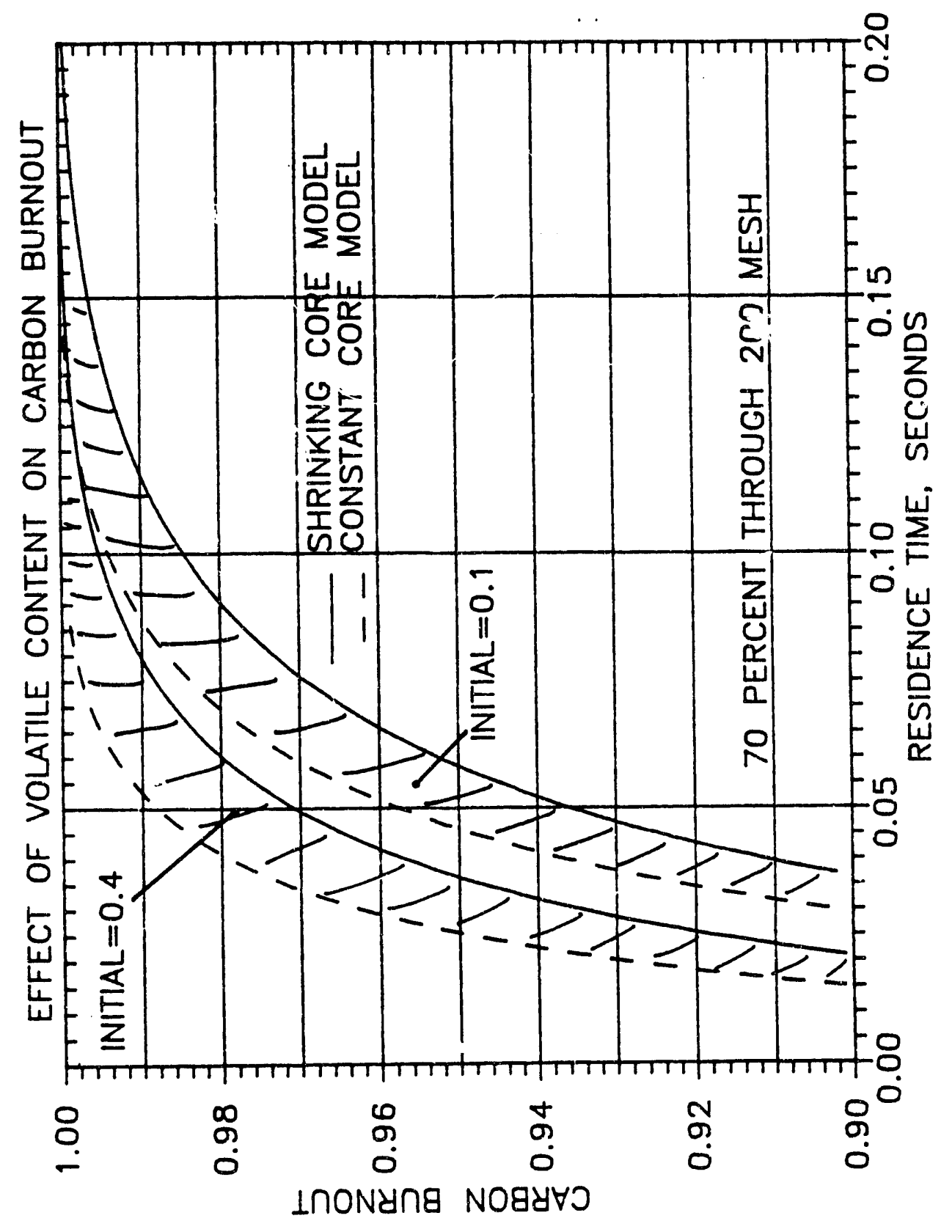




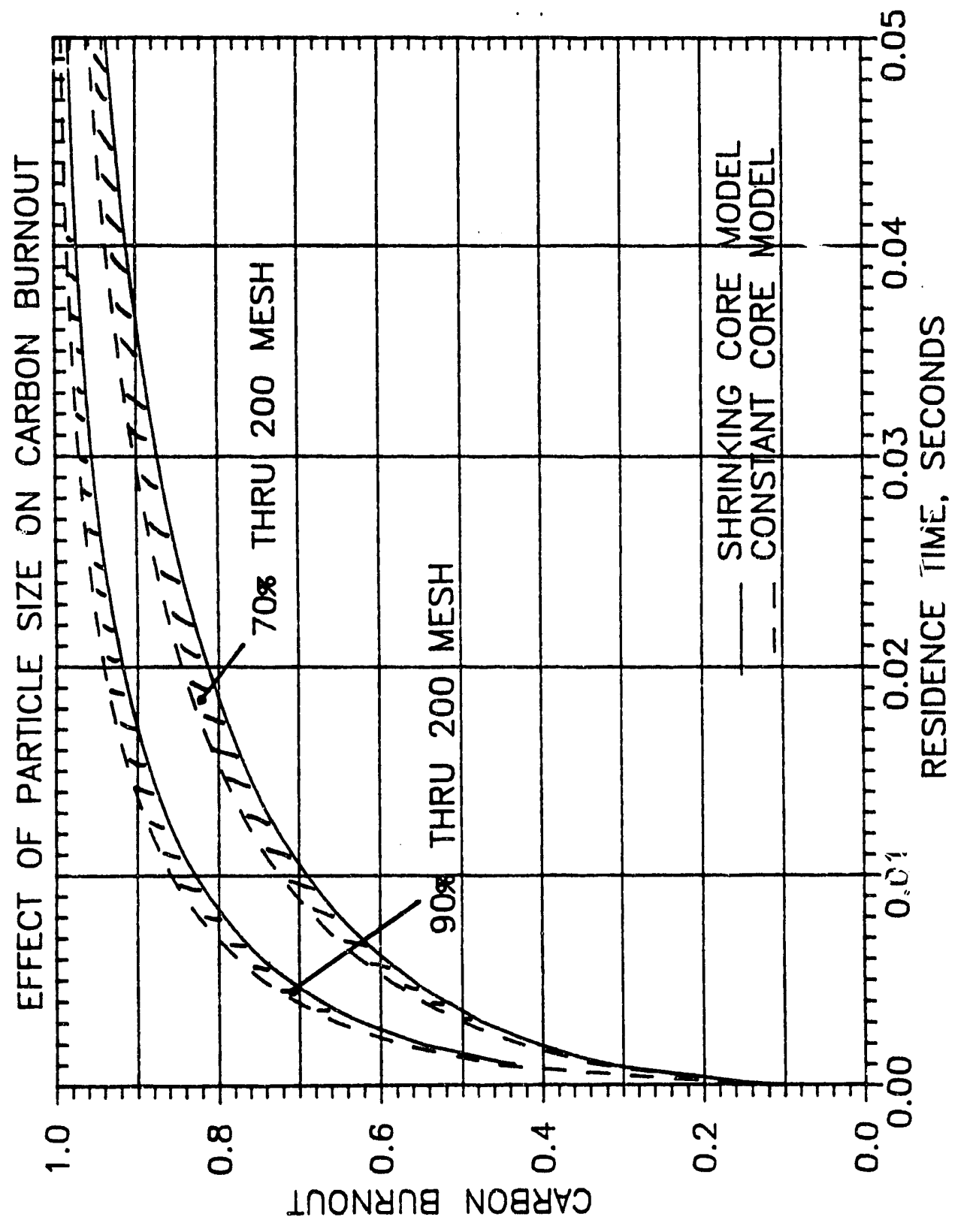

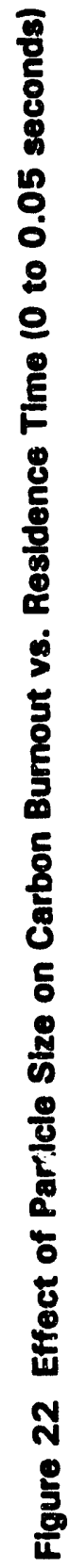




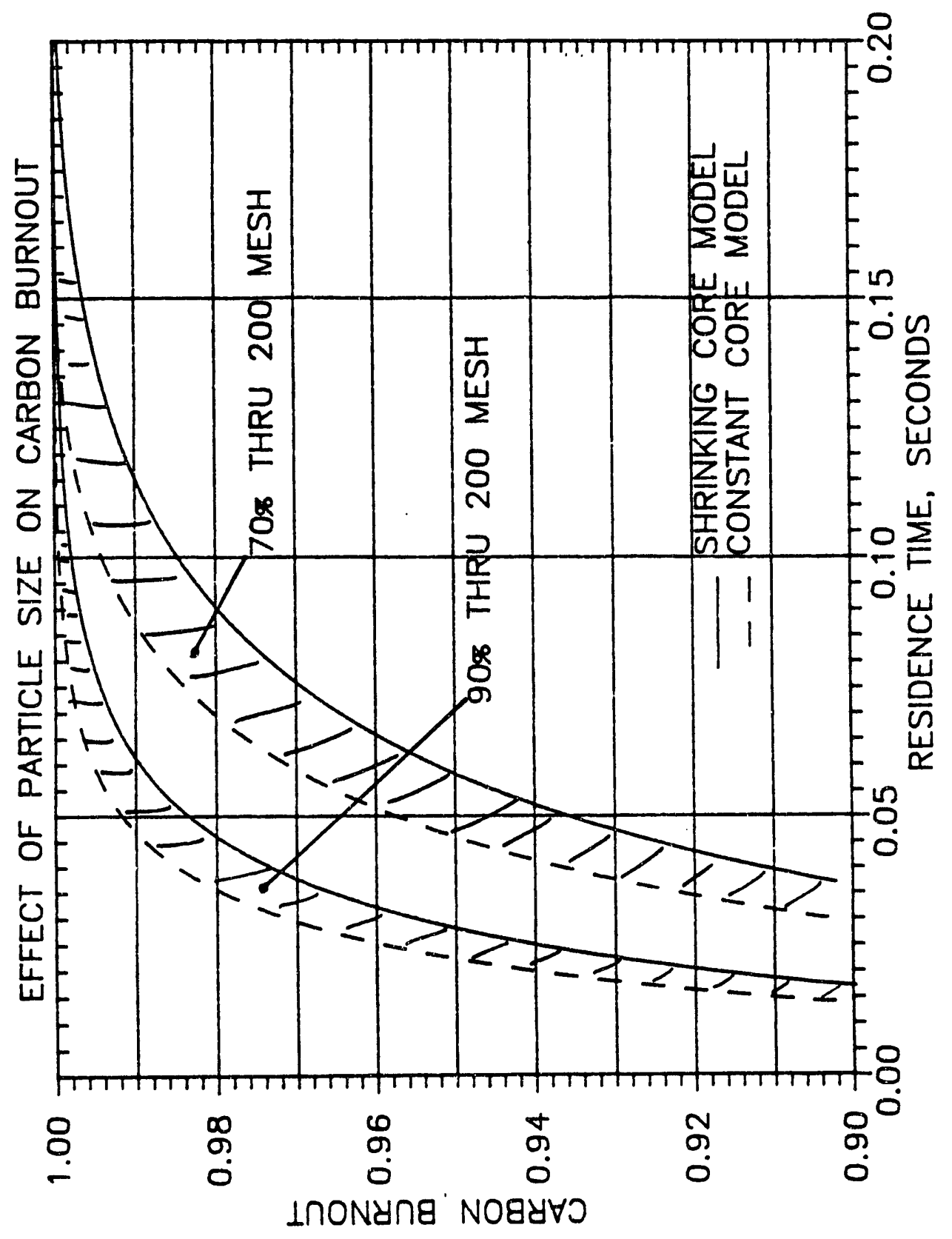




\section{Subtask.3.7-Candidate Air Heater Materials}

Allied Signal, AiResearch Division, conducted a study of candidate materials for the hightemperature air heater. The results of this study are included in the June 1992 Quarterly Report.

Three materials have been selected for further consideration. These materials are shown in Table 5. They will be tested for corrosion resistance in Subtask 3.8.

Table 5 Candidate Secondary Air Heater Materials

\begin{tabular}{|l|l|l|}
\hline \multicolumn{1}{|c|}{ Name } & Manufacturer & \multicolumn{1}{c|}{ Type of Material } \\
\hline Hexaloy SA & Carborundum & Alpha Sintered SiC \\
\hline $\begin{array}{l}\text { Silicon Carbide } \\
\text { Particulate- } \\
\text { Reinforced Alumina }\end{array}$ & Dupont Lanxide & $\mathrm{SiC}_{\mathrm{p}} / \mathrm{Al}_{2} \mathrm{O}_{3}$ Composite \\
\hline NT-230 & Norton & Siliconized SiC \\
\hline
\end{tabular}

\section{Subtask 3.8-Evaluation of Secondary Air Heater Corrosion}

The test conditions for the corrosion testing have been established based on the analysis done in Subtask 3.2, and the materials to be tested have been determined in Subtask 3.7. Specimens of Carborundum Hexaloy SA and Dupont Lanxide $\mathrm{SiC}_{p} / \mathrm{Al}_{2} \mathrm{O}_{3}$ have been received, and the Norton Siliconized SiC is due to be received in October. New furnaces have been purchased with nonproject funds, and installation of these furnaces will be completed in November.

The conditions for the first test will be based on cooling the fuel gas to control alkalies. We have assumed that the fuel gas will be cooled to the point where gaseous-phase alkalies will be condensed on equipment surfaces and particles. Particles will then be removed from the fuel gas stream either by a cyclone or barrier filter. The mechanism of alkali contamination of the secondary air heater tubes is then the deposition of ash particles that get through the particulate cleanup device.

An analysis was performed of the particulate flow rate through the air heater. This analysis was based on a circulating bed pyrolyzer with a primary and secondary cyclone. The system, with particulate flow rates indicated, is shown in Figure 24.

The fuel gas goes to the fuel gas burners where it is burned. The ash particles then enter the air heater along with the products of combustion. An important consideration is how many 
Ref.: DE-AC22-91PC91154

Date: November 1992

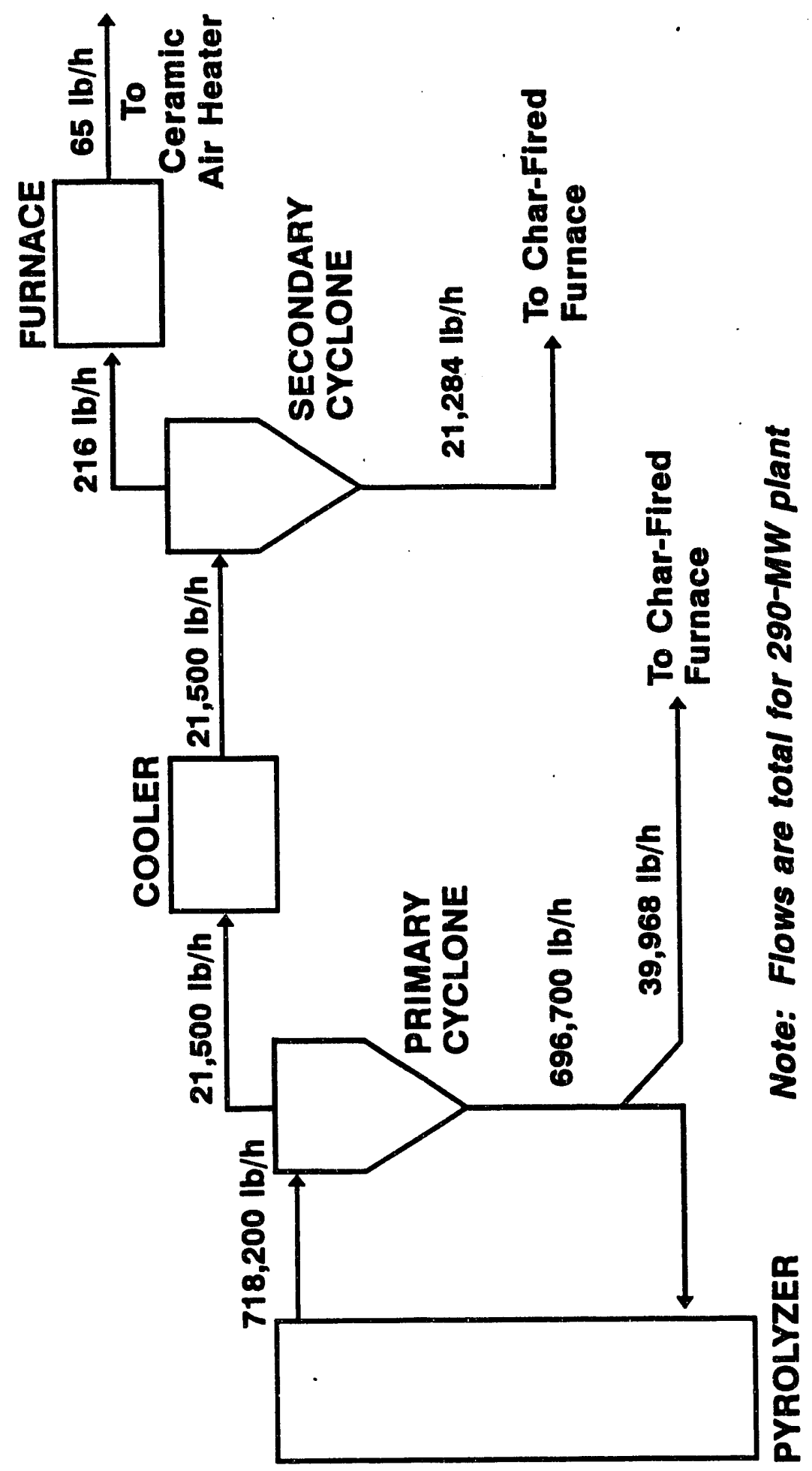

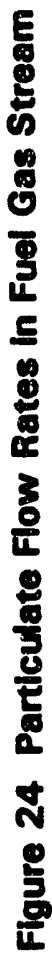


ash particles will actually deposit on the air heater tubes. In another research project, ResearchCottrell analyzed particle deposition under similar conditions. Inertial impaction, diffusion, interception, and thermophoretic mechanisms were analyzed for different particle sizes. The specified conditions for the study and the collection efficiency results are shown in Table 6 . The particle sizes in the proposed HITAF system will be less than 5 microns. A conservative value of 0.03 percent was used to determine the ash collection rate. An ash deposition rate was then calculated based on the ash flow rate, collection efficiency, and one-half the tube surface area per row. The result is a deposition rate of $3.55 \times 10^{-2} \mathrm{mg} / \mathrm{h}-\mathrm{cm}^{2}$.

Table 6 Particle Collection Efficiency

- Gas Temperature $=2500^{\circ} \mathrm{F}$

- Tube Diameter = 2 in. O.D.

- Velocity $\quad=150 \mathrm{ft} / \mathrm{s}$

\begin{tabular}{|c|c|}
\hline $\begin{array}{c}\text { Particle Diameter } \\
(\mathrm{m})\end{array}$ & $\begin{array}{c}\text { Collection Efficiency } \\
(\%)\end{array}$ \\
\hline 5 & 0.02 \\
\hline 1 & 0.01 \\
\hline 0.5 & 0.00 \\
\hline 0.1 & 0.01 \\
\hline 0.01 & 0.12 \\
\hline
\end{tabular}

This deposition rate will be used as a starting point for the corrosion tests. The specimens will be loaded with 100-hours worth of ash at a time, and they will be maintained in furnaces kept at $2300^{\circ} \mathrm{F}$. The specimens are flat plates approximately 1 in. $\times 2$ in. $\times 1 / 4$ in. Actual ash from the FWDC Second-Generation PFBC pilot plant pyrolyzer tests will be used. The ash will be from Pittsburgh No. 8, Illinois No. 6, and Eagle Butte coals. The atmosphere in the furnace will be simulated flue gas. The total test time wi!? be 1000 hours; however, we will review the initial test conditions after the first 100 or 200 hours to be sure we are in a region of interest. If there are no signs of corrosion, we will probably make changes to simulate less-stringent fuel gas cleanup. If all the specimens are corroding at unacceptable rates, we will simulate more stringent fuel gas cleanup.

A second set of tests will be run to simulate the condensation of alkalies that would occur in the air heater if the fuel gas were not cleaned of alkalies. In these tests, the ash will be doped with additional alkalies to simulate the condensation of alkalies from the gas phase. 


\section{Subtask 3.10-Char Characterization Tests}

During the last quarter, planning for the upcoming fuel characterization testing continued. Actual testing commenced in October 1992, and the results will be discussed in the next quarterly report. Testing is being performed at Brigham Young University's (BYU's) Advanced Combustion Engineering Research Center (ACERC), with close cooperation between personnel at TRW and BYU. The overall objective of the testing is to obtain experimental data on hightemperature char reactivity and combustion characteristics in support of combustor analytical modeling and conceptual design activities.

Preliminary analysis of the char produced from FWDC's second-generation PFB combustion project indicates that, although the char contains only a fraction of the original coal volatiles, it still appears to be fairly reactive, apparently because of the conditions under which it is pyrolyzed. tion on:

Analyses and experiments to be performed at BYU are being planned to provide informa-

- Expected volatile yields at high heating rates (and comparison with ASTM tests)

- Char reaction rates as a function of particle size and gas environment

- Preliminary information on expected rates of $\mathrm{NO}_{x}$ formation.

Before testing, some laboratory analyses must be performed and the char must be prepared for the tests. Standard ASTM fuel analyses will be performed, including proximate analysis, ultimate analysis, ash ultimate analysis, and determination of particle size distribution. All char and spent sorbent samples will be provided by FWDC. Separate analyses are required for the parent coal and its ash and the derivative char and its ash. Results will be compared with data from previous examinations of coals and chars.

Morphology analyses will be performed on the parent coal and its char, and the results will be compared with existing data. Analyses on the coal and char will include apparent density and $\mathrm{N}_{2}$ BET internal surface area.

Coal and char samples from FWDC will be prepared for experiments, including segregation of samples into distinct particle size ranges. The proposed size for the majority of experiments is 63 to 75 microns (250 to 200 mesh), since that is the size range used in many experiments at BYU and elsewhere and is close to the mass mean size range typically used in industry ( 55 microns). Before char reactivity experiments, the char particles will be separated as much as possible from the sorbent particles using a small fluidized bed. The sorbent samples will be retained for future characterization testing. 
The rates of char combustion, sulfur release, and nitrogen release will be determined in a flat flame burner (FFB) experiment as a function of flame temperature, gas composition, particle residence times, and particle size. Both the parent coal and the char will be characterized. Gas temperatures and compositions will be similar to the actual slagging-stage combustor environment (approximately $2000 \mathrm{~K} / 3000^{\circ} \mathrm{F}$ ). Since the slagging combustor design calls for complete conversion of the char particle in 70 to 90 percent of stoichiometric air, reactivities are desired in both oxygen environments and in steam $/ \mathrm{CO}_{2}$ environments. The post-flame gases in the FFB experiment can be adjusted to contain 0 to 20 mole percent $\mathrm{O}_{2}$ by changing the air-to-fuel ratio of the flame. These post-flame gases generally contain 13-mole percent steam and 6-mole percent $\mathrm{CO}_{2} . \mathrm{CO}_{2}$ concentrations of up to 15 mole percent may be required, which can be accomplished by adding additional $\mathrm{CO}_{2}$ gas at the burner inlet. Char samples will be collected in the FFB at different residence times so that kinetic rates can be determined. Residence times in the FFB will be determined by streak photography. The maximum residence times in the FFB is $500 \mathrm{~ms}$.

A schematic of the FFB test configuration is shown in Figure 25. Air and methane are transported separately through a monolithic structure, as shown in Figure 26. A steady, flat flame is produced at the top of the structure. Coal or char is fed pneumatically upward through the middle of the FFB. An adjustable collection probe with a nitrogen quench is located above the FFB to collect and extinguish the burner char particles. The char particles are then separated in a cyclone and retained for post-test analyses.

A preliminary test matrix is presented in Table 7. Key tests parameters include coal type, particle diameter, flame temperature, gas concentration, and particle residence time. Tests will also be performed at a previously characterized gas composition and flame temperature to provide a baseline for comparison with the existing database.

Post-test fuel analyses will be performed on collected char and compared with pretest analyses to determine carbon, sulfur, and nitrogen loss. Results will be compared with those obtained with the parent coal. Analyses to be performed on the parent coal and collected char samples include:

- Proximate analysis (ASTM volatiles, fixed carbon, moisture, and ash)

- Ultimate analysis (C,H,N,S; $O$ by difference)

- Ti tracer analysis (by ICP atomic adsorption spectroscopy)

- Apparent density (tap density technique)

- Internal surface area $\left(N_{2} B E T\right)$. 
Ref.: DE-AC22-91PC91154

Date: November 1992

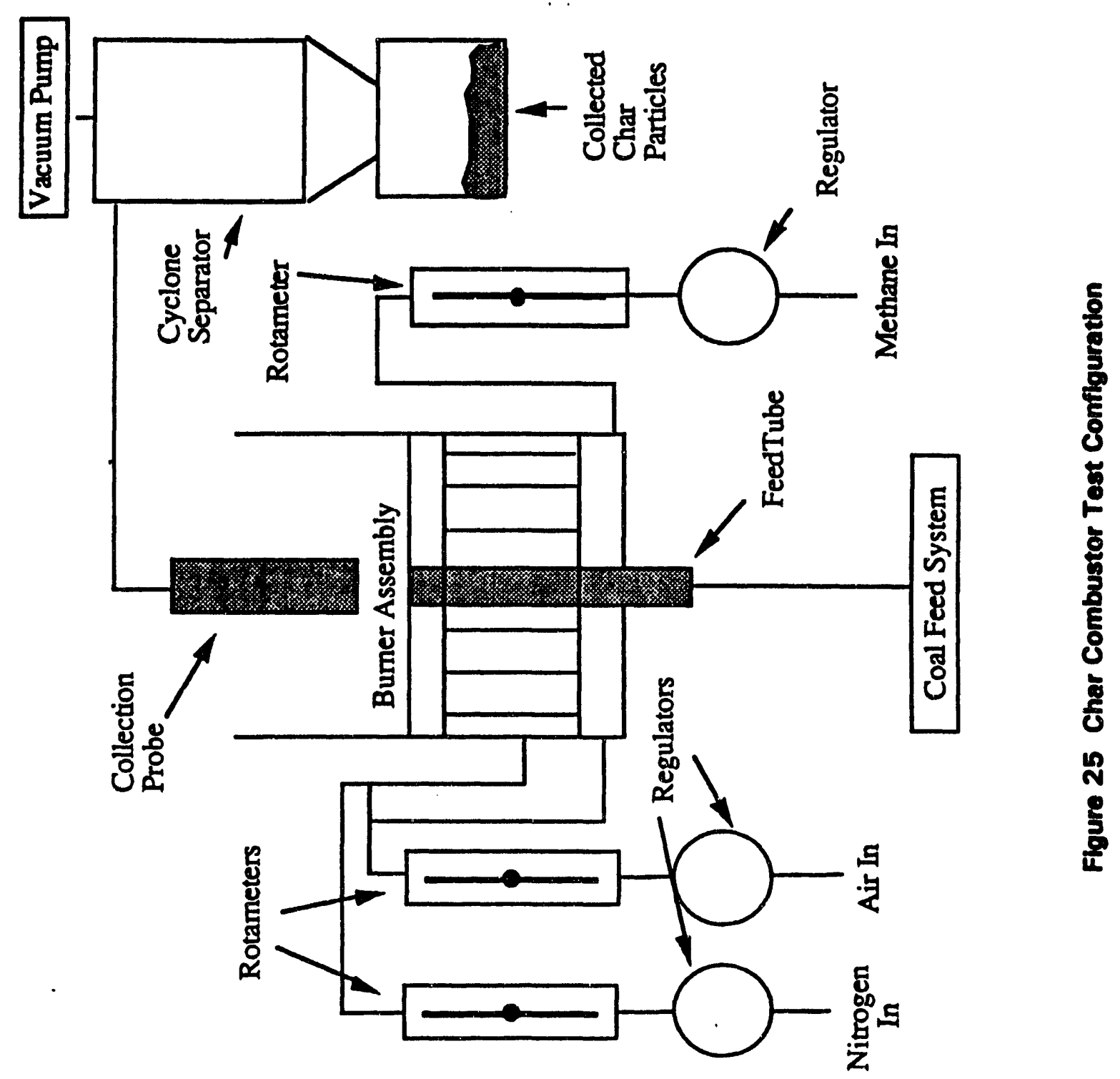




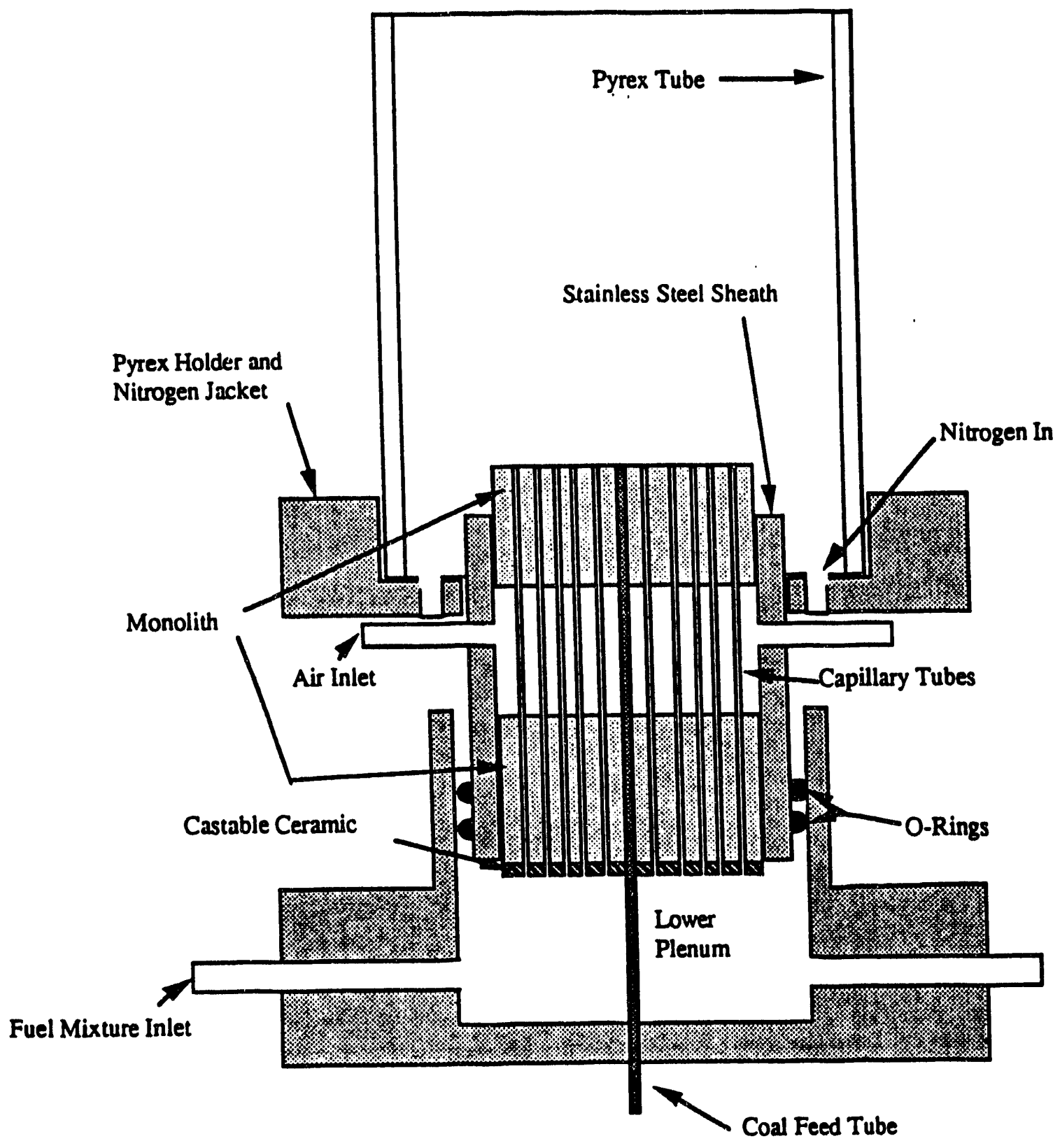

Figure 26 Flat Flame Burner 
Table 7 Char Combustion Experiments

\begin{tabular}{|l|l|l|}
\hline \multicolumn{1}{|c|}{ Test Parameter } & \multicolumn{1}{|c|}{ Nominal } & \multicolumn{1}{c|}{ Test Range } \\
\hline Coal Type & Pittsburgh No. 8 & $\begin{array}{l}\text { Coal and Char From } \\
\text { Three Different Coals }\end{array}$ \\
\hline Particle Diameter & 65 microns & $30-120$ microns \\
\hline Flame Temperature & $3000^{\circ} \mathrm{F}$ & $1600-3300^{\circ} \mathrm{F}$ \\
\hline $\mathrm{O}_{2}$ Concentration & $6 \%$ & $0-15 \%$ \\
\hline $\mathrm{CO}_{2}$ Concentration & $6 \%$ & $6-15 \%$ \\
\hline $\mathrm{H}_{2} \mathrm{O}$ Concentration & $13 \%$ & $8-15 \%$ \\
\hline Particle Residence Time & $100 \mathrm{~ms}$ & $10-500 \mathrm{~ms}$ \\
\hline
\end{tabular}

\section{Subtagk 3.13-Prellminary Deglan of Secondary Air Heater}

Work was completed on quantifying the effects of radiation heat transfer in the overall performance of the secondary air heater design. The ceramic air heater was conservatively designed for the proposal, considering forced convection heat transfer only-no benefit was taken from radiation heat transfer. The high operating temperatures suggest that there may be significant radiation effects. These effects are mitigated by two factors:

- The heat exchanger is positioned outside the combustion furnace and has no direct view of the flame

- The tubes are tightly spaced, suppressing radiation from the flue gas.

In general, radiation will enhance the heat-transfer performance and provide for increased heat-transfer margins for a fixed unit. However, since the air heater already includes a conservative 20-percent thermal conductance margin, the effects of radiation need to be considered.

There are two main radiation mechanisms that must be considered-radiation from the flue gas and radiation from the enclosure walls. These components of the heat transfer were calculated. Table 8 summarizes the assumptions and results of this analysis. The radiation heat transfer represents approximately 30 percent of the required thermal duty, so the inclusion of this heat load will significantly reduce the required heat exchanger size. 
Table 8 Secondary Air Heater Redlation Heat-Transfer Assumptions

\begin{tabular}{|l|l|}
\hline \multicolumn{2}{|c|}{ Gas Radiation } \\
\hline Mean Gas Temperature & $2221^{\circ} \mathrm{F}$ \\
\hline Mean Tubewall Temperature & $1739^{\circ} \mathrm{F}$ \\
\hline Tube Diameter & $2.0 \mathrm{in}$. \\
\hline Tube Surface Area & $11.417 \mathrm{ft}^{2}$ \\
\hline Gas Radiation Heat Flux & $1735 \mathrm{Btu} / \mathrm{htt}^{2}$ \\
\hline Gas Radiation Heat Load & $19.8 \times 10^{\circ} \mathrm{Btu} / \mathrm{h}$ \\
\hline \multicolumn{1}{|c|}{ Enclosure Wall Radiation } \\
\hline Mean Wall Temperature & $2221^{\circ} \mathrm{F}$ \\
\hline Mean Tubewall Temperature & $1739^{\circ} \mathrm{F}$ \\
\hline Enclosure Wall Surface Area & $523.2 \mathrm{ft}^{2}$ \\
\hline Enclosure Radiation Heat Load & $20.3 \times 10^{\circ} \mathrm{Btu} / \mathrm{h}$ \\
\hline
\end{tabular}

Preliminary costs were estimated for different sizes of the basic AiResearch ceramic air heater design. The air heater module dimensions are shown irı Figures 27 and 28 . The size variations were accomplished by shortening the length of the tubes. The sizes analyzed represent the maximum module size and moduls sizes capable of three-quarters and half this heat duty. Based on the original 290-MW plant heat and material balance, four of the three-quarter size modules would be required for the plant.

The estimated prices of the three unit sizes are listed in Table 9. Details of the cost analyses are contained in Tables 10, 11, and 12.

Table 9 Secondary Air Heater Preliminary Prices

\begin{tabular}{|c|c|}
\hline Module Size & Cost per Module \\
\hline Full-Size Module & $\$ 2,049,000$ \\
\hline 3/4-Size Module & $\$ 1,696,000$ \\
\hline $1 / 2-$ Size Module & $\$ 1,338,000$ \\
\hline
\end{tabular}


Ref.: DE-AC22-91PC91154

Date: November 1992

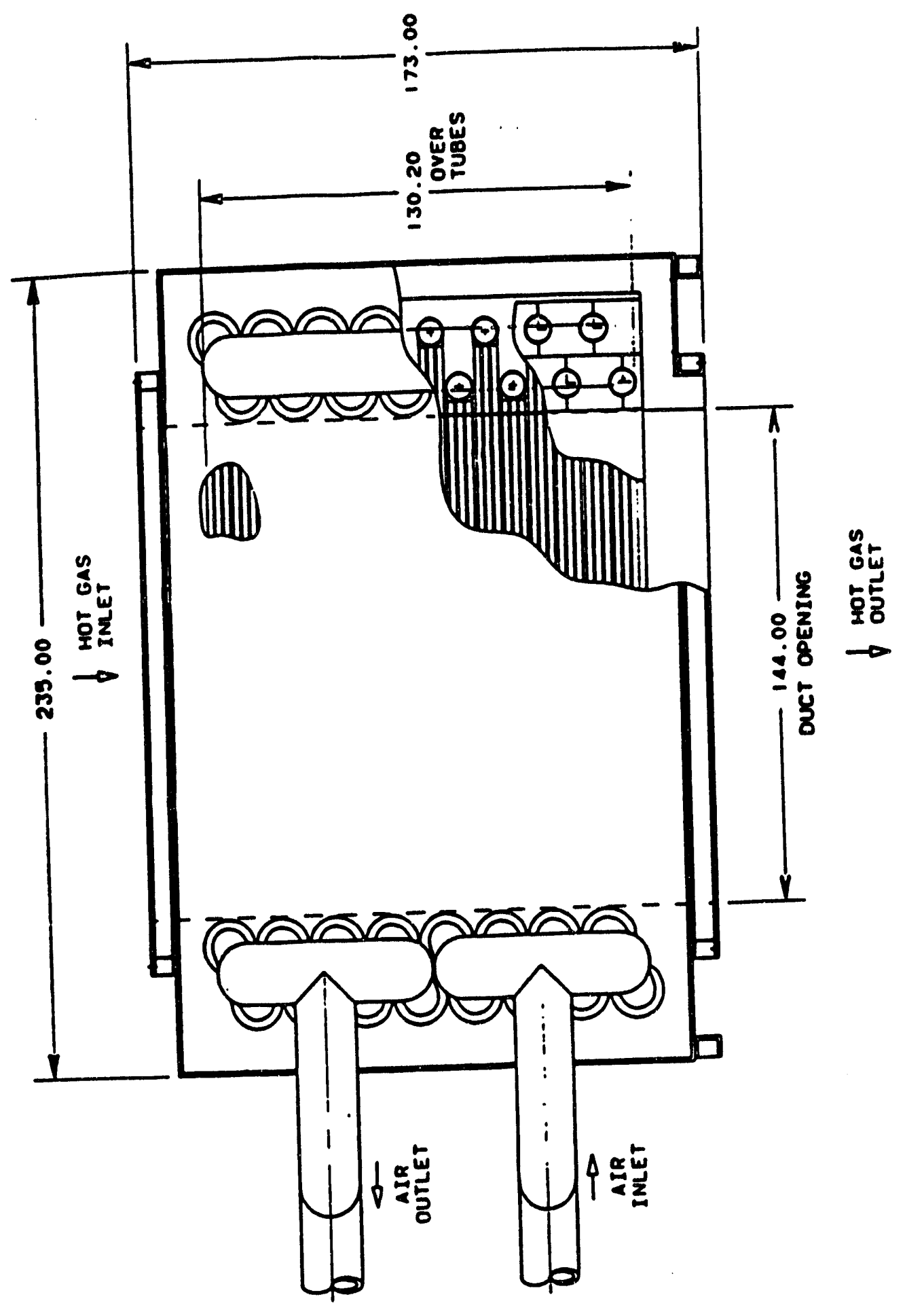

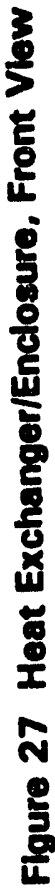




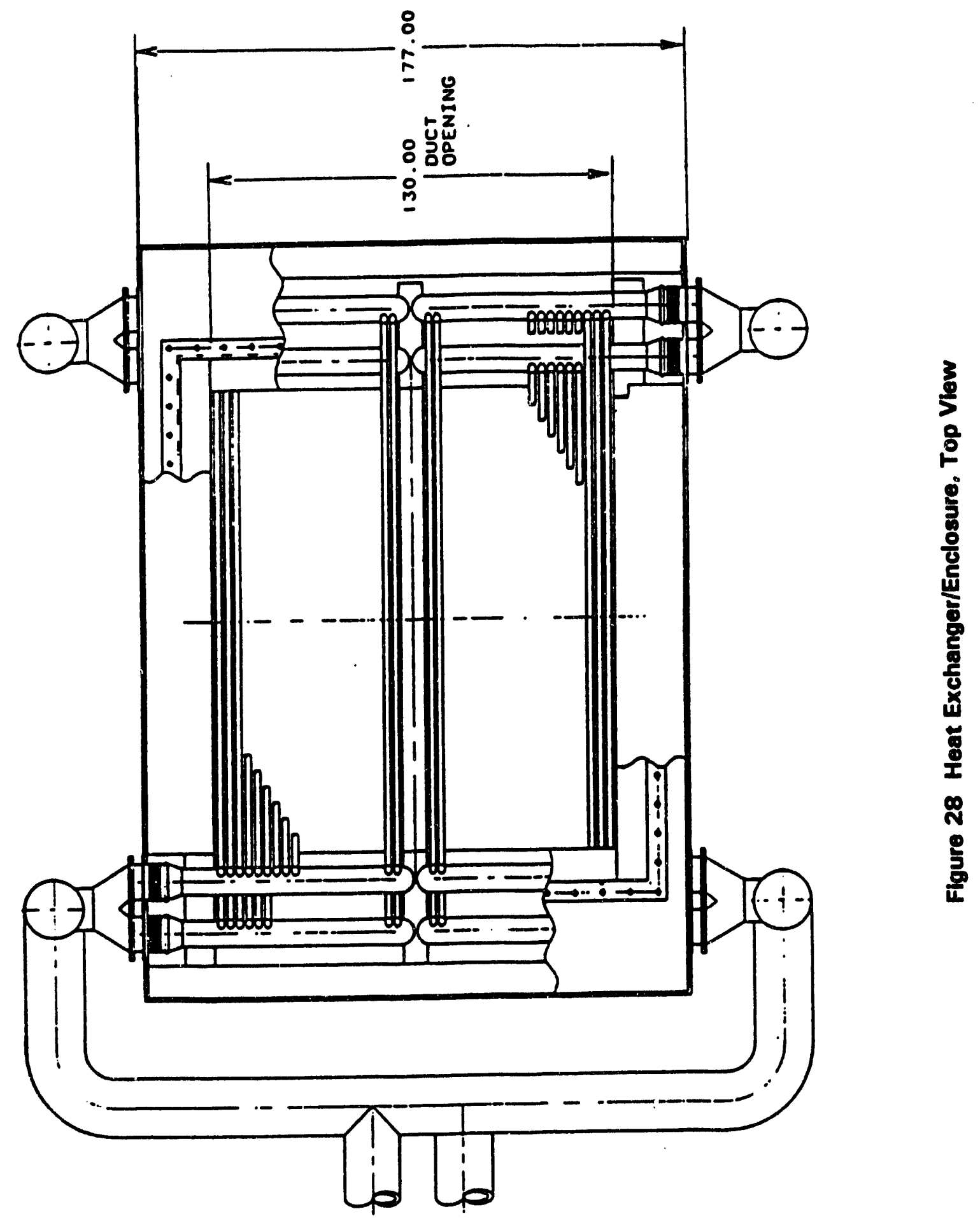


Ref.: DE-AC22-91PC91154

Date: November 1992

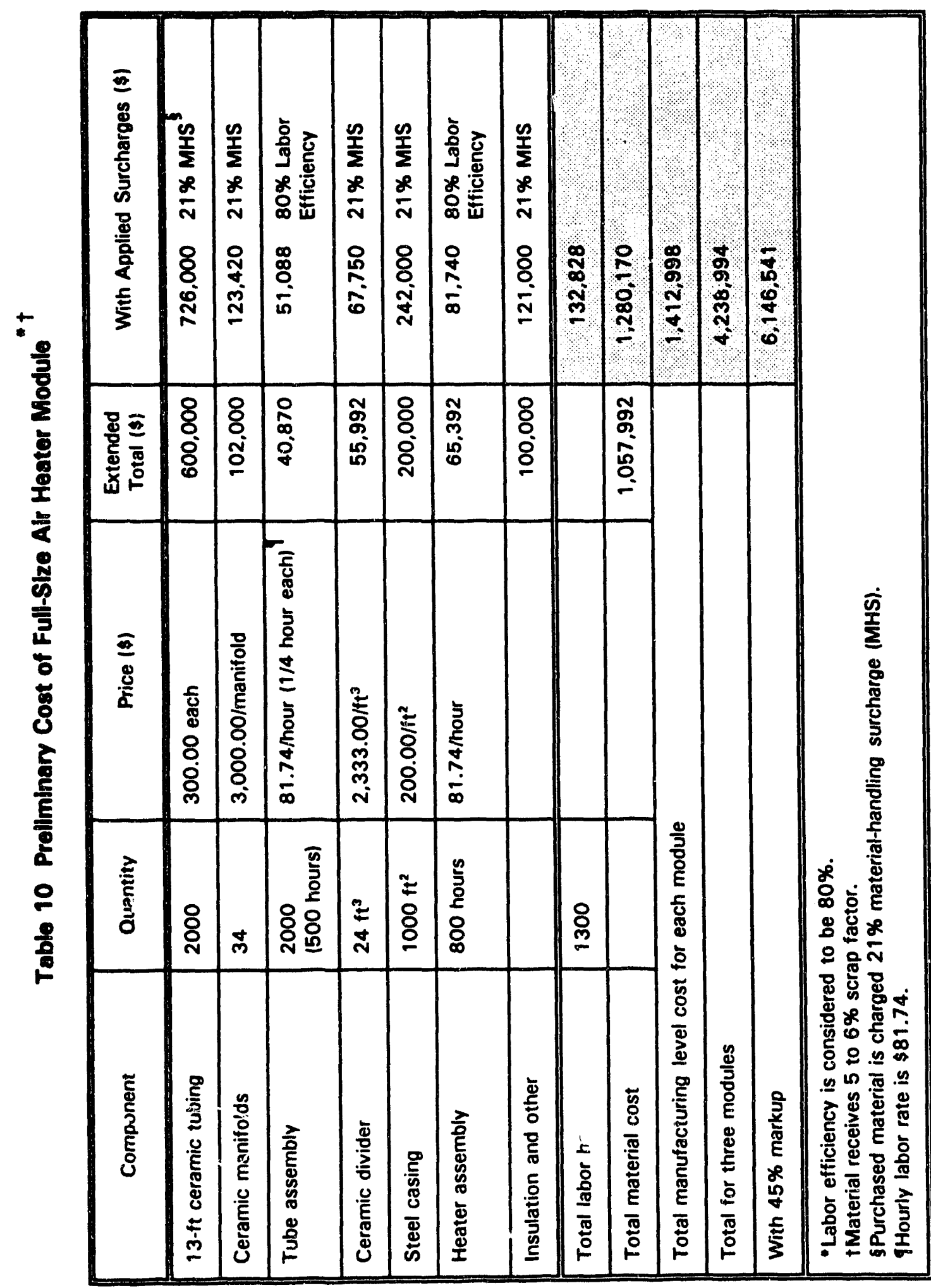




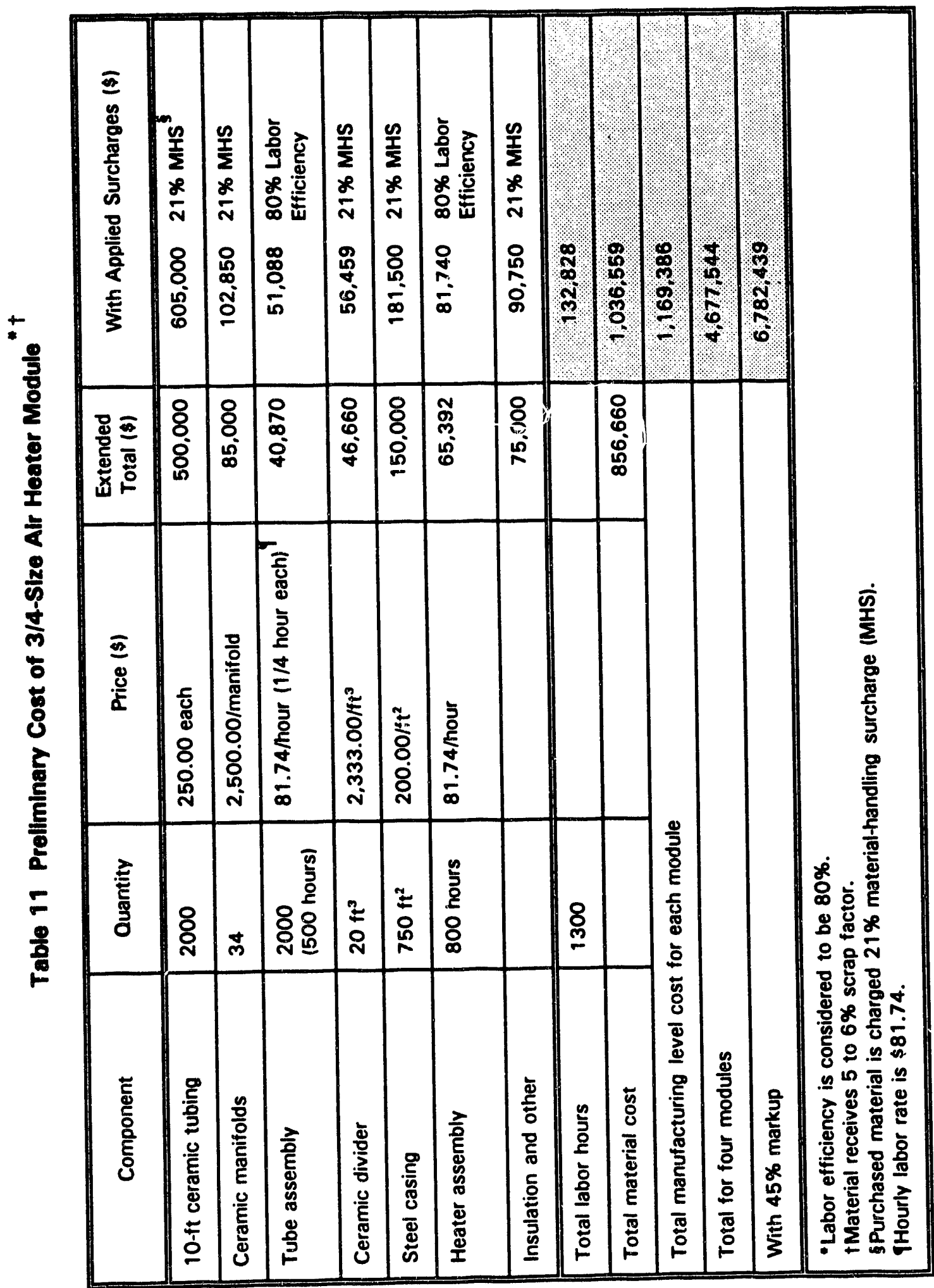




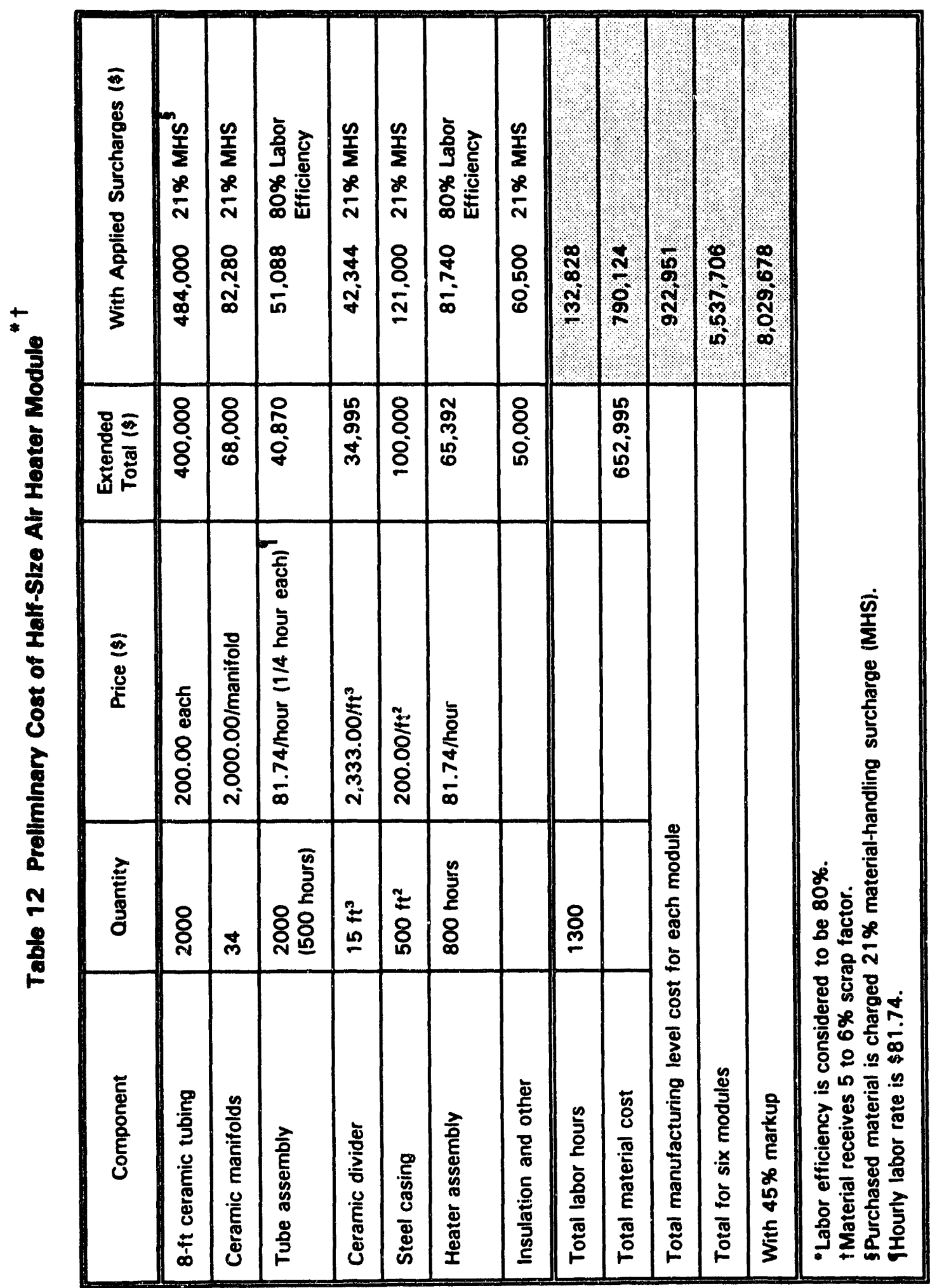




\section{Subtask.3.14-Secondary Air Heater/Furnace Compatibility}

Design options for the integration of the secondary air heater and a fuel-gas fired furnace were investigated. An attempt was made to integrate the secondary air heater and its furnace in the general envelope of the char-fired furnace. This approach was found impractical because of the many headers required in the ceramic air heater design. No other way was found to incorporate the ceramic air heater within furnace walls and still provide access for maintenance. The team thus decided that it would be best to keep the air heater as a separate unit that would attach to a fuel-gas-fired furnace.

A conceptual arrangement of a possible furnace/air heater arrangement is shown in Figure 29. The furnace would be of tubewall construction, but the inside would be refractory lined to minimize the gas heat loss before the air heater units. With the furnace temperatures that result from the fuel gas combustion at low excess air, an uncooled furnace enclosure is not practical. Figure 30 shows furnace exit gas temperatures that can be achieved with different levels of furnace absorption. The maximum absorption with a base furnace wall is $\mathbf{3 8}$ percent, and the minimum is about 8 percent with refractory applied to the inside.

\section{Subtask 3.20-Analyze Sorbent Reactions in Char Combustor}

The objective of this task is to estimate (based on existing data and analytical models) the extent of sulfur released into the char combustor gas stream, as well as the amount of sulfur retained by the slag rejected from the combustor.

Existing data indicate that approximately 90 percent of the sulfur released in the pyrolyzer can be captured with the injection of limestone or dolomite into the bed. Sulfur will be captured primarily as CaS and will subsequently be fed to the char combustor, since it will be economically difficult to separate the spent sorbent from the char. The evolution of spent sorbent particles in the char combustor is of practical interest for designing the emissions control system as well as for determining the leaching ability of the slag rejected from the combustor.

During the last quarter, a literature search was begun to identify CaS decomposition rates as a function of particle size and surface morphology, gas and particle temperatures, and gas composition. As expected, much of the work in this area has focused on the forward reaction (i.e., the formation of $\mathrm{CaS}$ in a reducing environment through the reaction of $\mathrm{CaO}$ and $\mathrm{SO}_{2}$ ). In addition, decomposition rates are expected to be highly dependent on particle heating rates and sorbent surface morphology.

Because of the lack of conclusive data on calcium sulfide (CaS) decomposition rates in a slagging combustor environment, a series of sorbent characterization tests at BYU is being considered. The main objective of these tests would be to characterize the decomposition rates of spent sorbent produced in the FWDC pyrolyzer in both gas and slag environments. 


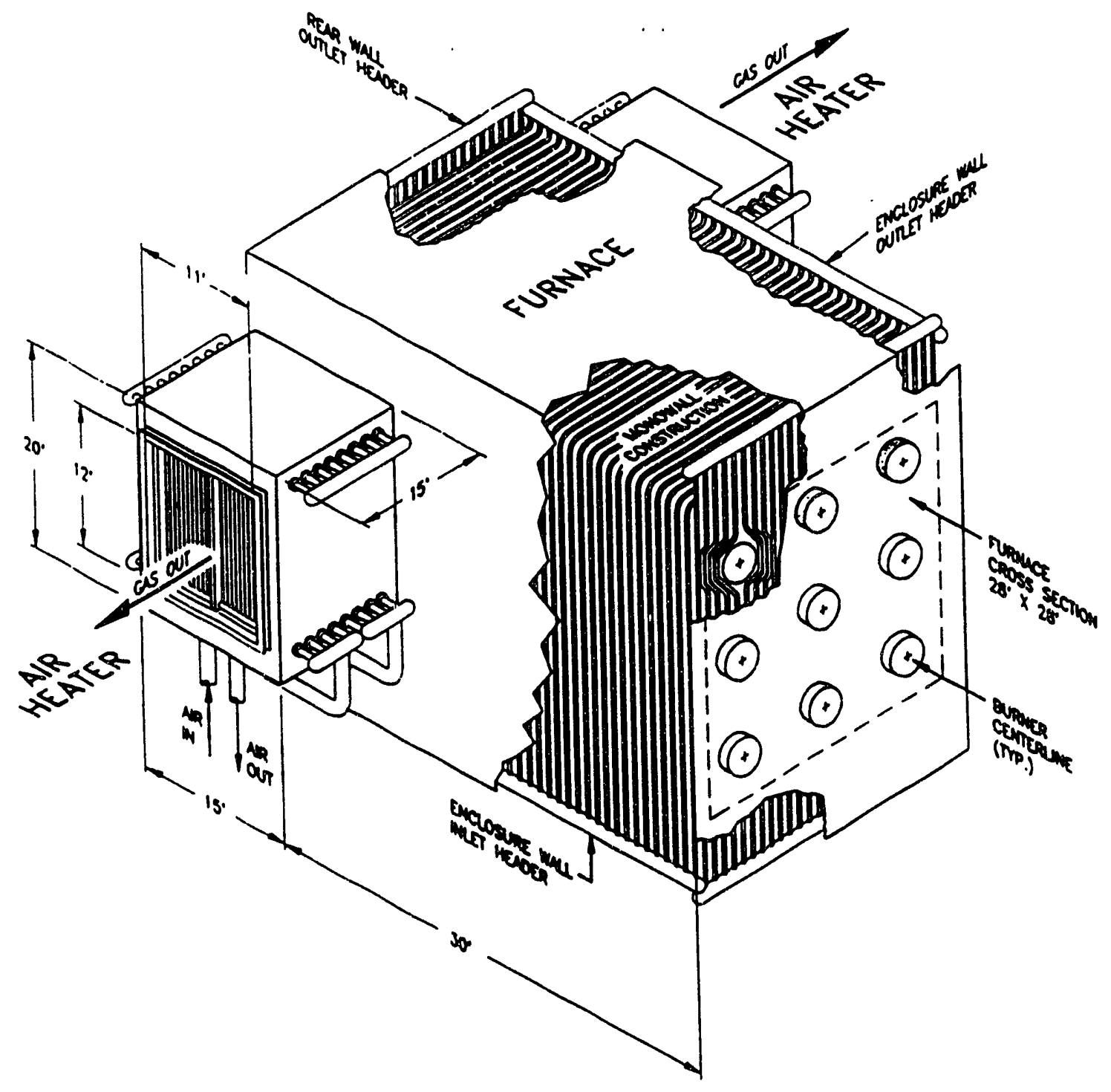

Figure 29 Conceptual Arrangement of Furnace/Air Heater Combination 


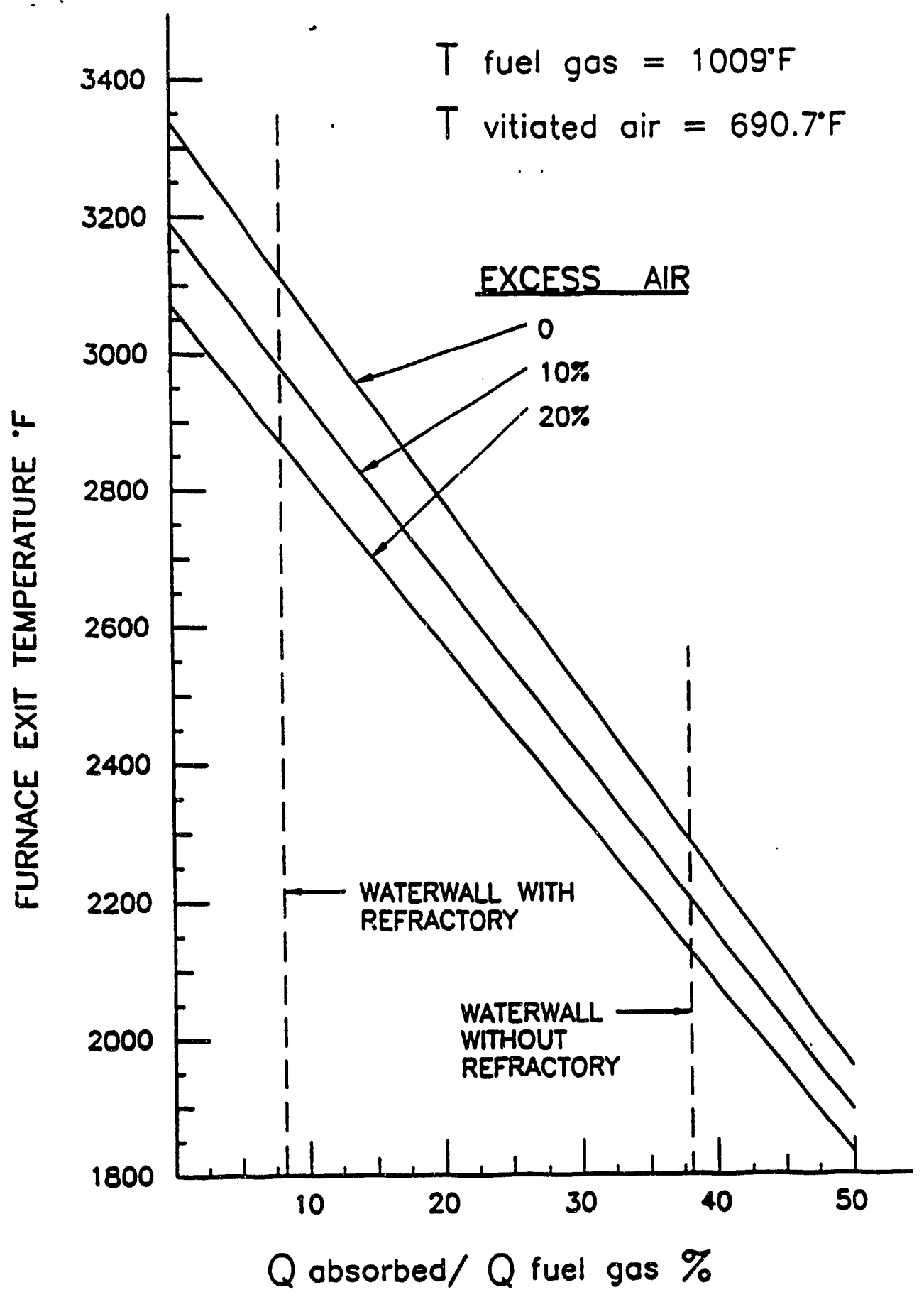

Figure 30 Preliminary Prediction of Furnace Exit Temperature 
The sulfur release rate from the sorbent material in the slagging combustor gas environment can be examined in the FFB experiments previously proposed to characterize char reactivity and combustion. Tests can be performed by injecting size-graded sorbent particles (63 to 75 micron) into the FFB in both $\mathrm{O}_{2} / \mathrm{H}_{2} \mathrm{O} / \mathrm{CO}_{2}$ and $\mathrm{H}_{2} \mathrm{O} / \mathrm{CO}_{2}$ environments at high temperature $(1500$ to $2000 \mathrm{~K})$. Particles can then be collected at different residence times and analyzed for sulfur content to determine sulfur release rates.

Experiments can also be performed to determine spent sorbent decomposition and sulfur release rates that can be expected in the slag layer of a slagging combustor. An ash and spent sorbent mixture can be maintained at slagging temperatures for various periods of time to characterize sulfur release rates. BYU is currently looking into the feasibility of installing a platinum crucible over the FFB to conduct these tests. Use of the FFB is desirable for simulating the approximate gas temperature and composition near the walls of the combustor. Gas temperature and composition could also be varied to assess the dependence of release rates on each of these parameters. A possible test matrix includes sorbent material mixed with the ash from each of three coals, three residence times, two temperatures, and two gaseous environments.

\section{Subtask 3.21-Pollution Control Systems}

Testing has been completed to evaluate the feasibility of a char adsorption system for $\mathrm{SO}_{2}$ control.

- A baghouse cannot be used as a char-gas contacting medium because the filter cake is not deep enough to prevent immediate $\mathrm{SO}_{2}$ breakthrough.

- Pulverized coal does not have adequate $\mathrm{SO}_{2}$ adsorption capacity, and the adsorptive capacities of the char samples are marginal.

As a result of these findings, we determined that a moving bed of char would be necessary for sufficient $\mathrm{SO}_{2}$ removal and decided that the pressure drop of such a bed would need to be measured. Also, because of the marginal $\mathrm{SO}_{2}$ adsorption capacities measured, we decided to reexamine the adsorption capacity requirements of the chars.

The pressure-drop characteristics of char beds was investigated first. The fixed-bed apparatus used for the adsorption tests was also used to determine the pressure drops at various depths of fixed beds with different chars. At a face velocity of $0.1 \mathrm{ft} / \mathrm{min}$, the pressure drop of the Eagle Butte cyclone catch char was 2.25 in. $\mathrm{H}_{2} \mathrm{O} / \mathrm{in}$. bed depth, increasing linearly with face velocity and bed depth. This value is about an order of magnitude higher than could be allowed in a commercial moving bed. The high measured pressure drop resulted from the fine particle size inherent in the cyclone catch chars. A repeat of the test using the much more coarse bed drain char of the lllinois No. 6 coal gave a pressure drop of $1.6 \mathrm{in}$. $\mathrm{H}_{2} \mathrm{O} / \mathrm{in}$. bed depth for a face velocity of $10 \mathrm{ft} / \mathrm{min}$. This result indicates that only the bed drain char in a movingbed reactor yields acceptably low pressure drop. 
A new calculation of the required $\mathrm{SO}_{2}$ adsorption capacity of the char was made, based upon the assumptions that the pyrolyzer will produce $44 \mathrm{lb}$ char/100 lb coal and that only the bed drain portion of the char produced would be acceptable for the moving-bed adsorber. These assumptions lead to the curves in Figure 31, showing that, for the 50- to 60-percent $\mathrm{SO}_{2}$ removals typically achieved for furnace sorbent, the char must be capable of adsorbing between 5 and 15 percent of its weight of $\mathrm{SO}_{2}$.

In an effort to increase the adsorptive capacity of the chars, tests were run at lower temperatures, and efforts were made to enhance the char with an acid wash. Also, tests were carried out to measure the adsorption capacity based on higher breakthrough levels.

Before July, all adsorption capacity tests were carried out at $200^{\circ} \mathrm{F}$. Low temperatures favor higher adsorption, and a test was carried out to document this temperature dependence for the program chars. Figure 32 shows the result for the lllinois No. 6 coal char. As expected, more $\mathrm{SO}_{2}$ can be adsorbed at lower temperature; however, the difference in adsorption capacity between 200 and $150^{\circ} \mathrm{F}$ is not large enough to bring the adsorption capacity up to the 5-percent threshold.

A test was also performed to measure the amount of $\mathrm{SO}_{2}$ that could desorbed from the char by a water wash. The principle of operation is shown in Figure 33 . If this technique proved successful, furnace limestone injection would not be required, and the sulfur would be removed from the system as weak sulfuric acid. The test showed that approximately 20 percent of the adsorbed $\mathrm{SO}_{2}$ could be desorbed as sulfuric acid when the char was slurried with water and stirred for 30 minutes. For this technique to work commercially, at least 50 percent of the sulfur must be removed by washing; therefore, the technique cannot be considered for the program.

Figure 34 shows the results of adsorption capacity tests obtained with the char produced from Pittsburgh No. 8 coal, where some runs were made under conditions designed to achieve maximum capacity. Higher capacities were achieved by allowing up to 10 percent breakthrough and by increased water vapor content. At best, 1-percent adsorption capacity can be attained, which is well below the 5-percent threshold shown to be required.

As a result of the inadequate adsorption capacities found for the chars tested, activity in the second quarter concentrated on a more detailed analysis of the alternative $\mathrm{SO}_{2}$ technologies. These alternative technologies are the recirculating reactor and two variations of the Wellman-Lord regenerable scrubbing system. The activity included a study of the recently reported results of these technologies so that we could verify acceptable removal efficiencies. More detailed cost analyses were prepared in an effort to determine the cost effectiveness of each technology more closely.

The mass balance program was modified to calculate the efficiency of the recirculating reactor. The flow diagram for this calculation is given by Figure 35, and results from a sample calculation are shown in Table 13. Figure 36 gives the results of a series of calculations for 


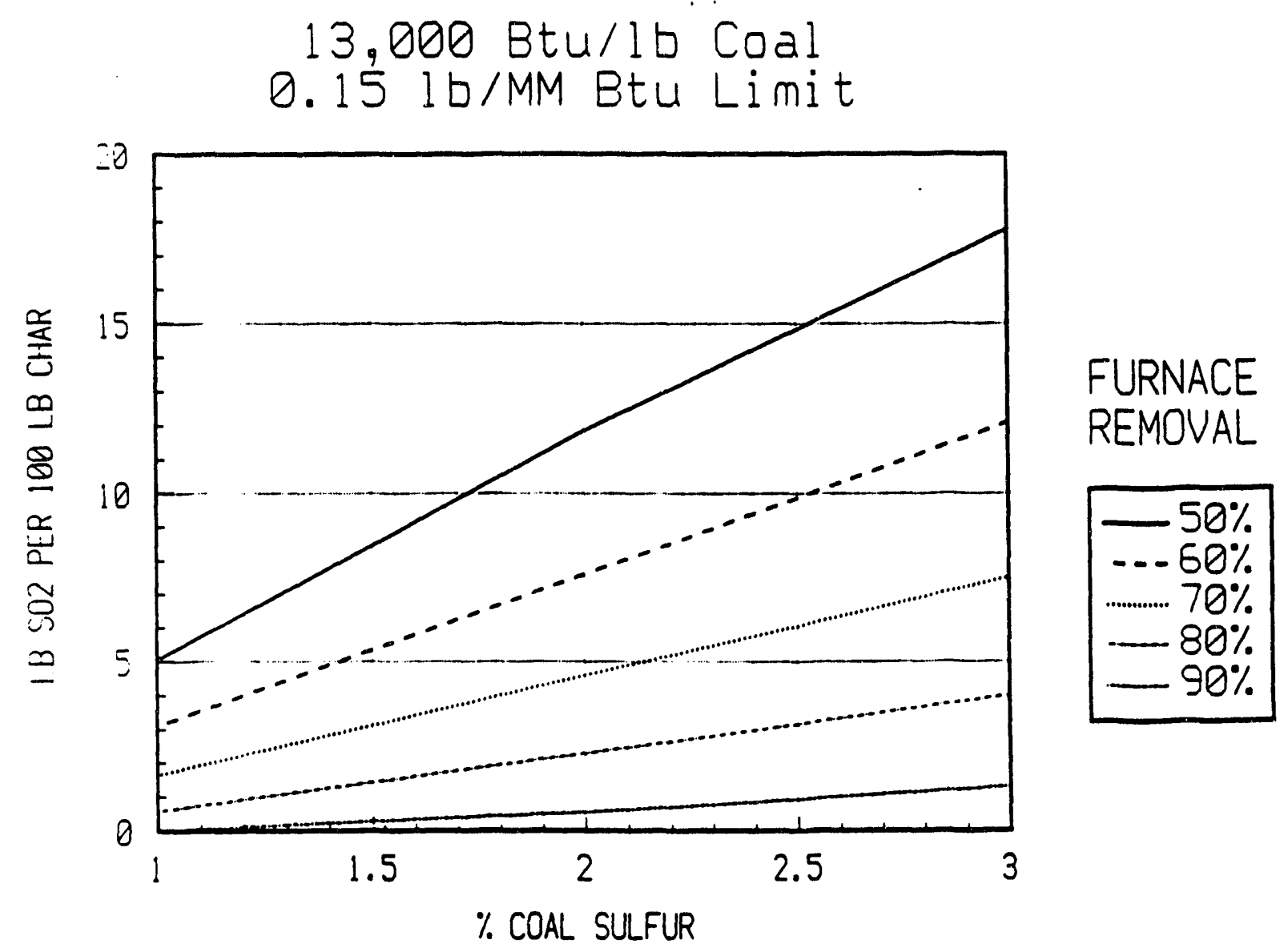

Figure 31 Effect of Coal Sulfur on Adsorption Capacity 
Il \#6 Coal Char, Cyclone Catch

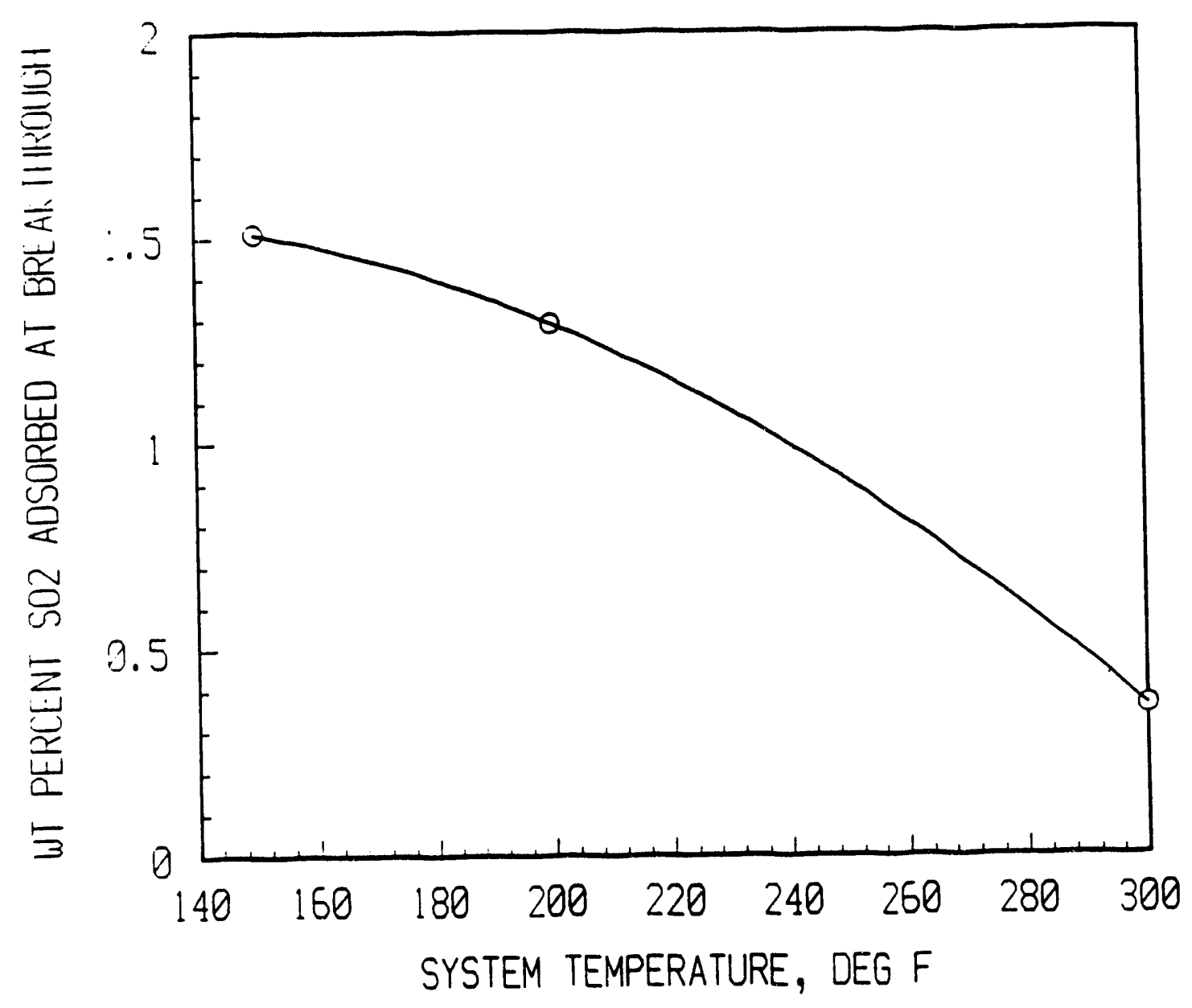

Figure 32 Effect of Temperature on Adsorption Capacity 


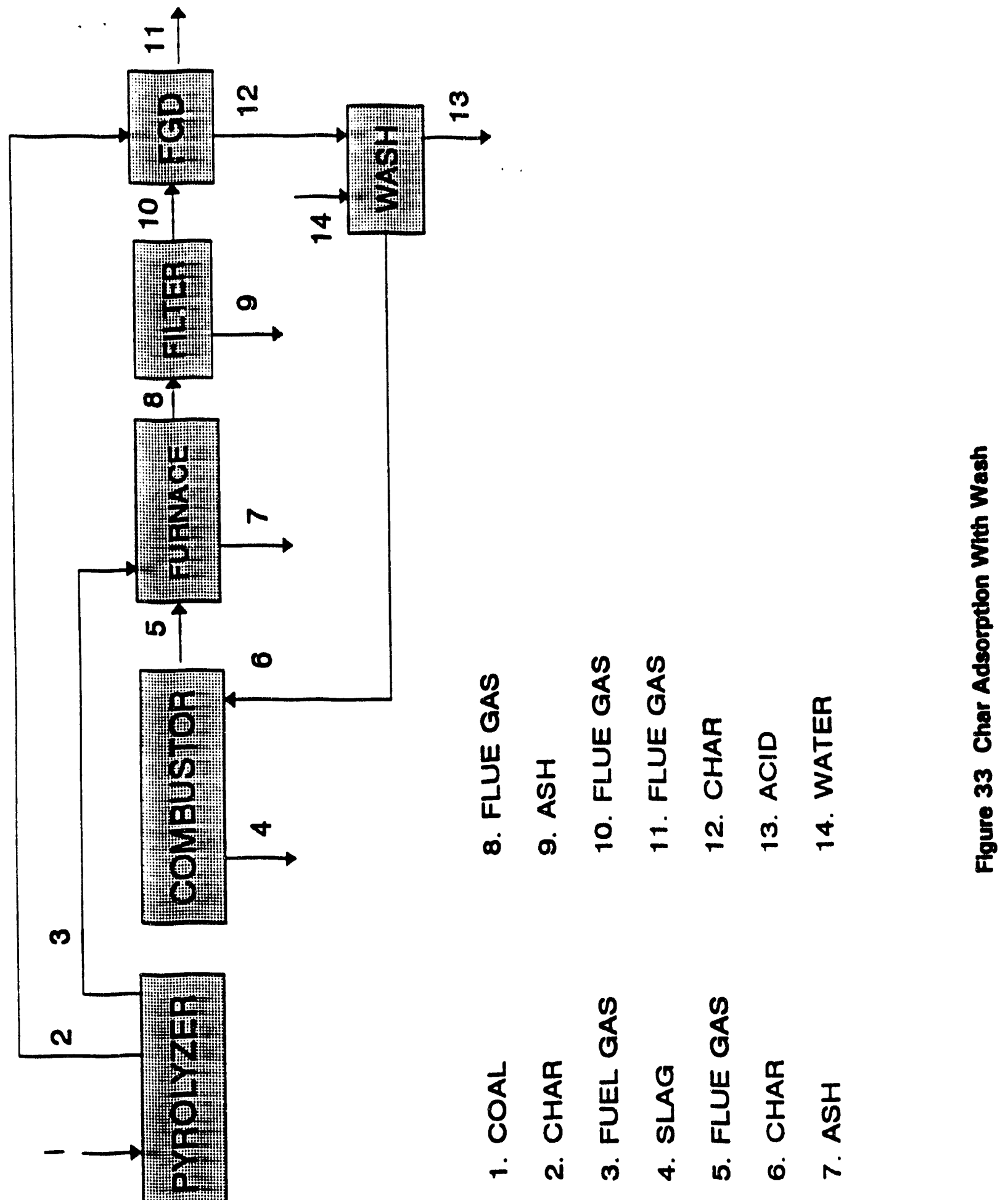




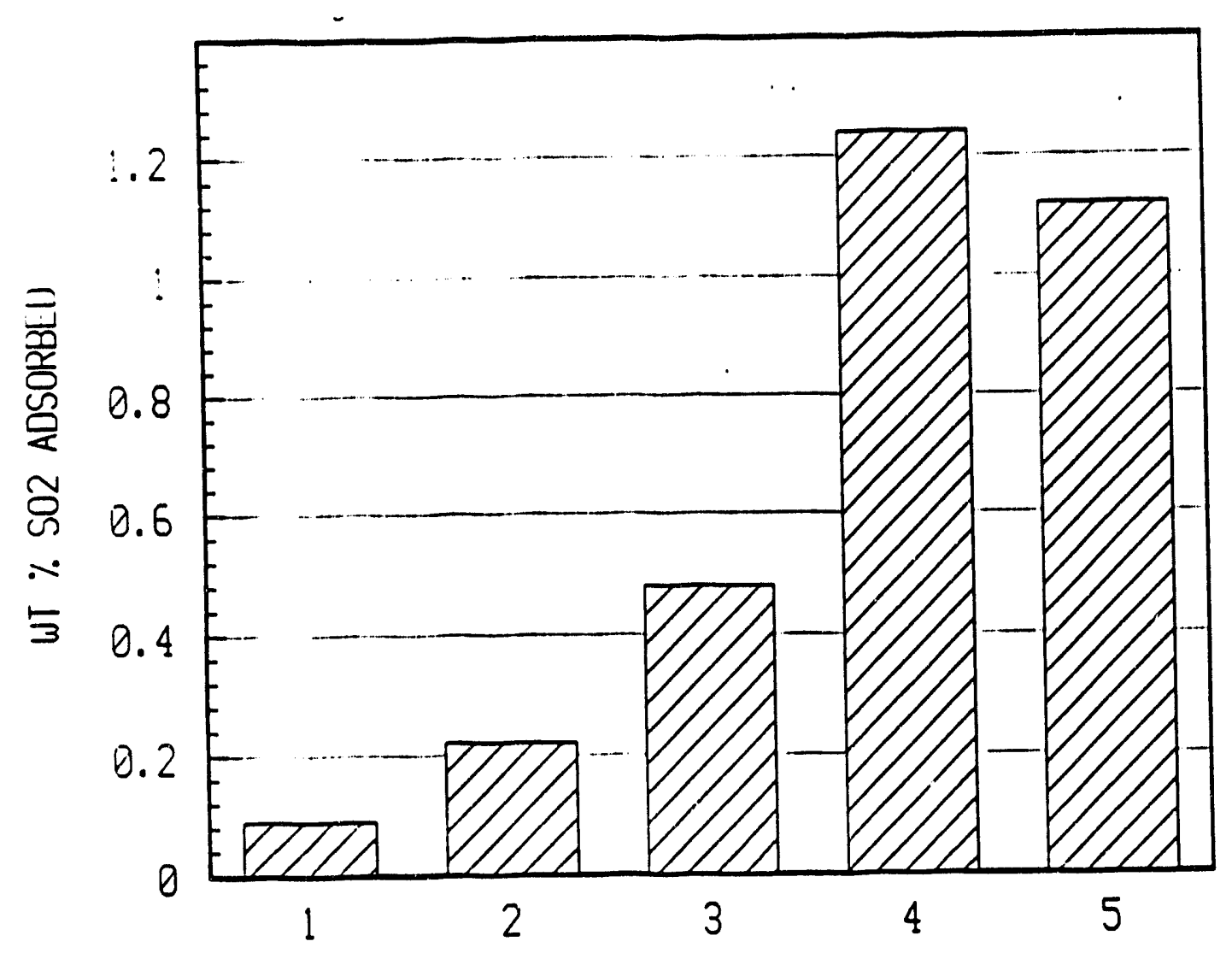

1 Coal, $1 \%$ breakthrough

2 Bed drain char, $1 \%$ breakthrough

3 Bed drain char, $10 \%$ breakthrough

4 Bed drain char, $10 \%$ breakthrough, $30 \%$ water

5 Cyclone catch char, $1 \%$ breakthrough

Figure 34 Adsorption Capacities of Chars Derived From Plttsburgh No. 8 Coal 


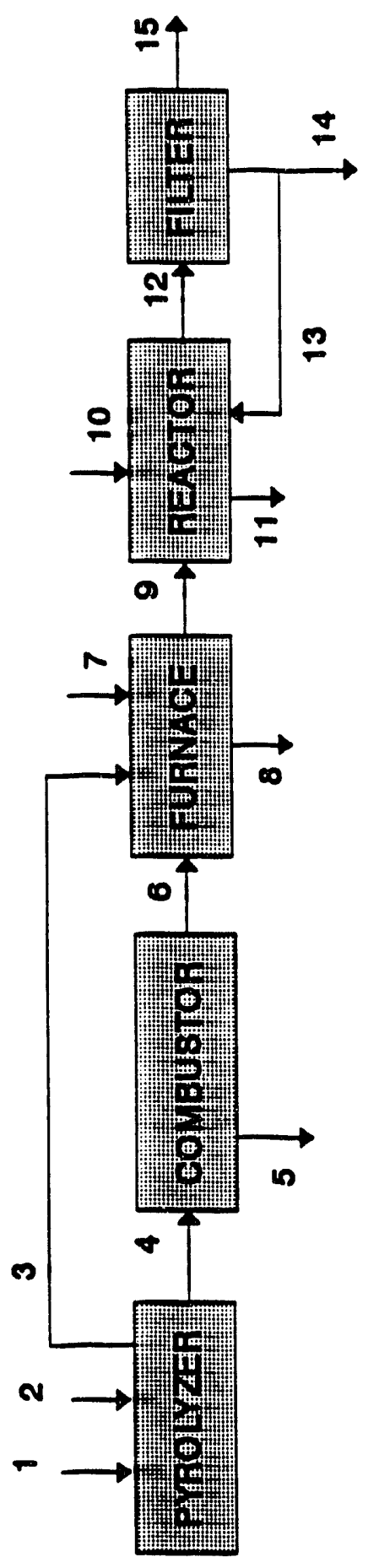

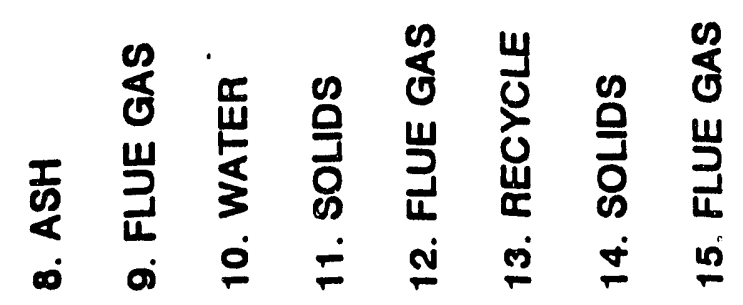

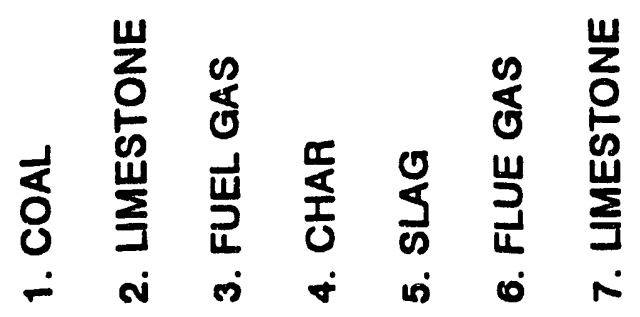




\section{Table.13 Recirculating Reactor Mass Balance (Input Values Marked by *)}

\begin{tabular}{|c|c|}
\hline Lb/h Sulfur to Pyrolyzer, S* & 1.00 \\
\hline Lb/h Ash to Pyrolyzer, A* & 1.00 \\
\hline Limestone/Sulfur to Pyrolyzer, CASP* . . & 1.00 \\
\hline Fraction Sulfur to CaS in Pyrolyzer, EPS & 0.50 \\
\hline Fraction Sulfur to $\mathrm{H}_{2} \mathrm{~S}$ in Pyrolyzer, FHS & 0.50 \\
\hline Fraction $\mathrm{SO}_{2}$ Reformed in Combustor, ESO & 0.50 \\
\hline Fraction Solids to Slag, ESS * & 0.70 \\
\hline Limestone/Sulfur to Boiler, CASB * & 2.00 \\
\hline Fraction Sulfur Capture in Boiler, EBS * & 0.50 \\
\hline Fraction Solids Capture in Boiler, EBA & 0.20 \\
\hline Fraction Particulate Capture by Filter, EFP* & 1.00 \\
\hline Fraction Sulfur Capture in Absorber, ESA & 0.90 \\
\hline Fraction Solids Recycle to Absorber, RSA * & 0.90 \\
\hline Fraction Solids Removal From Absorber, AS * & 0.20 \\
\hline Overall Sulfur Capture Efficiency, OE & 0.96 \\
\hline $\mathrm{SO}_{2}$ at $\mathrm{Adsorber} / \mathrm{SO}_{2}$ from Coal & 0.38 \\
\hline Limestone Into Pyrolyzer, CASO3P & 3.13 \\
\hline $\mathrm{H}_{2} \mathrm{~S}$ in Fuel Gas, PHS & 0.53 \\
\hline Calcium Sulfide in Char, CAS & 1.13 \\
\hline Sulfur in Char, CS & 0.00 \\
\hline Lime in Char, CAOP & 0.88 \\
\hline $\mathrm{SO}_{2}$ in Combustor Gas, CGSO & 0.50 \\
\hline $\mathrm{CaSO}_{4}$ in Combustor Gas, CGCASO & 0.32 \\
\hline Ash in Combustor Gas, CGA & 0.30 \\
\hline $\mathrm{CaO}$ in Combustor Gas, CGCAO & 0.26 \\
\hline Sulfur in Slag, SS & 0.18 \\
\hline
\end{tabular}


Table 13 .(Cont) Recirculating Reactor Mass Balance (Input Values Marked by ")

\begin{tabular}{|l|l|}
\hline $\mathrm{CaCO}_{3}$ Into Boiler, BCACO & 4.69 \\
\hline $\mathrm{SO}_{2}$ in Boiler Gas, BGSO & 0.75 \\
\hline $\mathrm{CaSO}_{4}$ in Boiler Gas, BGCASO & 1.53 \\
\hline $\mathrm{CaO}_{\text {in Boiler Gas, BGCAO }}$ & 1.79 \\
\hline Ash in Boiler Gas, BGA & 0.24 \\
\hline CaSO, in Boiler Solids, BSCASO & 0.38 \\
\hline CaO in Boiler Solids, BSCAO & 0.45 \\
\hline Ash in Boiler Solids, BSA & 0.06 \\
\hline CaSO, Out of Absorber, ACASO & 0.59 \\
\hline CaO Out of Absorber, ACAO & 0.12 \\
\hline Ash Out of Absorber, AA & 0.05 \\
\hline CaSO, Out of Filter, FCASO & 2.37 \\
\hline CaO Out of Filter, FCAO & 0.46 \\
\hline Ash Out of Filter, FA & 0.19 \\
\hline Total Sulfur Out of System & 1.00 \\
\hline
\end{tabular}




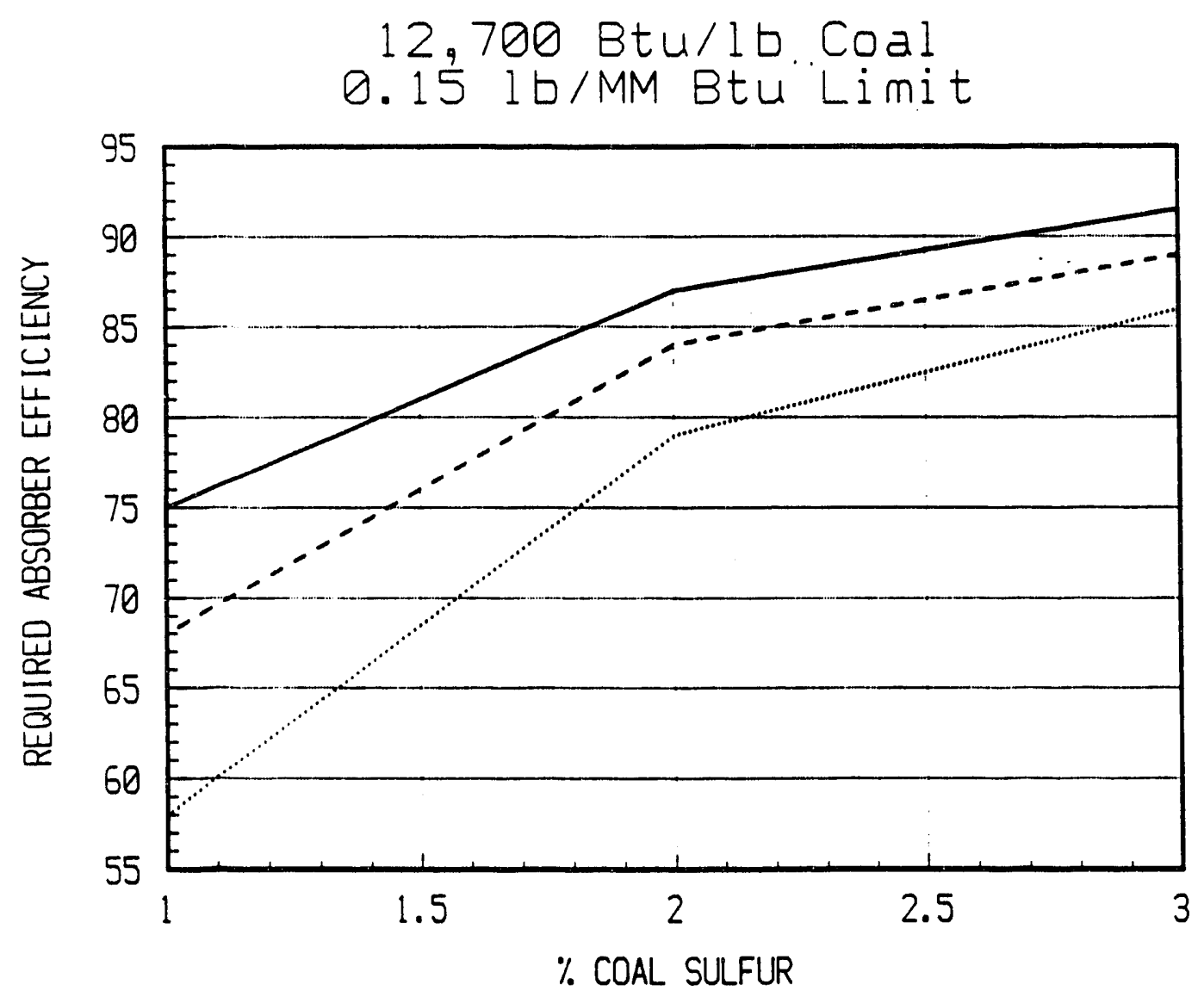

$$
\begin{aligned}
-50 \% & \text { Furnace Removal } \\
-.-60 \% & \text { Furnace Removal } \\
\text {-.......... } 70 \% & \text { Furnace Removal }
\end{aligned}
$$

Figure 36 Effect of Coal Sulfur on Required Absorber Efficiency 
various coal sulfur levels and furnace limestone injection removal efficiencies. As the figure shows, the required efficiency of the recirculating reactor needs to be between 80 and 90 percent for coal sulfur levels between 2 and 3 percent. The commercial Lurgi-type recirculating reactor can achieve this efficiency; however, that device does not utilize lime produced by the furnace injection of limestone, but instead operates with the injection of fresh hydrated lime. A literature survey was carried out to determine whether the use of lime carried over from furnace-injected limestone would yield acceptable $\mathrm{SO}_{2}$ removal efficiencies. Five studies of the reactivation of furnace-injected limestone were found. They are listed in Table 14.

The first four studies in the table, comparing the reactivation of furnace-injected calcium sorbents with the direct injection of hydrated lime, indicate more or less equivalent performance. However, in the fifth study, investigators found that furnace-injected solids did not react with $\mathrm{SO}_{2}$ unless a hydration step is carried out first. Most likely (actually it is necessary that) the furnace-injected solids used in the first four studies became hydrated while entrained in the flue gas flow through contact with water droplets; but this is not demonstrated-only inferred. No liquid water was present in the fixed-bed tests in the fifth study. Although one assumption might be that the presence of liquid water is required, more evidence should be obtained. As a Combustion 2000 resource person, David Livengood of ANL has been asked to also look into the reactivation of furnace-injected solids for $\mathrm{SO}_{2}$ absorption.

Work was done on conceptual designs of the three proposed systems and on the costs of these designs. A general-purpose cost computer program was used for this purpose. The ECONEVAL program is a LOTUS 123 format designed to provide a quick means of determining capital and operating costs for $\mathrm{SO}_{2}$ and $\mathrm{NO}_{x}$ control equipment. The user selects facility, equipment, and operating parameters. The program then calculates the Capital Cost in $\$ / k W$ and the First Year Operating Cost in $\$ /\left(\right.$ ton $\mathrm{SO}_{2}+\mathrm{NO}_{2}$ ).

The facility information that must be input consists of:

- Plant size, MW

- Annual interest rate

- Expected plant lifetime

- Cost of electricity, $\$ / k W h$

- Yearly operating hours
- Thermal conversion efficiency

- $\mathrm{SO}_{2}$ concentration, ppm

- $\mathrm{NO}_{x}$ concentration, ppm

- Required $\mathrm{SO}_{2}$ removal, \%

- Required $\mathrm{NO}_{x}$ removal, $\%$

The program contains generic equipment costs and related energy consumption, such as the installed cost of a precipitator and its operating cost in Watts per $\mathrm{sft}^{3} / \mathrm{min}$. The user must select the equipment items that comprise the system. The program then summarizes the total installed cost and total electrical operating cost for the complete system. In addition to direct installed costs, indirect costs such as fees and contingencies can be included as a percentage of the installed cost, as instructed by the user. 


\section{Table 14 Reactivation of Furnace Injected Limestone}

- R. Beittel and R. Dahlin, "Mechanistic Studies of Sorbent Utilization Enhancement by Humidification," Proceedings of the First Combined FGD and Dry $\mathrm{SO}_{2}$ Control Symposium, October 1988.

- Laboratory-scale work

- Injected the product of hydrate furnace injection into a lab scale humidifier at $\mathrm{Ca} / \mathrm{S}=\mathbf{2}$

- Composition: $33 \% \mathrm{CaO}, 23 \% \mathrm{CaOH}_{21}, 7 \% \mathrm{CaCO}_{3}, 30 \% \mathrm{CaSO}_{4}$

- Also injected $100 \% \mathrm{CaOH}_{2}$

- The resuits were $6 \%$ incremental $\mathrm{SO}_{2}$ removal for calcine, $12 \%$ increase for $100 \% \mathrm{CaOH}_{2}$

- C. Jorgensen, et al., "Pilot Plant Evaluation of Post-Combustion LIMB $\mathrm{SO}_{2}$ Capture," Proceedings of the First Combined FGD and Dry $\mathrm{SO}_{2}$ Control Symposium, October 1988.

- LIMB solids (52\% CaO, $42 \%$ ash) injected upstream of spray dryer

- Incremental $\mathrm{SO}_{2}$ removal $=10$ to $20 \%$

- N. Hiroyuki, et al., "Dry FGD Process Using Calcium Sorbents," Proceedings of the $1991 \mathrm{SO}_{2}$ Control Symposium, December 1991.

- Pilot scale tests of a Tampella-type reactivation reactor

- Furnace injection of $\mathrm{CaCO}_{3}$ at $2: 1$ gave $25 \% \mathrm{SO}_{2}$ removal, which increased to $70 \%$ after passage through humidifier/reactor

- Corresponds to about $60 \%$ incremental $\mathrm{SO}_{2}$ removal

- Injection of $\mathrm{CaOH}_{2}$ directly into the reactor also gave about $70 \%$ overall $\mathrm{SO}_{2}$ removal

- T. Enwald and M. Ball, "IIFAC Demonstration at Poplar River," Proceedings of the $1991 \mathrm{SO}_{2}$ Control Symposium, December 1991.

- 300-MW demonstration of LIFAC

- At $\mathrm{Ca} / \mathrm{S}=2,16 \%$ furnace removal and $57 \%$ reactor removal of $\mathrm{SO}_{2}$ was obtained

- Total $\mathrm{SO}_{2}$ control was therefore $63 \%$

- W. Jozewicz, et al., "Reactivation of Solids from Furnace Injection of Limestone for $\mathrm{SO}_{2}$ Control," Proceedings of the 1986 Joint Symposium on $\mathrm{Ory} \mathrm{SO} \mathrm{S}_{2}$ and Simultaneous $\mathrm{SO}_{2} / \mathrm{NO}_{x}$ Control Technologies, December 1986.

- Laboratory-scale tests, utilizing a fixed bed of furnace-injected solids

- Results showed that the furnace-injected solids will only absorb $\mathrm{SO}_{2}$ after a separate hydration process. 
The operating cost is subsequently calculated for the specified system. Power, maintenance, and disposal costs are determined, based upon the system equipment selected, its associated power consumption, and waste production. If a reagent is required, it must be specified by the user, along with its mole ratio with respect to $\mathrm{SO}_{2}$ or $\mathrm{NO}_{x}$. The program contains bulk costs for all reagents. If the system produces a byproduct, such as sulfur, this fact must also be indicated by the user, and the program will calculate a byproduct credit based upon the chemical produced and its calculated quantity. A yearly capital recovery cost is calculated based upon interest rate and plant lifetime. The program then summarizes the operating and capital recovery costs and the cost of reagents minus the byproduct recovery cost to yield First Year Operating Cost in $\$ /\left(\right.$ ton $\left.\mathrm{SO}_{2}+\mathrm{NO}_{2}\right)$.

The systems analyzed were:

- Adsorption of $\mathrm{SO}_{2}$ by a moving bed of carbonizer-produced char, reduction of $\mathrm{NO}_{x}$ by ammonia injection, and removal of particulates by a baghouse.

- Absorption of $\mathrm{SO}_{2}$ by reactivated lime solids in a recirculating reactor, reduction of $\mathrm{NO}_{\kappa}$ by ammonia injection, and removal of particulates by a baghouse.

- $\mathrm{SO}_{2}$ removal by a Wellman-Lord type scrubber with sulfur recovery, reduction of $\mathrm{NO}_{x}$ by ammonia injection, and removal of particulates by a baghouse. The costs were calculated with and without limestone injection at the carbonizer and combustor.

There is a two-page result for each system. The first page starts with a summary of assumptions and calculated results and concludes with a capital cost inventory. The second page documents the operating cost calculations, concluding with the first-year cost per ton of $\mathrm{SO}_{2}$ and $\mathrm{NO}_{\mathrm{x}}$ removed. The char adsorption system capital costs are shown in Table 15, and the operating costs are shown in Table 16. These costs are also shown in Tables 17 and 18 for the recirculating reactor system. There are two sets of cost data for the Wellman-Lord system. The costs that would result from operation with furnace limestone injection are contained in Tables 19 and 20. These costs are also tabulated for the Wellman-Lord system without limestone injection in the furnace. Tables 21 and 22 contain the cost information unde: tirese conditions.

The costs for all systems were close, with capital costs in the range of $\$ 200$ to $\$ 300 / \mathrm{kW}$ and operating costs about $\$ 300$ to $\$ 500 /$ ton. Table 23 summarizes the calculations. The most important cost is the first-year operating cost, which includes a capital recovery element. It also takes into account the limestone consumption of the carbonizer/combustor, as well as the disposal costs of the resultant spent sorbent. When limestone is used in the carbonizer and combustor, the char adsorption system gives the lowest operating cost, but the Wellman-Lord system can yield a lower operating cost when given the entire $\mathrm{SO}_{2}$ removal responsibility (i.e., no limestone used or $\mathrm{SO}_{2}$ removal by the carbonizer and combustor) because there are no limestone purchase or disposal costs, and the sale of sulfur results in a credit. 
Table 15. Char Adsorption, Ammonia Injection, and Baghouse Capltal Costs

PLANT SIZE, MW

ANNUAL INTEREST, \%

PLANT LIFE, YR

ELECT COST, \$/KWHR

HOURS PER YEAR

CONVERSION EFFICIENCY

$\begin{array}{rlr}290 & \text { PPM SO2 } & 2000 \\ 5 & \text { PPM NOX } & 200 \\ 30 & \text { \% SO2 REMOVAL } & 95 \\ 0.05 & \text { \% NOX REMOVAL } & 50 \\ 6000 & \text { CAPITAL S/KW } & 200 \\ 47 & \text { \$/T SO2+NO2 } & 437\end{array}$

CAPITAL COSTS

NO. OF UNITS

\section{\$ISCFM}

0.00

0.00

7.01

7.01

0.00

5.26

0.00

17.53

0.00

0.00

0.00

5.26

0.00

0.00

0.00

0.00

14.02

0.00

TOTAL PROCESS CAPITAL

56.1
\$/KW

KWISCFM

$O E+00$

$O E+00$

7E-04

$4 \mathrm{E}-04$

$O E+00$

$4 E-03$

$O E+00$

4E-03

$O E+00$

OE+00

OE+00

2E-03

$O E+00$

$0 E+00$

$O E+00$

$O E+00$

2E-03

$O E+00$

114.5

0.01

$\%$ CAPITAL

10.0

15.0

20.0

20.0

10.0
GENERAL FACILITIES

ENG \& HOME OFFICE FEES

PROJECT CONTINGENCY

PROCESS CONTINGENCY

PREPRODUCTION COSTS

TOT CAPITAL INVESTMENT
5.61

11.4

$8.41 \quad 17.2$

$11.22 \quad 22.9$

$11.22 \quad 22.9$

$5.6 \quad 11.4$

98.1 
Table 16. Char Adsorption, Ammonia Injection, and Baghouse Operating Costs

OPERATING
COSTS:
POWER USAGE MAINTENANCE

DISPOSAL

CATALYST

\section{\$YYR/SCFM}

3.5

2.9

1.6

0.0

NORMALIZED MOLE RATIO SO2 NOX

SO2

NOX

REAGENT

$\begin{array}{ll}0 & 0 \\ 0 & 0 \\ 3 & 0 \\ 0 & 0 \\ 0 & 0 \\ 0 & 1 \\ 0 & 0 \\ 0 & 0\end{array}$

LIME
HYDRATE
LIMESTONE
SODA ASH
BICARB
AMMONIA
METHANE
CARBON

0.0

0.0

0.0

2.8

0.0

0.0

0.0

0.0

0.0

0.0

0.0

0.0

0.2

0.0

0.0

0.0

OOR 1

BYPRODS

$\begin{array}{ll}0 & 0 \\ 0 & 0 \\ 0 & 0 \\ 0 & 0 \\ 0 & 0\end{array}$

FIRST YEAR COST:

SULFUR

SULFURIC ACID

GYPSUM

AMMONIUM BISULFIT

POTASSIUM SULFAT

0.0

0.0

0.0

0.0

0.0

0.0

0.0

0.0

0.0

0.0 
Table 17. Recirculating Reactor, Ammonia Injection, and Baghouse Capital Costs

PLANT SIZE, MW

ANNUAL INTEREST, \%

PLANT LIFE, YR

ELECT COST, \$/KWHR

HOURS PER YEAR

CONVERSION EFFICIENCY

290

5

30

0.05

6000

47

$\begin{array}{lr}\text { PPM SO2 } & 2000 \\ \text { PPM NOX } & 200 \\ \text { \% SO2 REMOVAL } & 95 \\ \text { \% NOX REMOVAL } & 50 \\ \text { CAPITAL \$/KW } & 194 \\ \text { \$/T SO2+NO2 } & 453\end{array}$

CAPITAL COSTS

NO. OF UNITS

\$ISCFM \$/KW KWISCFM

$\begin{array}{ll}3 & \text { REACTION VESSEL } \\ 0 & \text { VESSEL INTERNALS } \\ 1 & \text { SORBENT PREP } \\ 1 & \text { SORBENT HANDLING } \\ 0 & \text { SLURRY RECIRC SYSTEM } \\ 2 & \text { SORBENT RECIRC SYSTEM } \\ 0 & \text { CATALYST (3OOO/HR) } \\ 0 & \text { MOVING ADSORBER BED } \\ 0 & \text { FG HEAT EXCHANGER } \\ 0 & \text { CLAUS SYSTEM } \\ 0 & \text { ACID PLANT } \\ 1 & \text { AMMONIA INJECTION } \\ 1 & \text { HUMIDIFICATION } \\ 0 & \text { SCR REACTOR } \\ 0 & \text { BURNER } \\ 0 & \text { PRECIPITATOR } \\ 1 & \text { BAGHOUSE } \\ 0 & \text { WASTE HANDLING }\end{array}$

10.52

0.00

3.51

7.01

0.00

10.52

0.00

0.00

0.00

0.00

0.00

5.26

3.51

0.00

0.00

0.00

14.02

0.00

21

$O E+00$

$O E+00$

$4 E-04$

7

$4 E-04$

$O E+00$

$7 E-03$

21

$O E+00$

$O E+00$

$O E+00$

$O E+00$

$O E+00$

2E-03

$4 E-03$

$O E+00$

$O E+00$

$O E+00$

WASTE HANDLING

54.3

110.9

2E-03

$O E+00$

TOTAL PROCESS CAPITAL

5.43

11.1

GENERAL FACILITIES

8.15

16.6

PROJECT CONTINGENCY

10.87

22.2

PROCESS CONTINGENCY

10.87

22.2

20.0

PREPRODUCTION COSTS

5.4

11.1

TOT CAPITAL INVESTMENT

95.1

194.0 
Table 18 Recirculation Reactor, Ammonia Injection, and Baghouse Operating Costs

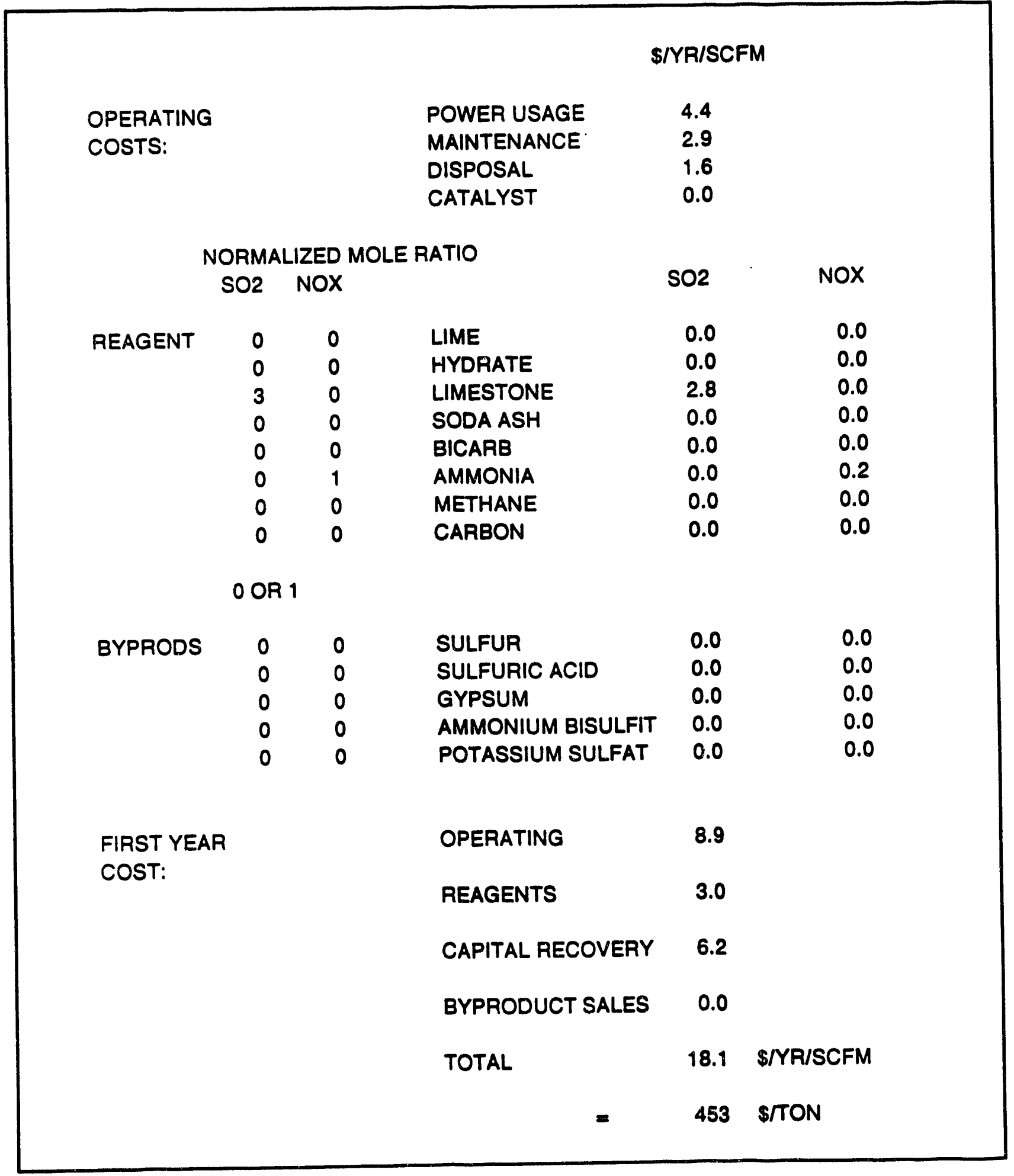


Table 19. Wellman-Lord, Ammonia Injection, and Baghouse Capital Costs - With Limestone Injection

PLANT SIZE, MW

ANNUAL INTEREST, \%

PLANT LIFE, YR

ELECT COST, S/KWHR

HOURS PER YEAR

CONVERSION EFFICIENCY

290
5
30
0.05
6000

47
PPM SO2

PPM NOX

$\%$ SO2 REMOVAL

$\%$ NOX REMOVAL

CAPITAL \$/KW

$\$ \pi T$ SO2+NO2
2000

200

95

50

240

495

CAPITAL COSTS

NO. OF UNITS

4
2
1
1
2
0
0
0
0
1
0
1
0
0
0
0
1
0

\% CAPITAL

10.0

15.0

20.0

20.0

10.0
REACTION VESSEL.

VESSEL INTERNALS

SORBENT PREP

SORBENT HANDLING

SLURRY RECIRC SYSTEM

SORBENT RECIRC SYSTEM

CATALYST (3000/HR)

MOVING ADSORBER BED

FG HEAT EXCHANGER

CLAUS SYSTEM

ACID PLANT

AMMONIA INJECTION

HUMIDIFICATION

SCR REACTOR

BURNER

PRECIPITATOR

BAGHOUSE

WASTE HANDLING

TOTAL PROCESS CAPITAL
\$SCFM

14.02

7.01

3.51

7.01

10.52

0.00

0.00

0.00

0.00

5.96

0.00

5.26

0.00

0.00

0.00

0.00

14.02

0.00

67.3

6.73

10.09

13.46

13.46

6.7

PROCESS CONTINGENCY

PREPRODUCTION COSTS

TOT CAPITAL INVESTMENT

\section{S/KW}

KW/SCFM

OE+00

$O E+00$

$4 E-04$

$4 E-04$

$7 E-03$

$O E+00$

$O E+00$

$O E+00$

$O E+00$

2E-03

$O E+00$

2E-03

$O E+00$

$O E+00$

$O E+00$

$O E+00$

2E-03

$O E+00$

137.3

0.01 
Table 20 Wellman-Lord, Ammonia Injection, and Baghouse Operating Costs - With Limestone Injection

\begin{tabular}{|c|c|c|c|c|c|}
\hline & & & \multicolumn{3}{|c|}{ \$/YR/SCFM } \\
\hline \multirow{4}{*}{\multicolumn{3}{|c|}{$\begin{array}{l}\text { OPERATING } \\
\text { COSTS: }\end{array}$}} & POWER USAGE & 3.9 & \\
\hline & & & MAINTENANCE & 3.5 & \\
\hline & & & DISPOSAL & 1.4 & \\
\hline & & & CATALYST & 0.0 & \\
\hline \multicolumn{6}{|c|}{ NORMALIZED MOLE RATIO } \\
\hline & & NOX & & $\mathrm{SO} 2$ & NOX \\
\hline \multirow[t]{9}{*}{ REAGENT } & 0 & 0 & LIME & 0.0 & 0.0 \\
\hline & 0 & 0 & HYDRATE & 0.0 & 0.0 \\
\hline & 3 & 0 & LIMESTONE & 2.8 & 0.0 \\
\hline & 0 & 0 & SODA ASH & 0.6 & 0.0 \\
\hline & 0 & 0 & BICARB & 0.0 & 0.0 \\
\hline & 0 & 1 & AMMONIA & 0.0 & 0.2 \\
\hline & 0 & 0 & METHANE & 0.3 & 0.0 \\
\hline & 0 & 0 & CARBON & 0.0 & 0.0 \\
\hline & OF & & & & \\
\hline \multirow[t]{5}{*}{ BYPRODS } & 0 & 0 & SULFUR & 0.7 & 0.0 \\
\hline & 0 & 0 & SULFURIC ACID & 0.0 & 0.0 \\
\hline & 0 & 0 & GYPSUM & 0.0 & 0.6 \\
\hline & 0 & 0 & AMMONIUM BISULFIT & 0.0 & 0.6 \\
\hline & 0 & 0 & POTASSIUM SULFAT & 0.0 & $0 . c$ \\
\hline \multirow{6}{*}{$\begin{array}{l}\text { FIRST YEAR } \\
\text { COST: }\end{array}$} & & & OPERATING & 8.8 & \\
\hline & & & REAGENTS & 3.9 & \\
\hline & & & CAPITAL RECOVERY & 7.7 & \\
\hline & & & BYPRODUCT SALES & -0.7 & \\
\hline & & & TOTAL & 19.7 & \$/YR/SCFM \\
\hline & & & $=$ & 495 & \$/TON \\
\hline
\end{tabular}


Table 21 Wellman-Lord, Ammonia Injection, and Baghouse Capital Costs - Without Limestone Injection

\section{PLANT SIZE, MW}

ANNUAL INTEREST, \%

PLANT LIFE, YR

ELECT COST, \$/KWHR

HOURS PER YEAR

CONVERSION EFFICIENCY

290
5
30
0.05
6000
47

PPM SO2

PPM NOX

\% SO2 REMOVAL

\%.NOX REMOVAL

CAPITAL S/KW

\$/T SO2+NO2
2000

200

95

50

203

320

CAPITAL COSTS

NO. OF UNITS

\$ISCFM S/KW KWISCFM

REACTION VESSEL
VESSEL INTERNALS
SORBENT PREP
SORBENT HANDLING
SLURRY RECIRC SYSTEM
SORBENT RECIRC SYSTEM
CATALYST (3OOO/HR)
MOVING ADSORBER BED
FG HEAT EXCHANGER
CLAUS SYSTEM
ACID PLANT
AMMONIA INJECTION
HUMIDIFICATION
SCR REACTOR
BURNER
PRECIPITATOR
BAGHOUSE
WASTE HANDLING

14.02

7.01

0.00

0.00

10.52

0.00

0.00

0.00

0.00

5.96

0.00

5.26

0.00

0.00

0.00

0.00

14.02

.0 .00

TOTAL PROCESS CAPITAL

56.8

115.9

$O E+00$

$0 E+00$

OE+OO

$O E+00$

7E-03

$0 E+00$

$O E+00$

$0 E+00$

$O E+00$

2E-03

OE+00

2E-03

OE+00

$O E+00$

$O E+00$

$O E+00$

2E-03

$O E+00$

\% CAPITAL

10.0

GENERAL FACILITIES

5.68

11.6

15.0

ENG \& HOME OFFICE FEES

8.52

17.4

PROJECT CONTINGENCY

11.36

23.2

20.0

PROCESS CONTINGENCY

11.36

23.2

PREPRODUCTION COSTS

5.7

11.6

TOT CAPITAL INVESTMENT

99.4

202.8 
Table 22 Wellman-Lord, Ammonia Injection, and Baghouse Operating Costs - Without Limestone Injection

\$/YR/SCFM

OPERATING COSTS:

$\begin{array}{lr}\text { POWER USAGE } & 3.7 \\ \text { MAINTENANCE } & 3.0 \\ \text { DISPOSAL } & -0.2 \\ \text { CATALYST } & 0.0\end{array}$

NORMALIZED MOLE RATIO

SO2 NOX

$\mathrm{SO} 2$

NOX

REAGENT

$\begin{array}{ll}0 & 0 \\ 0 & 0 \\ 0 & 0 \\ 0 & 0 \\ 0 & 0 \\ 0 & 1 \\ 1 & 0 \\ 0 & 0\end{array}$

LIME

HYDRATE

LIMESTONE

0.0

0.0

SODA ASH

0.0

0.0

0.0

0.0

BICARB

0.6

0.0

AMMONIA

0.0

0.0

METHANE

0.0

0.2

CARBON

0.8

0.0

0.0

0.0

OOR 1

BYPRODS

$\begin{array}{ll}1 & 0 \\ 0 & 0 \\ 0 & 0 \\ 0 & 0 \\ 0 & 0\end{array}$

SULFUR

SULFURIC ACID

GYPSUM

AMMONIUM BISULFIT

1.7

0.0

0.0

0.0

0.0

0.0

POTASSIUM SULFAT

0.0

0.0

0.0

0.0

FIRST YEAR

OPERATING

6.5

COST:

$\begin{array}{lcc}\text { REAGENTS } & 1.5 \\ \text { CAPITAL RECOVERY } & 6.5 & \\ \text { BYPRODUCT SALES } & -1.7 & \\ \text { TOTAL } & 12.8 & \$ \text { TYRISCFM } \\ & =320 & \$ / T O N\end{array}$


Table 23 Pollution Control Systems Cost Summary

(All Systems Include Ammonia Injection and Baghouse)

\begin{tabular}{|l|c|c|}
\hline \multicolumn{1}{|c|}{ System } & $\begin{array}{c}\text { Capital Cost } \\
\$ / \mathrm{kW}\end{array}$ & $\begin{array}{c}\text { Operating Cost } \\
\$ / \text { ton }\left(\mathrm{SO}_{2}+\mathrm{NO}_{2}\right)\end{array}$ \\
\hline $\mathrm{SO}_{2}$ Adsorption by Char & 200 & 437 \\
\hline $\mathrm{SO}_{2}$ Adsorption by Recirculating Reactor & 194 & 453 \\
\hline Wellman-Lord Regenerable System & 240 & 495 \\
\hline Wellman-Lord (no limestone injection) & 203 & 320 \\
\hline
\end{tabular}




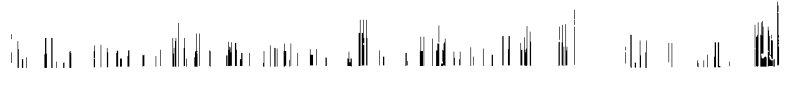
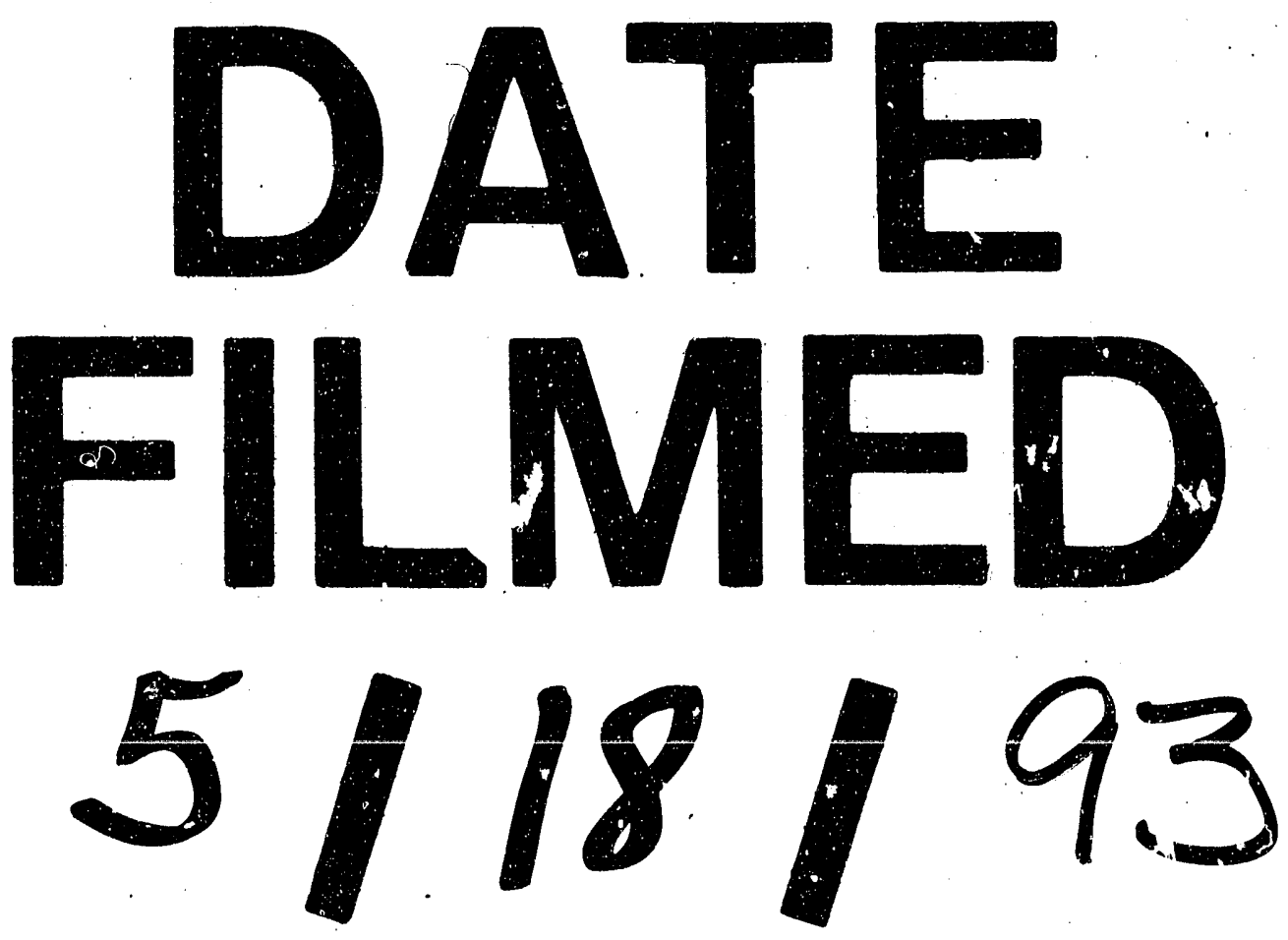
